\title{
WestVirginiaUniversity
}

THE RESEARCH REPOSITORY @ WVU

Graduate Theses, Dissertations, and Problem Reports

2000

\section{Relationship between cutting parameters and bit geometry in rotary cutting}

\author{
Srikanth Addala \\ West Virginia University
}

Follow this and additional works at: https://researchrepository.wvu.edu/etd

\section{Recommended Citation}

Addala, Srikanth, "Relationship between cutting parameters and bit geometry in rotary cutting" (2000). Graduate Theses, Dissertations, and Problem Reports. 1094.

https://researchrepository.wvu.edu/etd/1094

This Thesis is protected by copyright and/or related rights. It has been brought to you by the The Research Repository @WVU with permission from the rights-holder(s). You are free to use this Thesis in any way that is permitted by the copyright and related rights legislation that applies to your use. For other uses you must obtain permission from the rights-holder(s) directly, unless additional rights are indicated by a Creative Commons license in the record and/ or on the work itself. This Thesis has been accepted for inclusion in WVU Graduate Theses, Dissertations, and Problem Reports collection by an authorized administrator of The Research Repository @ WVU. For more information, please contact researchrepository@mail.wvu.edu. 


\section{RELATIONSHIP BETWEEN CUTTING PARAMETERS AND BIT GEOMETRY IN ROTARY CUTTING}

Srikanth Addala

Thesis Submitted to the

College of Engineering and Mineral Resources

at West Virginia University

in partial fulfillment of the requirements

for the degree of

Master of Science

in

Mining Engineering
Abdul W. Khair, Ph.D., Chair
Syd S. Peng, Ph.D.
Y. Luo, Ph.D.

Department of Mining Engineering

Morgantown, West Virginia

2000

Keywords: Bits, Bit geometry, Respirable dust, Bit spacing, Continuous miners. 


\section{ABSTRACT \\ RELATIONSHIP BETWEEN CUTTING PARAMETERS AND BIT GEOMETRY IN ROTARY CUTTING}

\section{Srikanth Addala}

The main objective of this research was to investigate the relationship between cutting parameters (cutting force, penetration force, specific energy, specific respirable dust) and the bit geometry parameters (angle of the bit tip, bit tip size and shape of the bit) in order to reduce the amount of specific respirable dust generated and the specific energy consumed in rotary cutting. In the cutting process when two grooves are made in the rock at certain spacing, a land/ridge is formed between the two adjacent grooves. If that land/ridge can be removed in a cutting cycle, then a clean surface will be available for the subsequent cutting. When two cuts are made at optimum spacing the two bits starts interacting and will result in removal of the land/ridge. In order to investigate the relationship, five conical bits with tip angles ranging from $70^{\circ}$ to $100^{\circ}$ and two wedge shaped bits with different gage widths were used in this study. The relationship between penetration and cutting forces and the bit geometry parameters were evaluated. The relationship between specific energy consumed, specific respirable dust generated and the bit geometry was also evaluated. 
My Family 


\section{ACKNOWLEDGEMENTS}

I would like to express my sincere gratitude to my research advisor $\boldsymbol{D r}$. $\boldsymbol{A}$. W. Khair, for his guidance and encouragement throughout this study. Without his support and permission this research would not have been possible. I would to express my thanks to the other committee members Dr. Syd S. Peng and Dr. Y. Luo for their constructive criticism and suggestions at several stages of this work.

I am thankful to the Coal and Energy Research Bureau for their financial support during the course of this research work.

Special thanks to Mr. Shiva Kolli for his help in the experimental work, Ms. Karen Centofanti for her assistance in the official work. I would like to express thanks to all my friends who helped me in many ways during my stay in Morgantown.

Finally, I am greatly indebted to my entire family whose support can never be expressed in words. 


\section{TABLE OF CONTENTS}

Content

Page

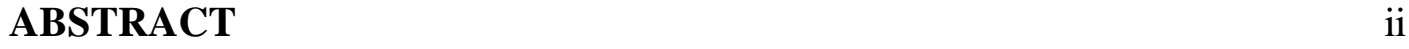

ACKNOWLEDGEMENTS IV

TABLE OF CONTENTS

LIST OF FIGURES vii

LIST OF TABLES - X X

Chapter

1. INTRODUCTION 1

$\begin{array}{ll}1.1 \text { Overview } & 1\end{array}$

1.2 Problem Definition 2

2. LITERATURE REVIEW 4

2.1 Background 4

2.2 Rock Cutting Theories 5

$\begin{array}{ll}\text { 2.3 Parameters effecting dust generation } & 14\end{array}$

$\begin{array}{ll}2.4 \text { Theories of rock breakage } & 19\end{array}$

\begin{tabular}{ll}
3. & METHODOLOGY \\
\hline
\end{tabular}

3.1 Description of the ARCCS 23

3.2 Physical and Mechanical Properties of Indiana Limestone 24

3.3 Data Acquisition Methods 25 
3.4 Dust Sampling 26

3.5 Characteristics of Cutting Bits 28

3.6 Experimental Work $\quad 30$

4. EXPERIMENTAL RESULTS AND DISCUSSION 32

$\begin{array}{lll}\text { 5. CONCLUSIONS } & 62\end{array}$

6. REFERENCES 64

$\begin{array}{llr}7 . & 69\end{array}$ 


\section{LIST OF FIGURES}

Figure 2.1 Sequence of rock failure and crater formation $\quad 6$

$\begin{array}{ll}\text { Figure 2.2 Assumed indentation failure modes for rocks } & 7\end{array}$

Figure 2.3 Force-displacement and macroscopic models of failure in rocks $\quad 7$

Figure 2.4 Force-penetration curves in Indiana limestone $\quad 8$

$\begin{array}{ll}\text { Figure 2.5 Fracture patterns for wedges } & 9\end{array}$

Figure 2.6 Force-penetration curves for wedge indentation in Indiana limestone. 12

$\begin{array}{ll}\text { Figure 2.7 Force-penetration loading curves } & 13\end{array}$

$\begin{array}{ll}\text { Figure 2.8 Shapes of presently used bits } & 14\end{array}$

$\begin{array}{ll}\text { Figure 2.9 Coal cutting bit description } & 16\end{array}$

Figure 3.1 Automated rotary coal cutting simulator 22

$\begin{array}{ll}\text { Figure 3.2 Conical bits used } & 28\end{array}$

$\begin{array}{ll}\text { Figure 3.3 Drag bits used } & 29\end{array}$

Figure 3.4 Cutting sequences used 31

Figure 4.1a Penetration and cutting forces in first cut using U76K 33

Figure 4.1b Penetration and cutting forces at 0.5 in spacing in U76 33

Figure 4.1c Penetration and cutting forces at 1.0 in spacing in U76K 34

Figure 4.1d Penetration and cutting forces at 1.5 in spacing in U76K 35

Figure 4.2a Comparison of penetration forces in U76K 35

Figure 4.2b Comparison of cutting forces in U76K 36

Figure 4.2c Specific respirable dust in U76K 36

Figure 4.2d Comparison of specific energy in U76K 37

Figure 4.3a Comparison of penetration forces in U82HDLR 37 
Figure 4.3b Comparison of cutting forces in U82HDLR

Figure 4.3c Specific respirable dust in U82HDLR

Figure 4.3d Comparison of specific energy in U82HDLR

Figure 4.4a Comparison of penetration forces in U85HLR

Figure 4.4b Comparison of cutting forces in U85HLR

Figure 4.4c Specific respirable dust in U85HLR

Figure 4.4d Comparison of specific energy in U94HDLR

Figure 4.5a Comparison of penetration forces in U94HDLR

Figure 4.5b Comparison of cutting forces in U94HDLR

Figure 4.5c Specific respirable dust in U94HDLR

Figure 4.5d Comparison of specific energy in U94HDLR

Figure 4.6a Comparison of penetration forces in U95HDLR

Figure 4.6b Comparison of cutting forces in U95HDLR

Figure 4.6c Specific respirable dust in U95HDLR

Figure 4.6d Comparison of specific energy in U95HDLR

Figure 4.7a Comparison of penetration forces in KR225

Figure 4.7b Comparison of cutting forces in KR225

Figure 4.7c Specific respirable dust in KR225

Figure 4.7d Comparison of specific energy in KR225

Figure 4.8a Comparison of penetration forces in KR300

Figure 4.8b Comparison of cutting forces in KR300

Figure 4.8c Specific respirable dust in KR300

Figure 4.8d Comparison of specific energy in KR300 
Figure 4.9a Comparison of penetration forces in conical bits

Figure 4.9b Comparison of cutting forces in conical bits

Figure 4.9c Comparison of specific respirable dust in conical bits

Figure 4.9d Comparison of specific energy in conical bits

Figure 4.10a Comparison of penetration forces in drag bits

Figure 4.10b Comparison of cutting forces in drag bits

Figure 4.10c Comparison of specific respirable dust in drag bits 57

Figure 4.10d Comparison of specific energy in drag bits 58

Figure 4.11 Comparison of specific energy in two alternate cutting sequences 59 


\section{LIST OF TABLES}

Table 3.1 Physical and mechanical properties of Indian limestone

Table 3.2 Different stages and their GMD in a cascade impactor 


\section{Chapter 1}

\section{INTRODUCTION}

\subsection{Overview}

The continuous mining machines which were introduced in the late 1940s now account for more than half of the coal production from the underground mines in the United States ( Roepke, et al. , 1983 ). These cutting machines, which were introduced to increase the production and productivity, have also increased the amount of respirable dust generated in the cutting process. The bit - coal/rock interaction have directly caused "Coal Miners Pneumoconiosis" which is also called as "black lung" disease. Rock cutting also produces fine dust accretion, which results in "silicosis" and many occupational diseases like "siderosis", "asbestosis". Millions of dollars are spent in the form of compensation for respirable dust related diseases.

The rock/coal cutting also impacts the cutting bits, requiring their quick replacement. There are two shapes of cutting bits commonly utilized, namely, conical or point attack bits and wedge type bits. Point attack bits are more frequently used in the United States. Research indicates that point attack bits suffer lot bit wear. The research conducted by Reddy (1988) indicates that the point attack bits does not have any precisely defined edges, and have negative side clearance angle making them responsible for production of lot of dust and high energy consumption.

The major areas that require researchers' attention are reduction of respirable dust generated and reduction of the energy consumed in the cutting process. The efficient bit 
design and cutting sequences can be a solution to these problems. The appropriate bit design is accomplished through a maneuver of a number of bit-related parameters including bit geometry, mounting configuration on the cutting head, bit spacing and cutting depth etc.

\subsection{Problem definition}

Cutting bits are arranged in a crescent shaped path on the cutting head of the continuous mining machine, the bit's depth of cut varies along the cutting path starting from zero, reaching a maximum and falling back to zero. This research was conducted with a view to remove the land/ridge between two adjacent cuts to provide a clean cut face for the subsequent cutting cycle. The cutting parameters which influence the cutting process are bit spacing, depth of cut, cutting pressure and penetration pressures. The bit geometry parameters that influence the cutting process are angle of the bit tip, bit tip size etc.

The experiments were conducted utilizing an Automated Rotary Coal/rock Cutting Simulator (ARCCS) designed and developed by Khair (1984) in the Rock Mechanics Laboratories at the West Virginia University. The ARCCS machine has arrangements to vary the RPM, penetration rate of the cutting head, depth of cut and bit spacing. It also has the arrangements to record these parameters and cutting pressure on a chart plotter. Through a correct combination of bit spacing and depth of cut two adjacent grooves starts interacting and the land/ridge between the two cuts can be removed which will result in large chip formation and less dust generation. If these lands/ridges can be removed effectively then the amount of respirable dust generated will be reduced 
considerably. So the experiments were conducted with an objective to produce clean cut face using several conical and wedge shaped bits with different bit tip angles and bit tip sizes.

Specific respirable dust is defined as the amount of dust generated in cutting a unit mass of rock/coal. Specific energy is defined as the amount of energy consumed in cutting a unit mass of rock/coal. The specific respirable dust depends on various parameters like depth of cut, bit spacing, angle of the bit tip, bit tip size, and various other factors like the compressive, tensile and shear strengths of the rock/coal.

The objectives of this research were to produce less amount of respirable dust, to consume less amount of specific energy and to produce a clean cut face, to investigate the relationship between bit geometry parameters like the bit tip angle and bit tip size and the cutting parameters like the bit spacing, depth of cut, cutting and penetration forces, and to study the effect of the type of cutting bit (conical and wedge shaped bits) on the cutting parameters.

The results of this study will provide better understanding of the effect of cutting parameters and bit geometry parameters on the respirable dust generation and energy consumption. The results will suggest the correct bit type that can be used to produce less amount of respirable dust and consume less energy. 


\section{Chapter 2}

\section{LITERATURE REVIEW}

\subsection{Background}

A review of literature indicates that vast amount of research has been conducted in the areas of rock cutting to improve the efficiency of the cutting machines. European nations, particularly the National Coal Board (NCB) of Great Britain, is the pioneer in coal cutting research since 1950's. The research of coal cutting mechanism and tools used in the United States started in the early 1970's, after the enactment of the 1969 Health and Safety Act. Since then the United States Bureau of Mines has been engaged in an intensive study of the relationship of coal cutting to the generation of airborne dust.

Bureau of Mines had on-going research programs, both in-house and contract. In 1981 USBM commissioned the South West Research Institute (SWRI) to summarize results into airborne respirable dust and recommend a course for future study (Stecklein et al. 1982). Among others, the SWRI recommended that the future research is needed to investigate the following operating and insitu parameters listed in the order of their importance to airborne respirable dust generation:

- Establish Depth of Cut as Basic Cutting Parameter, $5 \mathrm{~cm}$. (2 in.)

- Investigate Geometric Description of Bits (Wedge and Point attack)

- Investigate Cut Spacing (space to depth ratio of 1.0-4.0)

- Investigate Cut Direction $\left(0^{0}-180^{\circ}\right.$ relative to main cleats and bedding planes) 
- Investigate Continued Increased Depth of Cut $5 \mathrm{~cm}$. (2 in.) to $15 \mathrm{~cm}(6 \mathrm{in}$.$) .$

\subsection{Rock Cutting Theories}

\subsubsection{Indentation Theories}

Indentation theories are classified into experimental and analytical studies

\subsubsection{Experimental Studies}

Experimental studies on bit penetration have been conducted by many means. Quasi-static tests and drop tests, with strain gage measurement and high speed photography were used most often. Although various methods have been used, the penetration phenomena of a bit into rock is similar, sequence of radial cracking, crushing and chipping. The Drilling Research Institute has conducted a series of experiments on rock failure and crater formation under the impact of a blunt wedge bit. The events were recorded using a high speed photography and strain gage measurements were taken, the observations can be summarized as (Figure 2.1):

1. Crushing of surface irregularities as bit first makes contact with the rock.

2. Elastic deformation of rock from continued application of load by bit. Surface cracks radiate out from the lines of stress concentration at boundary of cutting edges.

3. Crushing of central wedge of rock into fine fragments.

4. Chipping out of large fragments along curved trajectory to surface adjacent to crushed zone.

5. Crumbling away of crushed zone and displacement by bit as it continues to penetrate. Entire sequence may be repeated if blow energy is sufficient. 


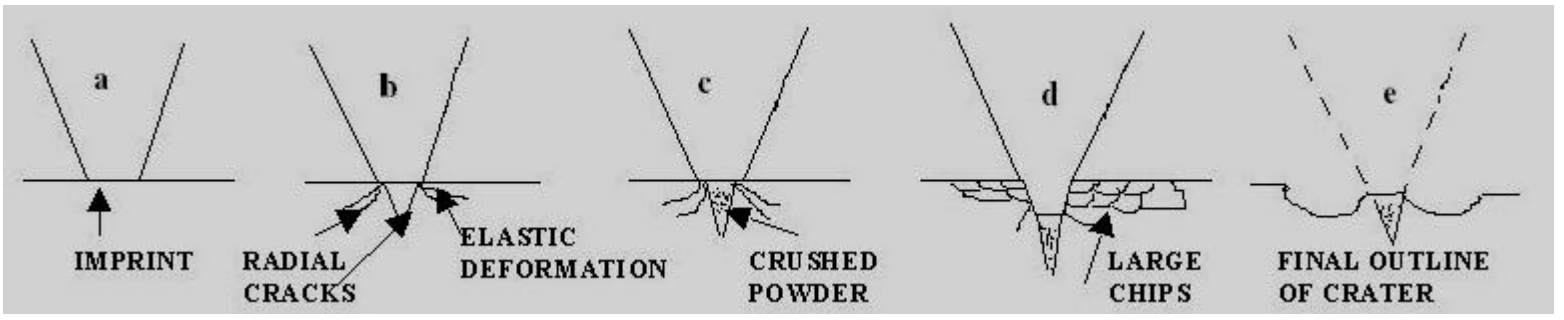

Figure 2.1 Sequence of rock failure and crater formation (After Hartman, 1959).

These observations have been generally confirmed by later investigators in both static and dynamic experiments (Hartman, 1959; Anon., 1953; Singh and Johnson, 1967; Khair and Devilder, 1986). Dynamic penetration of a conical bit into coal has been studied by Jung and Khair (1989).

Porosity is an important material property in bit penetration. Ladanyi (1972) used a flat ended cylindrical punch in his study and concluded that in the case of a dense rock of low porosity indentation failure initiated at the edge of the punch with a tensile crack forming a truncated cone beneath the punch. As the applied load increased, the cracks continued to grow up-to a certain load level. Eventually the cone is crushed and the cracks propagated to the free surface in an unstable manner (Figure 2.2a). In the case of porous brittle rock, the punch could be pushed to a certain depth with little damage to the surrounding material. With the increasing load, the crushed and compressed rock beneath the punch led to radial cracking in a way similar to the case of a dense rock (Figure 2.2b).

It is well know that the load applied to a bit has reached a threshold value, depending on the type of loading and the rock type, chipping occurs and a crater is formed. The force temporarily drops and the penetration increases suddenly. To obtain a second chipping event, the load must be increased to a higher level. The force- 
displacement curve is of a non-linear, discontinuous shape, typical for brittle rocks. If the rock behaves in a plastic manner, e.g. due to the pressure of the overburden and the drilling mud in a deep bore-hole, the force-displacement curve becomes increasingly linear as shown in the Figure 2.3 (Gnirk and Cheatham, 1965).
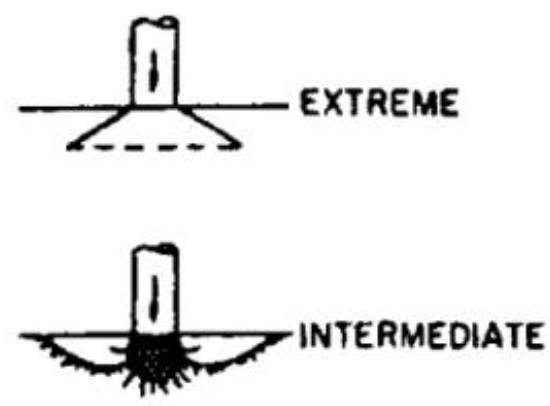

a. BRITTLE-DENSE
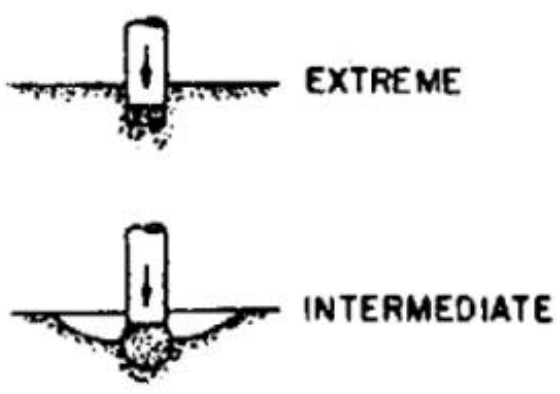

b. BRITTLE-POROUS

Figure 2.2a \& b Assumed indentation failure modes for extreme and intermediate cases of brittledense and brittle-porous rocks (Ladanyi, 1972).

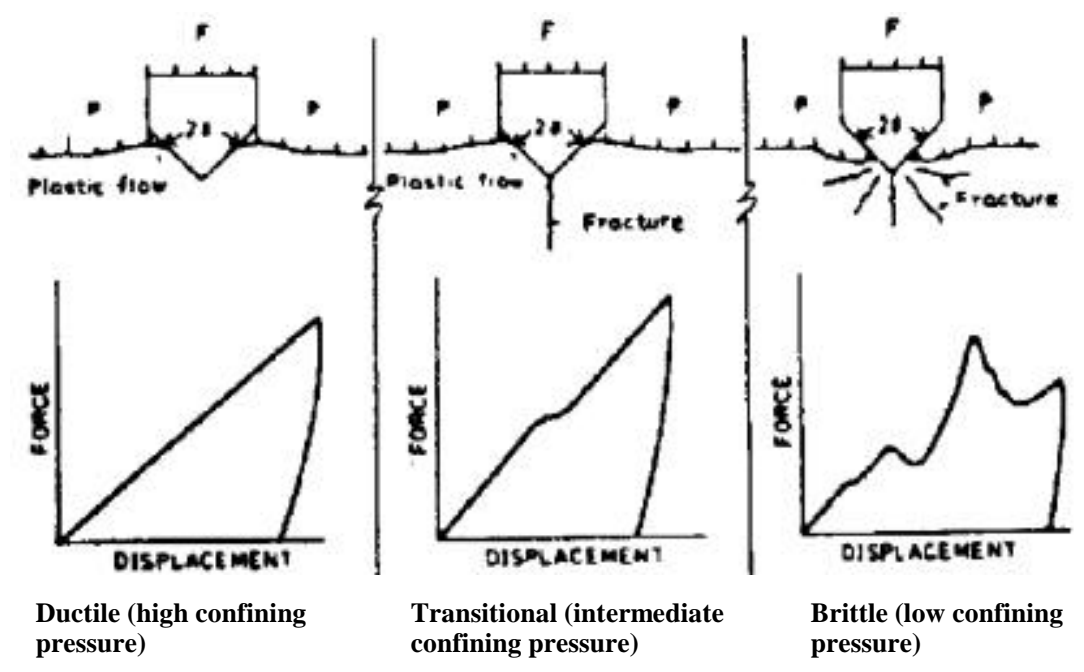

Figure 2.3 Different types of force-displacement and the associated macroscopic models of rock failure for single, sharp bit indentation (Gnirk and Cheatham, 1965). 
It is also obvious that a sharp tool will penetrate more into the rock than a blunt tool yielding a less steep force-displacement curve. For certain types of rocks, the curve will also show more ductile behavior when the included angle of the wedge is increased. Reichmuth (1963) recorded the force-penetration characteristic curve during the process of penetration using a load cell and a displacement transducer. As shown in the Figure 2.4a the oscillating curve represents cyclic material failure while the penetration process alternates phases of crushing and chipping. Figure $2.4 \mathrm{~b}$ shows a typical ForcePenetration curve in Indiana Limestone due to the impact of a blunt point bit. A crushed zone was formed along $\mathrm{AB}$ and a chip was formed at $\mathrm{B}$. Along $\mathrm{BC}$ the chip flow from the crater resulted in a collapse of the force. The process was repeated with different degrees of chipping at D and E. Force - Penetration curves are functions of loading rates, rock properties and tooth profiles (Reichmuth, 1963).
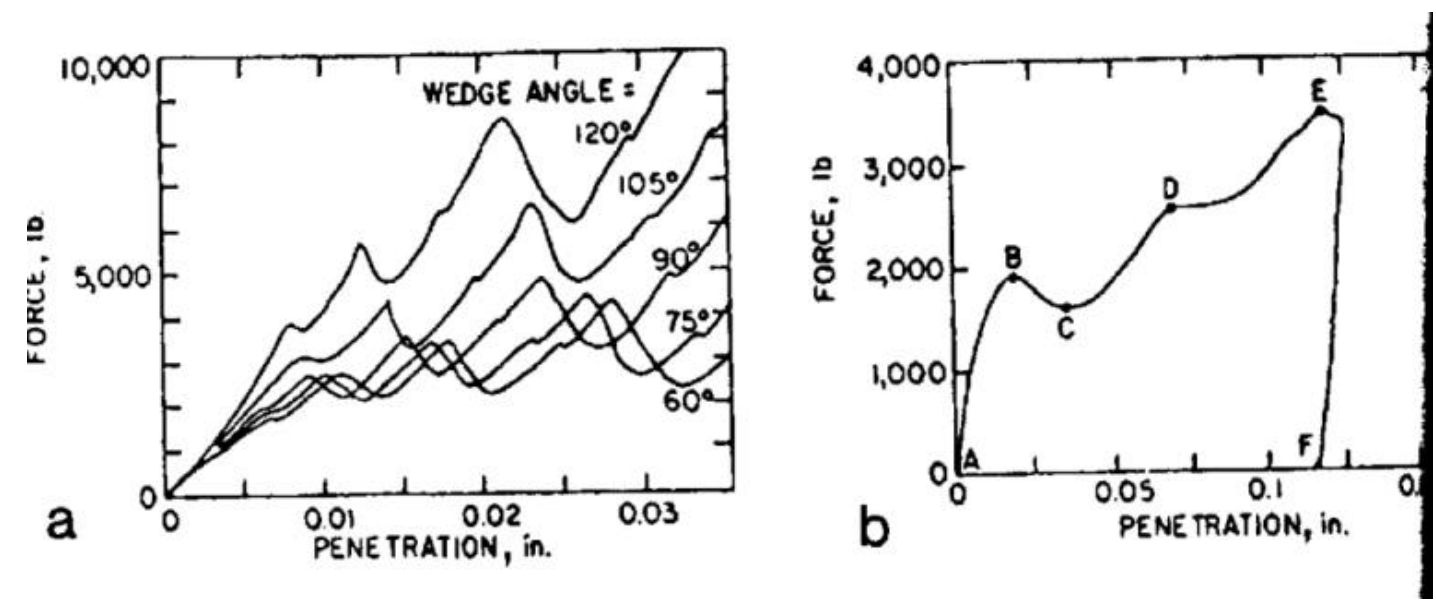

Figure 2.4a \& b Typical force-penetration curves. (a) Cyclic material failure behavior and (b) Forcepenetration curve in Indiana limestone (Reichmuth, 1973). 
Reichmuth and others have investigated the depth of penetration after cutting the indented specimen perpendicular to the wedge (Reichmuth, 1963; Singh and Johnson, 1967). The sectioned surfaces showed that the damaged depths were greater than those observed after removing the crushed material, and tensile cracks were initiated a short distance away from the bit-rock interface. These fractures started in directions radiating out from the bit. The vertical cracks ran deep into the rock while others tended to curve toward the free surface as shown in the Figure 2.5.

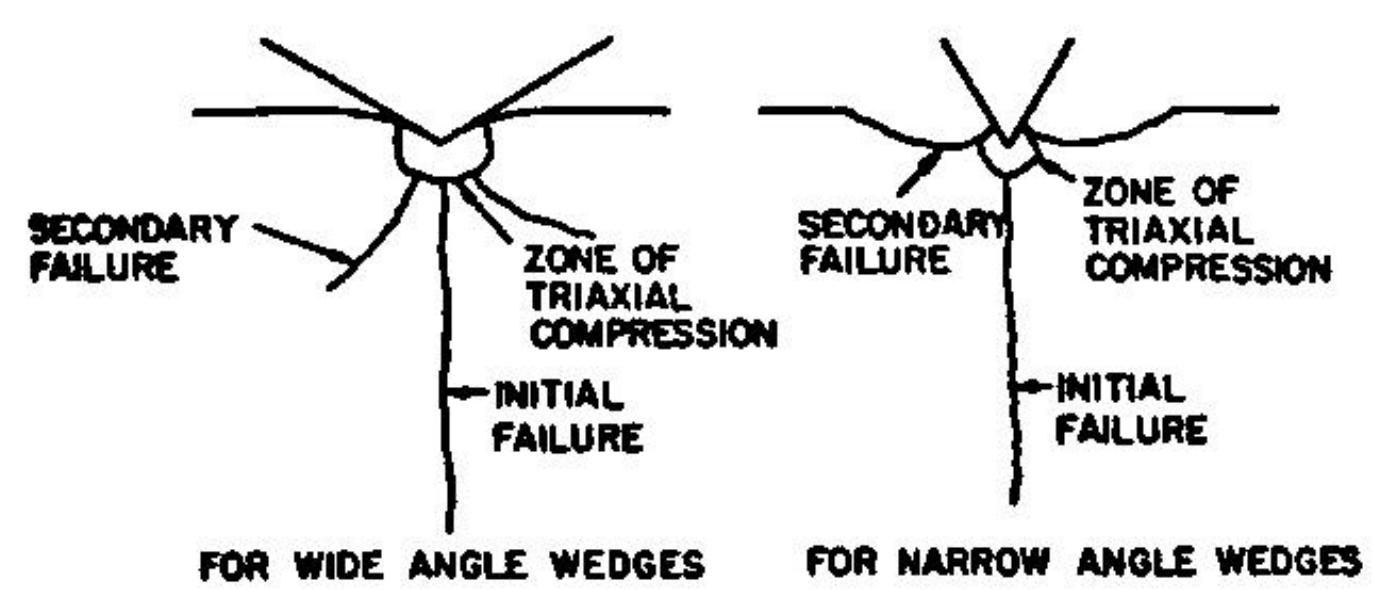

Figure 2.5 Fracture patterns for wedges (After Reichmuth, 1963).

Lindquist, et al. (1984) conducted indentation tests using a scanning electron microscope. In their experiments, they used a sharp and truncated wedge on three rock types namely limestone, marble and granite. They observed that the cracks initiated mainly at the edges and the corners of the wedges. All such cracks were much longer than the actual depth of penetration of the wedge. Crack initiation and crack paths observed in a scanning electron microscope in all the rock types are in good agreement with the assumed theoretical elastic stress fields, although the nature of the fractures is 
greatly influenced by different material properties such as grain size, cleavage planes and grain bonding.

\subsubsection{Analytical Studies}

The slip-line theory of plasticity has been applied in the study of stress field indentation problems (Cheatham, 1958; Pariseau and Fairhurst, 1967; Clark, 1972). Hill (1950) extended the theory to the case of a plastic material using an yield condition based on the Mohr - Coulomb criteria. He showed that two families of characteristics exist which are inclined at an angle of $+/-(? / 4-\varnothing / 2)$, where $\varnothing$ is defined as the angle of internal friction. The Mohr - Coulomb criteria was used to represent rock behavior because of its good first approximation with experimental results and also for mathematical simplicity. Cheatham (1958) used the same theory to study the maximum and minimum forces required to penetrate into a rock using a wedge type bit. These forces correspond to the limiting cases of rough and smooth bit-rock interface. Parieau and Fairhurst (1967) used the same theory on a wedge with smooth, frictional and rough interface conditions. Clark et al. (1972) extended the same theory to a blunt point, round point and cylindrical indentors using the same interface conditions.

Evans and Murrel (1958) used two simple models, the difference between the two being the consideration of friction. In the first case the friction was neglected, penetration resistance q, was assumed to be equal to the compressive strength, qo per unit area. 
This leads to the equation:

$$
\mathrm{F}=2 \mathrm{q}_{0} \mathrm{hw} \tan ?
$$

where, $\mathrm{F}$ is the load, $\mathrm{h}$ is the penetration measured from the level of undisturbed coal surface, w is the width of the wedge and ? is the half angle of the wedge. Experimental data on two different coal types was found to be in good agreement with the assumption that the penetration force equation becomes:

$$
\mathrm{F}=2 \mathrm{q}_{0} \mathrm{hw} \tan (?+\mu)
$$

where, $\mu$ is the coefficient of friction between the tool and the coal.

Paul and Sikarskie (1965) developed a two dimensional model which is symmetrical about the wedge axis and fracture surface and in which the chip failure was assumed to be planar. Also the frictional force exerted by the wedge on the chip was assumed to be negligible. Mohr - Coulomb failure criterion:

$$
\mathrm{S} 3=\mathrm{t}-\mu \mathrm{t}
$$

was assumed along the chip failure plane. Here $t$ and $t$ are the shear and the normal stresses on the plane and $S_{3}$ is the shear strength of the coal. Both constant displacement rate and constant load tests were conducted. In a constant displacement rate test, the force rises during the crushing phase until a chip is formed (fracture criteria) and drops to zero (curve b of Figure 2.6), while in the constant load test, the load remains constant after the chip is formed until the new equilibrium position is reached (curve $\mathrm{c}$ of Figure 2.6). The experimental results of curve $a$ in the Figure 2.6 qualitatively resemble the force penetration curve $b$ in the Figure 2.6. 
Sikarskie and Cheatham (1973) removed the planarity assumption of the chip surface and used a numerical approach to assess the "fracture function" which is conceptually equivalent to $|\mathrm{t}|-\mu \mathrm{t}$ as a function of position around the wedge-shaped indentor. When the maximum value of the fracture function reaches the critical value $\mathrm{S}_{3}$ of the Mohr-Coulomb criterion, fracture initiates at the point where the maximum stress occurs.

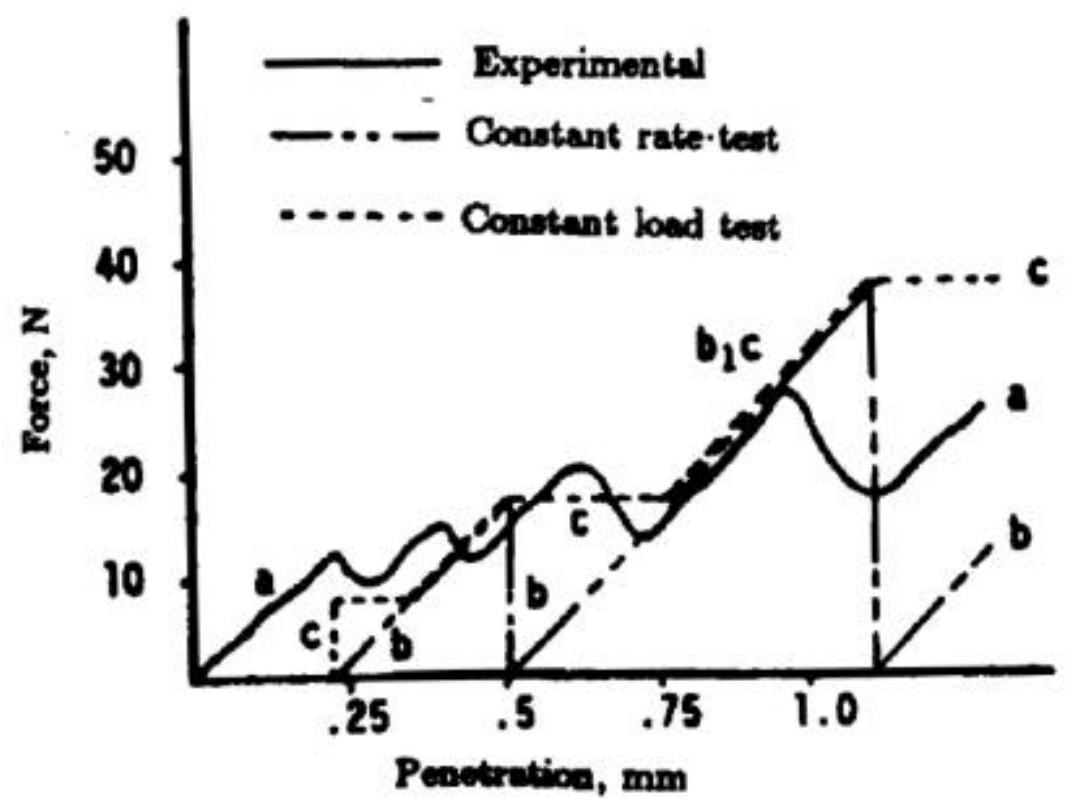

Figure 2.6 Force - penetration curve for wedge indentation of Indian Limestone (Paul andSikarskie, 1965).

Miller and Sikarskie (1973) used a conical indentor on Indiana limestone and Barre granite. The chips are assumed to be conical shells. The same behavior was observed in the case of constant rate test as in the wedge-indentor case, but with the same linear crushing law the force at chipping becomes parabolic rather than linear penetration depth (Figure 2.7). They also formulated equations to estimate the total volume of rock removed due to bit penetration. 
$\mathrm{V}=\left(? \mathrm{~d}_{\mathrm{i}}^{3} \cot ^{2} ?\right) / 3$ for cone shaped indentor.

$V=\left(4 d_{i}^{2} \cot ^{2} ?\right) / 3$ for pyramid shape indentor.

where, $\mathrm{V}$ is the volume of crater, $\mathrm{d}_{\mathrm{i}}$ is the depth of ith cutting and ? is the failure angle.

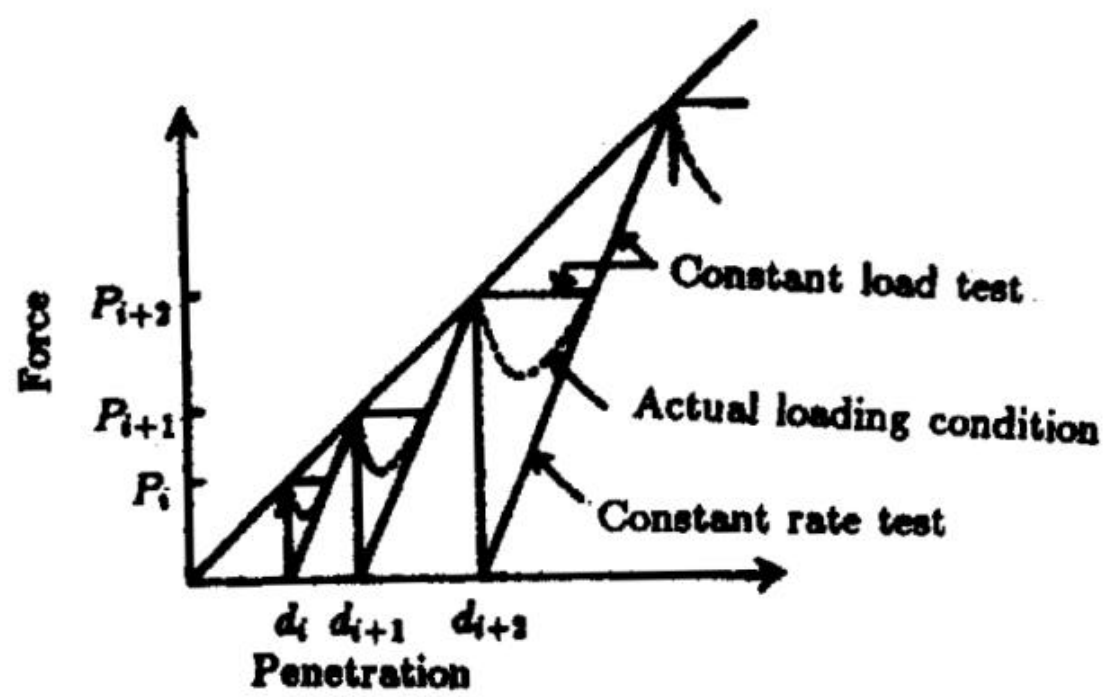

Figure 2.7 Force - penetration loading curves (Miller and Sikarskie, 1968).

Lundburg (1974) used the Paul and Sikarskie's (1965) model and conducted tests on Swedish Bohus granite. Seven indentors with apex angles in the range of $60^{0}$ to $150^{0}$ were tested. Results indicated that no chipping occurs for angles greater than $60^{\circ}$ apex angle while the crushing was observed to be predominant. Nishimatsu (1972) used the shear strength as the governing factor and analyzed the mechanics of coal cutting. He calculated the amount of plastic yield product during the cutting process. Sun et al. (1992) and Bieniawski (1967) used the fracture mechanics principles to explain the fundamentals of rock cutting process. 


\subsection{Parameters effecting dust generation}

\subsubsection{Geometric Description of the Cutting Bits}

Literature reveals that, based on the geometry there are two types of cutting bits available, point attack and the wedge shaped type (Figure 2.8a \& b). The wedge shaped bits are based on the simple two dimensional wedge. The edge of the bit may be curved or pointed. Point attack tools roughly have the shape of the common pencil and consists of a cone of hard material mounted symmetrically on a cylindrical body.
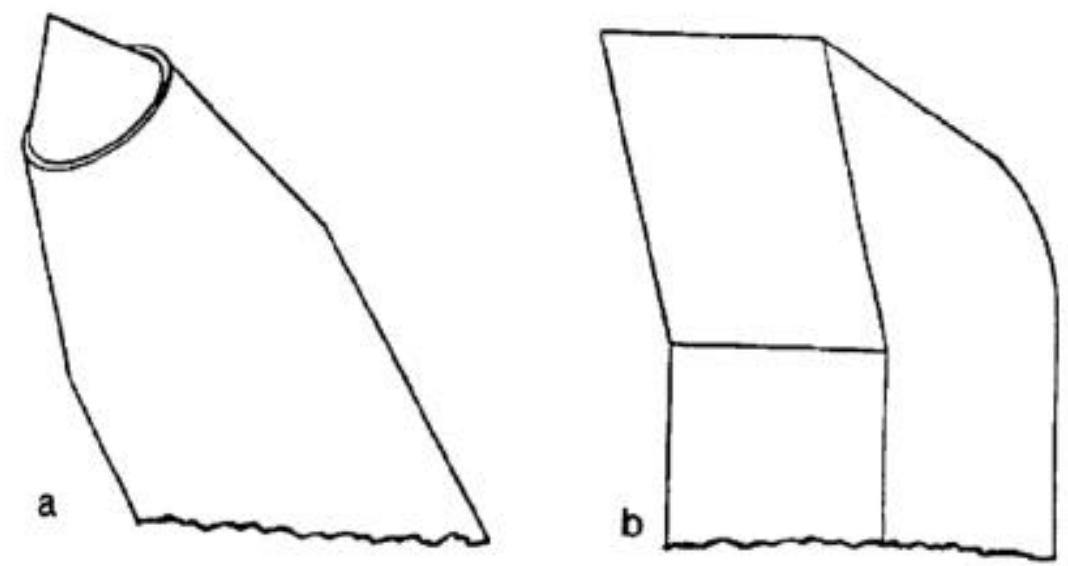

Figure 2.8 General shape of presently used bits (a) Conical bit, (b) Wedge shaped bit (Stecklien et al. 1982).

Wedge shaped bits are mostly used in the European countries and point attack bits are more frequently used in the United States. Stecklein et al. (1982) relates the use of these bits to the development of the mining industry in these countries. In Europe, longwall ploughs were initially developed and wedge shaped design was borrowed from the geometrically similar metal cutting industry. In the United States continuous miners were developed where bits are mounted on the periphery of the drum and cylindrical bits were developed. Ever since the evolution, the preference was a matter of controversy and remains even now. 
The various parameters affecting the generation of dust includes the geometric description of the cutting bits, depth of cut, cut spacing, and few other parameters like cut direction and cutting speed. The first three parameters have been studied in this work.

\subsubsection{Conical Bit s or Point Attack Bits}

The precise mode of action of the point attack bits has not been studied as extensively as the wedge shaped bits. Strebig and Zeller (1975) compared three wedge bits with two point attack bits. They concluded that bit type does not have significant effect on the dust generation. Roepke et al. (1976) used four different types of point attack bits and concluded that smaller diameter bits with overall sharp points are more efficient (they require low specific energy). This could be attributed to the fact that the cavity created by the bit is less than the diameter of the bit body travelling into the groove and hence rubs against the groove, thus creating more dust and consuming more energy.

Hurt and Evans $(1980,1981)$ concluded that point attack bits consume higher specific energy and generate more respirable dust when compared to the wedge shaped bits, regardless of the bit sharpness. However, the specific force requirements for point attack bits reduced at higher depths. Geometry of the cutting bit was also studied. Hurt (1980) noted that an angle of attack of $50^{\circ}$ would require the minimum cutting force and

a minimum back clearance angle of $12^{0}$ was necessary for point attack bits in place of $5^{0}$ for wedge shaped tools. 


\subsubsection{Wedge Shaped Bits}

Figure 2.9 illustrates the main design considerations and the forces associated with mechanical cutting. Dumbleton et al. (1958) said that, for wedge shaped bits the mean cutting forces increases as the included angle of the wedge increases from $10^{0}$ to $67^{0}$. The clearance angle of the wedge was constant at $3^{0}$ for all the bits. This suggests that the cutting forces decreases as the rake angle increases from $20^{\circ}$ to $77^{\circ}$, Pomeroy and Brown (1968) and Pomeroy (1964) studied the effect of varying rake angles $\left(0^{0}\right.$ to $\left.50^{\circ}\right)$ and reported similar results. Normal forces acting on the pick also decreases with increasing rake angles and reduce to zero for rake angles of $25^{\circ}$ and above (Pomeroy, 1964; Pomeroy and Brown 1968; and Whittaker, 1962). However, the effect of increasing rake angle nearly diminished after about $40^{\circ}$.

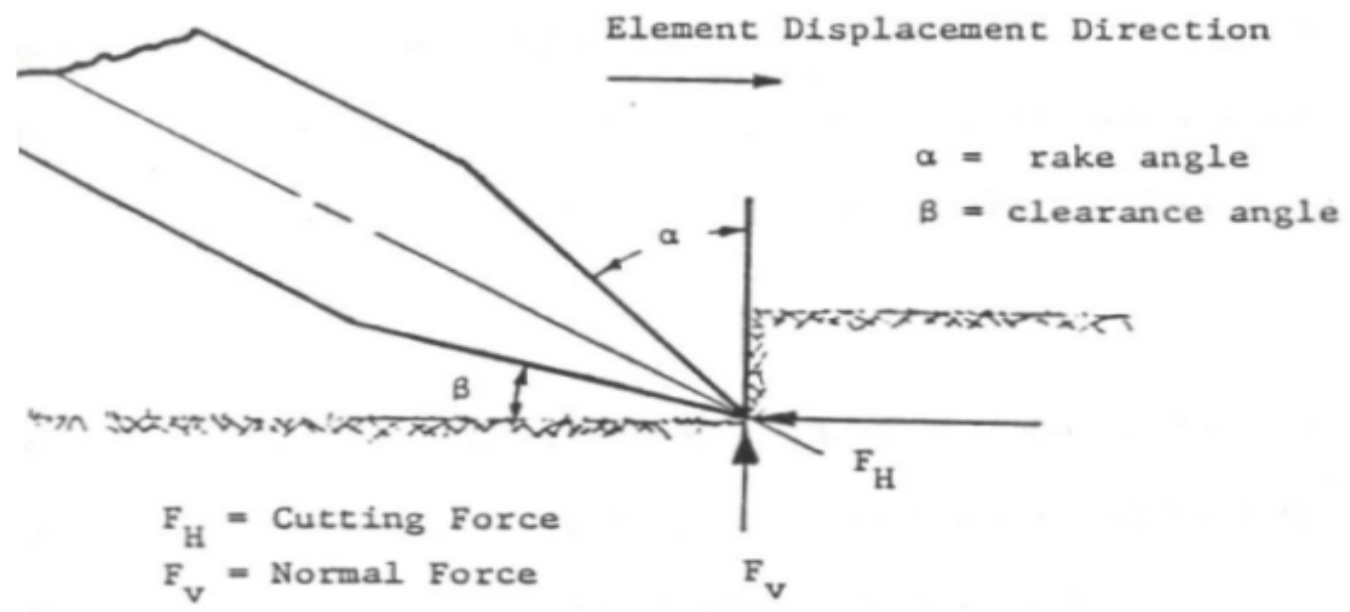

Figure 2.9 Coal cutting bit description (Stecklein, et al., 1982)

Increase in the clearance angle from $0{ }^{0}$ to $5^{0}$ has been reported to decrease the cutting and normal forces substantially but increase beyond $5{ }^{0}$ cause little further reduction in forces (Pomeroy, 1964; Evans and Pomeroy, 1966). Cutting forces alone do not measure 
the efficiency of cutting since the low cutting force might be associated with low yield of coal. A useful measure of cutting efficiency is the specific energy consumption. The specific energy consumed decreases with increasing rake angles but significant difference was not observed beyond $40^{\circ}$ rake angle (Pomeroy, 1964). Effect of included angle was studied by Evans and Pomeroy (1966) and they have found that an included angle of $120^{\circ}$ to $150^{\circ}$ would require less specific energy in the case of normal penetration, but Achanti (1998) says that an attack angle of $45^{\circ}$ will be optimum in the case conical bits with $70^{0}$ included angle in particular.

\subsubsection{Depth of Cut}

Point attack bits

Effect of depth of cut was studied by Strebig and Zeller (1975) using point attack bits, they have found that specific air borne respirable dust reduces considerably with deep cutting. Roepke et al. (1979) found that specific dust and specific energy decreases significantly as the depth of cut increases to $2.5 \mathrm{~cm}$. Studies conducted by Hanson and Roepke (1976) using a symmetrically worn bit with varying depths of cut upto $2.5 \mathrm{~cm}$. indicate that the average cutting force increases as the depth of cutting increases but the specific dust and specific energy decreases with the increase of depth of cut. Studies conducted by Achanti (1998) using conical bits shows the same results.

\section{Wedge Shaped Bits}

Werblow (1961) varied the depth of cut in wedge shaped bits and found that the mean peak force required increases linearly with increase in cutting depth. Coal yields increases with increase in depth of cut ( Pomeroy and Brown, 1968), they have found that the energy consumption decreases with increasing depth of cut and rises after reaching a 
minimum, this minimum consumption of energy corresponds to the minimum production of fine particles.

\subsubsection{Cut Spacing}

Cut spacing is defined as the distance between centers of adjoining cuts in a sequence. There are two factors, which contribute to the removal of material from the face: (1) the cutting elements continue to penetrate into the grooves and remove the material, (2) neighboring grooves interact to remove the material in the form of large chips from the lands/ridges between two adjacent grooves. The efficiency of this process depends on correct spacing, depth of cut and several other parameters like the tool size, thrust and the type of the material.

Barker (1964) and Pomeroy and Borwn (1968) have reported that the optimum spacing depends on the depth of cut. For a cut spacing at which neighboring grooves interact, the cutting force decreases after reaching a maximum. This maximum normally corresponds to the optimum conditions of high volume, low specific energy and low specific dust. Cut spacing for point attack bits have been studied by Roepke et al. (1976), and suggested that a spacing to depth ratio of 2 and 3 to be optimal. Hurt and Evans reported that, the specific energy decreases with depth and spacing, rapidly at first and then more slowly. Roepke (1984) suggested that a spacing of 2 to 3 times $2 / 3$ maximum depth, while Roxborough et al. (1981) reported a space to depth ratio of 2 to be optimal. However, a proper space to depth ratio which assures that each bit is taking as deep a depth as possible, with efficient breakout can be found through experimentation for any set of operating conditions. 
Several other parameters like the cutting head velocity, confining pressure and cutting speed (rate of advance of the drum) effect the amount of respirable dust generated. Although considerable research has been conducted both experimentally and theoretically on rock cutting, most of those studies used linear cutting principle (Evans et al. 1966; Lundberg, 1974; O’Dougherty et al., 1963 and Pomeroy, 1963) at a constant cutting depth and later the results were employed to rotary cutting. But Khair (1984) designed a laboratory scale simulated continuous miner to investigate the rotary cutting concepts and to characterize the coal breakage. Khair et al. (1989) presented several stages in chip formation and primary sources of dust generation during both coal and rock cutting utilizing the simulated continuous miner.

\section{$2.4 \quad$ Theories of Rock Breakage}

One of the fundamental theories of rock cutting was proposed by Evans et al. (1966). Evans's model of tensile rock failure described the penetration of a wedge into the buttock of coal. Several other researchers made use of this theory to explain the general failure phenomenon of rock breakage ( Whittaker et al. 1973; Roxborough et al. 1982). Evans (1984) proposed a modified theory of cutting force for point attack bits in which most of the concepts were retained from his earlier theory. The following equation provides the cutting force required for cutting the rock as a function of its both compressive and tensile strength. 
$\mathrm{P}_{\mathrm{c}}=\left(16 ? \mathrm{ldd}^{2}\right) / \mathrm{u} \cos ^{2} \mathrm{t}$

where $\mathrm{P}_{\mathrm{c}}$ is the cutting force exerted by the cone of the bit, $\mathrm{u}$ is the unconfined compressive strength, $t$ is the tensile strength, $₫$ is the semi-angle of the cone, 1 is the slant cutting depth of the point of interest, and $d$ is the cutting depth.

2. Nishimatsu (1972) used the Mohr-Coulomb criterion of failure for stress conditions during the formation of chip. Assuming the shear strength is the parameter governing failure, he provided an equation to predict the required cutting force, $F_{c}$.

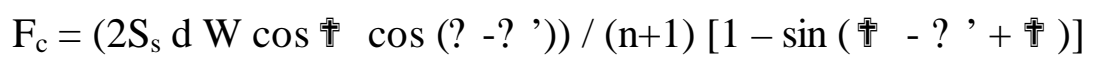

where $S_{s}$ is the shear strength of rock, $d$ is the depth of cut, $W$ is the width of the pick, $t$ is the angle of internal friction, ? is the angle of friction of rock cutting, ? 'is the rake angle, and $\mathrm{n}$ is the stress distribution factor. 


\section{Chapter 3}

\section{METHODOLOGY}

Literature review reveals that substantial quantities of dust are created by the process that follow the actual cutting of coal, including the crushing of pieces between the drum and the face, impact of pieces on the floor etc. However, it is important to know how much dust is being generated in the cutting process itself. Coal deposits are often encapsulated in sedimentary rocks such as shale, sandstone or limestone. During the extraction of coal, the roof and floor of the coal seams often consists one of these rocks. It is a common occurrence to cut these rocks during the cutting of coal. Studies carried out using rock material such as Indiana limestone can be meaningful for analyzing coal and other equal strength materials. It should be noted that the Indiana limestone has been used in many research works and it has good directional homogeneity. Thus, for the purpose of current studies Indiana limestone is chosen.

The continuous mining machines employ rotary cutting technique. The main cutting parameters that influence the cutting efficiency of a continuous miner include bit spacing, depth of cut, bit geometry. For the purpose of the current studies an Automated Rotary Coal Cutting Simulator (ARCCS) shown in the Figure 3.1 was used. This simulator enables the experimenter to simulate the in situ vertical and horizontal confining pressures and to vary several other operating parameters like the depth of cut, cut spacing, velocity of the cutting head etc. 


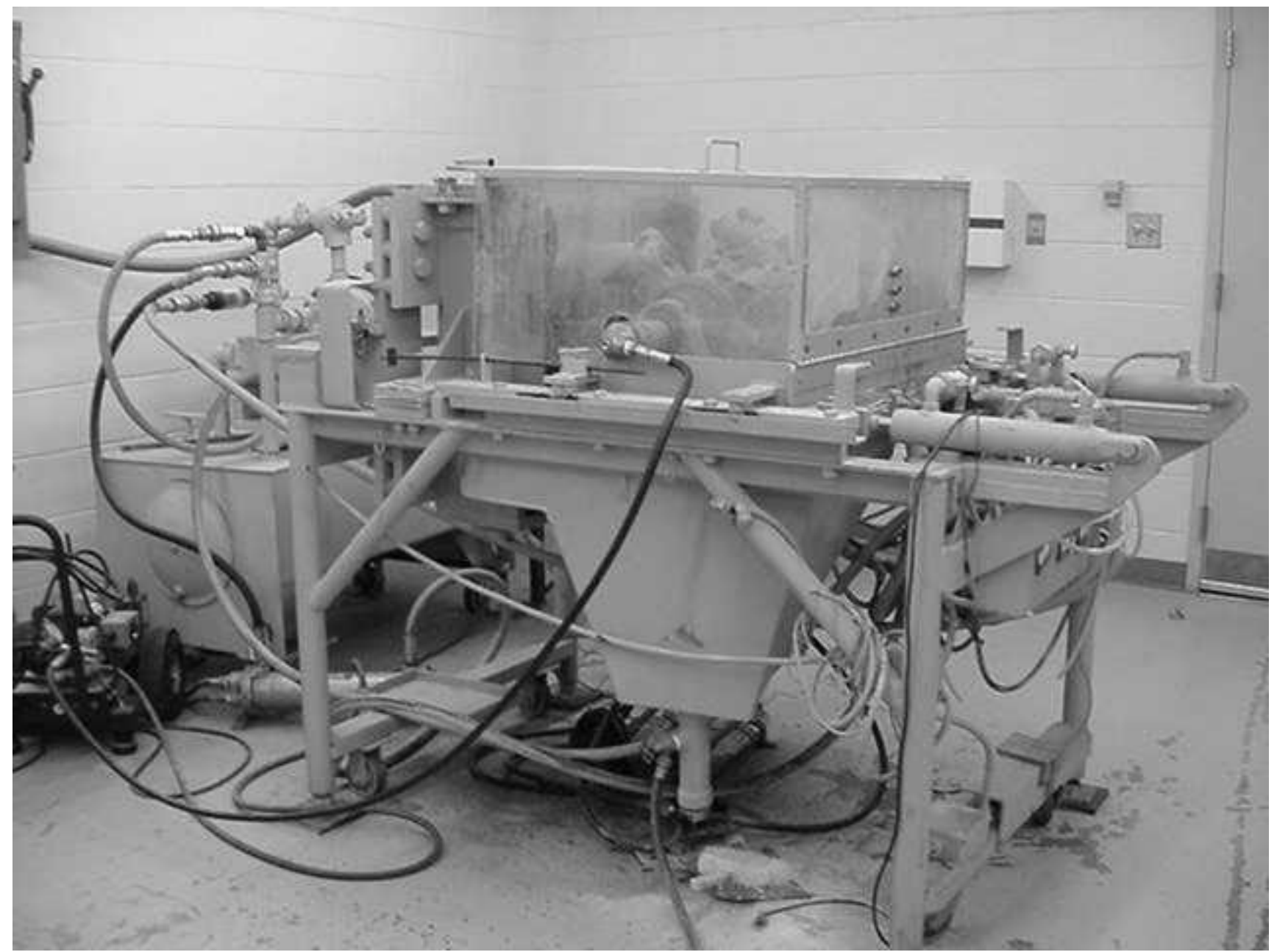

Figure 3.1 Automated Rotary Coal/Rock Cutting Simulator. 
The research work is essentially designed to investigate the relationship between the cutting parameters like the cutting force, penetration force, depth of cut, and bit spacing and the bit geometry parameters like the angle of the cutting tool, bit tip size with a view to reduce the amount of respirable dust generated in the cutting process. There is a land/ridge formed in between two adjacent grooves, if this land/ridge can be removed with minimum expense of energy then that cutting process will become efficient. If the spacing between two adjacent grooves is optimal then the two cuts will be interacting with each other and help in removing the land/ridge. If the land/ridge is removed in one cutting cycle then a clean cut face will be provided for the subsequent cutting cycles and it helps in reducing the amount of respirable dust that is being generated.

\subsection{Description of the ARCCS}

A brief description of the major parts of the ARCCS is given in the following sections.

\section{Main Frame:}

The machine is mounted on a rectangular frame of $1.5 \mathrm{~m} \mathrm{x} 1.1 \mathrm{~m}$ side dimensions and four legs. The legs are provided with wheels for easy maneuverability.

\section{Confining Chamber:}

The confining chamber is made of 1 in. thick steel. Inside dimensions are $76.2 \mathrm{~cm}$ x $50.8 \mathrm{~cm} \mathrm{x} 17.78 \mathrm{~cm}(30$ in $\times 20$ in $\times 7$ in ). The confining pressure to the blocks of material is applied by four hydraulic cylinders. Two of these were of 10 ton capacity each 
(which apply horizontal pressure), and the other two were of 20 ton capacity (which apply vertical pressure). Hydraulic pressure to the cylinders was applied by two manually operated hydraulic pumps.

\section{Cutting Drum:}

The cutting drum is $17.78 \mathrm{~cm}$ (7.0 in) in diameter and $30.5 \mathrm{~cm}(12 \mathrm{in}$.$) in width.$ The metered hydraulic fluid flow gives the flexibility to rotate the drum at different rotations per minute. Advancing and retreating of the cutting drum is accomplished by four hydraulic cylinders, two for advancing and two for retreating.

Other important parts of the ARCCS are the movable frame arrangement, air current generating unit, automated control and monitoring system.

\subsection{Physical and Mechanical Properties of Indiana Limestone}

The Indiana limestone rock is obtained in blocks with dimensions of 19in x 12.5in $x$ 7in. All the test blocks were finished to suit the testing conditions of the confining chamber of the ARCCS. The cutting bits were mounted on the cutting head and the attack angle of the bits was kept constant at $45^{\circ}$ for all the experiments. The Indiana limestone is popularly known as Standard Buff and is oolitic limestone. It is a calcite cemented calcareous stone formed of shells and shell fragments, practically a non-crystalline in character. It possesses a remarkable uniformity of composition, texture, and structure. Table 3.1 describes the physical and mechanical properties of this rock material obtained in the laboratory through standard test procedures. 
Table 3.1 Physical and mechanical properties of Indiana limestone

\begin{tabular}{|l|c|}
\hline Rock Property & Value \\
\hline Unconfined Compressive Strength, psi & 4786.3 \\
\hline Young's modulus, psi & $2.51 * 10^{6}$ \\
\hline Tensile Strength (Brazilian), psi & 449.6 \\
\hline Direct Shear Strength, psi & 565.6 \\
\hline Poisson's ratio & 0.25 \\
\hline Specific gravity & \\
\hline Flextural strength (3-point loading), psi & \\
\hline
\end{tabular}

\subsection{Data Acquisition Methods}

The data acquisition system and the physical measurement devices are available in the rock/coal cutting laboratory. Using the facilities the following parameters were studied in each experiment:

? Cutting Pressure

? Penetration Pressure

? Cutting Depth

? Amount of Respirable dust generated

? Mass of rock cut product. 
A model 1246 strip chart recorder is the main part of the data acquisition system with the ARCCS. The experimental data on cutting pressure, penetration pressure, and the depth of cut are fed to the strip chart recorder. Research suggest that an attack angle of $45^{\circ}$ is an optimum and also has least significant effect on other bit related parameters (Hanson and Roepke, 1979 and Reddy, 1988). So the angle of attack was kept at a constant $45^{\circ}$ for all the experiments. The vertical confinement pressure was kept at

approximately 2000 psi. The horizontal confinement pressure was about $\frac{1}{3}$ rd of the vertical confinement pressure. The maximum depth of cut was about $1.5 \mathrm{in}$. The advance rate of the cutting platform was kept at $0.525 \mathrm{~mm} / \mathrm{s}$. A number of experiments were conducted at 2.0 in., 2.5 in., and 3.0 in. of bit spacing but the lands/ridges were not removed at those spacings. So the experiments were conducted at 0.5 in., 1.0 in. and 1.5 in. of spacing and to a depth of cut of $1.5 \mathrm{in.}$

\subsection{Dust Sampling}

Series 296 type Marple personal cascade impactors were used to collect the respirable dust (after Anon, 1982). These impactors have six stages and a backup filter. They can give complete, accurate aerodynamic particle size distributions. Two impactors, one at the top and one at the bottom with respect to the cutting head, are mounted during every experiment. Du-pont air pumps were used to operate the cascade impactors. The air pumps were recharged to full before conducting each experiment. The suction rate of the air pumps was maintained at $2 \mathrm{~L} /$ minute. The principle of operation of the impactors in based on the flow entering the inlet cowl and accelerating through the six radial slots in 
the first stage. Particles larger than the cut point of the first stage impact on the perforated collection substrate. Then, the air stream flows through the narrower slots in the second stage of impactors, smaller particles impact on the substrate in the second stage and so on. The width of the radial slots is constant for each substrate but is smaller for each succeeding stage. The jet velocity is higher for each succeeding, and smaller particles eventually acquire sufficient momentum to impact on one of the stages.

The six stages of a cascade impactor, stages 3 to 8 , collect particles with different Geometric Mean Diameter (GMD) in each stage. Table 3.2 describes the GMD of different stages. The impactors were prepared 24 hours before they were used. The preparation includes the following: cleaning of each stage, cleaning the cowl, and evenly spraying the grease to form a film under the slots of the preceding stage. Model C-290MY mylar media filters, 34mm. in diameter were greased by model 290IGS Impaction Grease Sprayer. The original weight of the substrate was measured immediately before and after an experiment to the nearest $0.01 \mathrm{mg}$. by a Sartorius type 2462, semiautomatic, electronic analytical balance with digital readout. The amount of settled dust generated for each experiment was collected in a chamber under the cutting and was weighed subsequently.

Table 3.2 Different stages and their GMD in a cascade impactor.

\begin{tabular}{|l|l|l|l|l|l|}
\hline Stage & Stage 3 & Stage 4 & Stage 5 & Stage 6 & Stage 7 \\
\hline GMD microns & 12.25 & 7.75 & 4.58 & 2.65 & 1.34 \\
\hline
\end{tabular}




\subsection{Characteristics of Cutting Bits}

Conical and drag bits were used in this study. The conical bits used in the study were obtained from Kennametal Inc. of Bedford, Pennsylvania ( Kennametal, 1996). They were typically made of 15B35 steel and are simultaneously brazed and heat-treated. The tips are composed of tungsten carbide. The insert has an average density of $14.6 \mathrm{~g} / \mathrm{cm}^{3}$, contains $8.2-8.8 \%$ of cobalt.
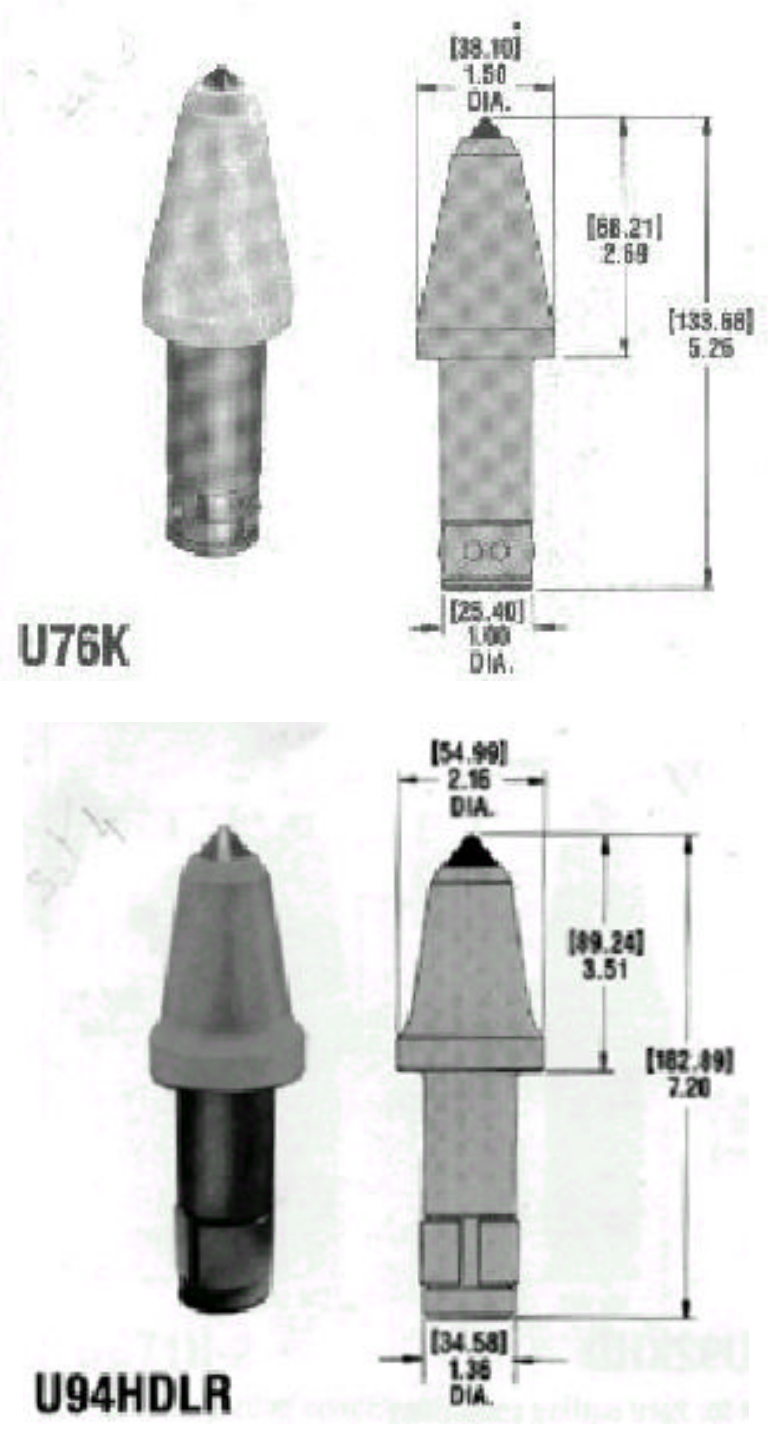

Figure 3.2 a \& b Two of the conical cutting bits used. 
The drag bits are made of fully heat treated alloy steel. They are commonly used in longwall and boring machines. They have gage sizes of 2.25", and 3.0".
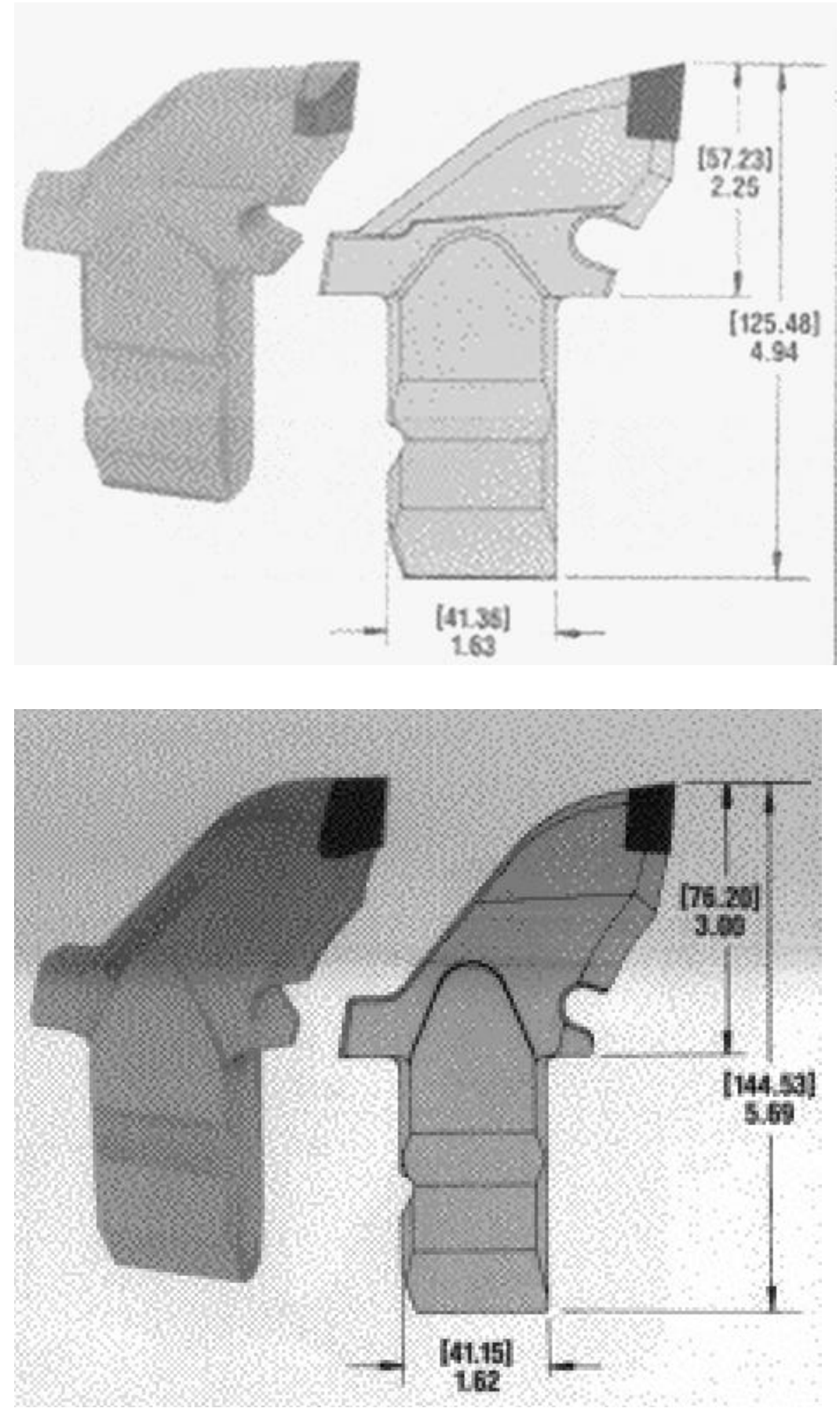

Figure 3.3 Drag bits used. (Top KR225, Bottom KR300) 


\subsection{Experimental Work}

The objective of these experiments was to remove the lands/ridges in a cutting cycle to produce a clean cut face for the subsequent cutting cycles which will reduce the amount of respirable dust being generated. In order to assess the bit spacing, which will produce a clean cut face, bits are tested using one bit at a time at several spacings. Additional experiments were conducted using a different cutting sequence to optimize the specific energy required in the cutting process. Figure 3.3 a shows the sequence in which the cuts were made in the experimental work. Bit 1 first cuts the rock, then Bit 2 cuts the rock in the second cutting cycle and Bit 3 cuts the rock in third cutting cycle. These tests were conducted at spacings 0.5 in., 1.0 in. and $1.5 \mathrm{in}$.

A second series of experiments was conducted to identify the influence of cutting sequence on the cutting process (in the removal of lands/ridges). Figure 3.3b shows the arrangement of alternative series of experiments conducted. Bit 1 was used to make a cut to a depth of $1.5 \mathrm{in}$. and then Bit 2 is used at a spacing of 1.5 in. to make a cut to a depth

of 1.5 in. Bit 3 was used to cut in between the two existing grooves to study the influence of two available free faces on both sides of a cut and to analyze the amount of specific energy required when there are two free faces in relation to the first case in which there is only one free face available.

The bit geometry parameters like the bit tip angle and bit tip size ranges and the cutting parameters like the spacing used in the studies are as follows: 
Bit tip angles: $70^{\circ}, 75^{\circ}, 100^{\circ}$.

Bit tip sizes (diameter): $9.53 \mathrm{~mm}, 11.11 \mathrm{~mm}, 12.7 \mathrm{~mm}, 19.05 \mathrm{~mm}, 24.61 \mathrm{~mm}$.

Bit spacing: 0.5 in., 1.0 in., 1.5 in.

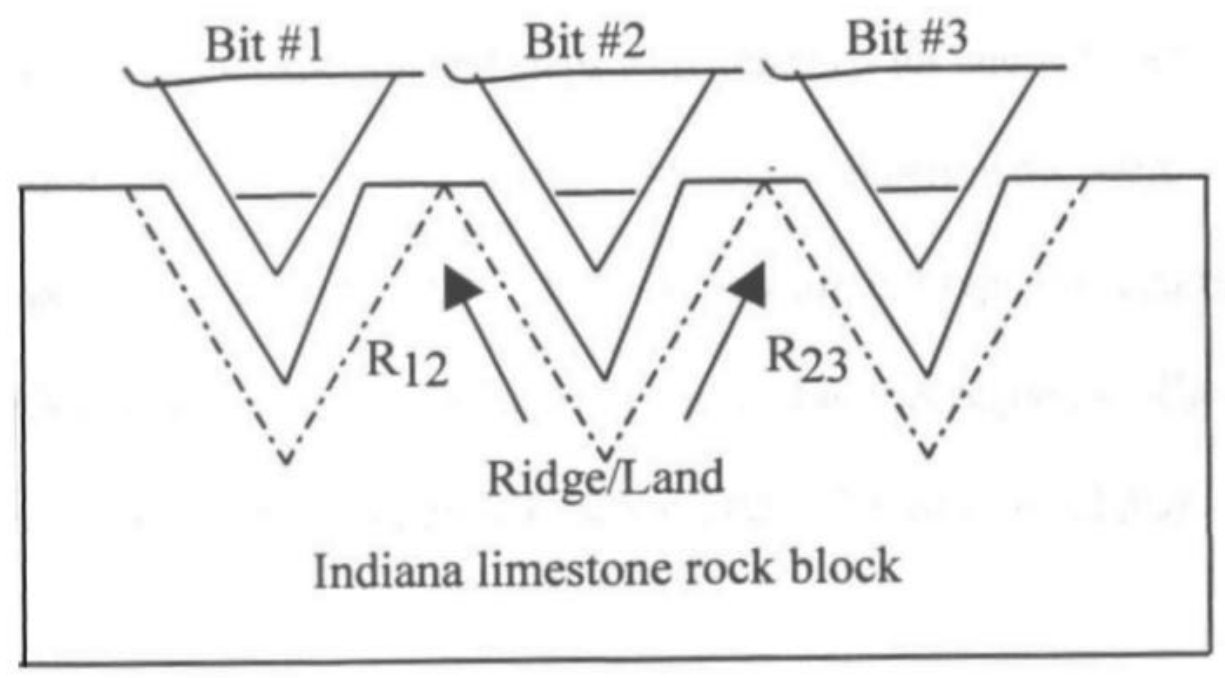

Figure 3.4 a Cutting sequence used in the studies.

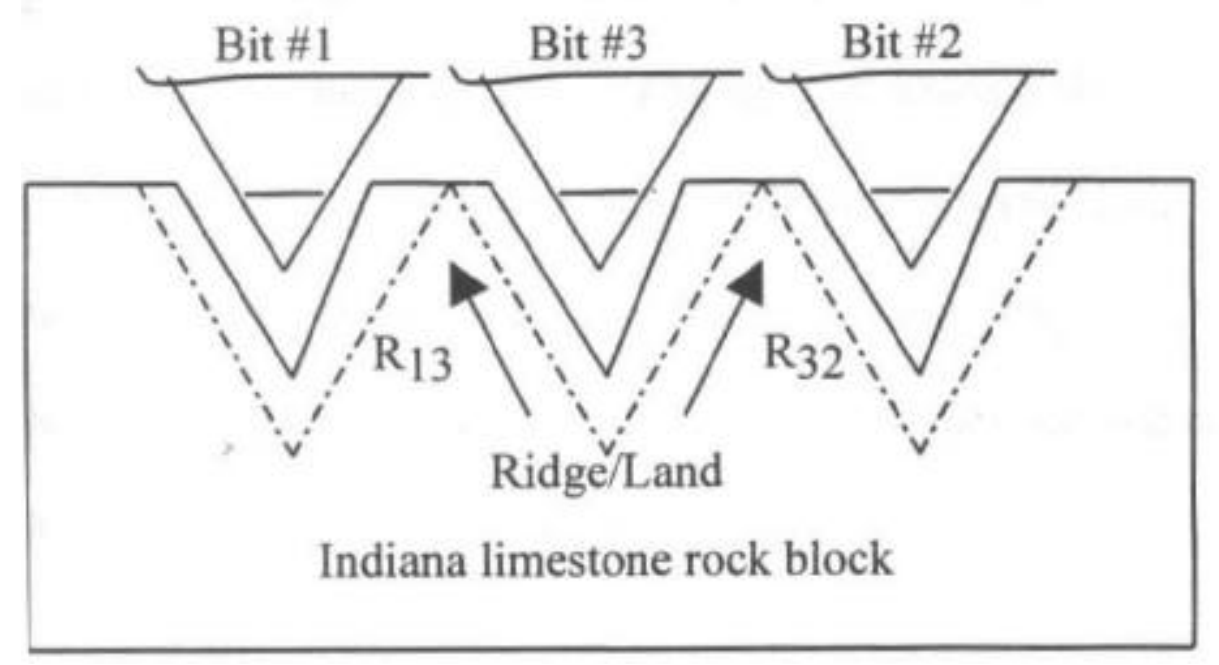

Figure 3.5 b Alternate Cutting sequence used in the studies. 


\section{Chapter 4}

\section{Experimental Results and Discussion}

In this study a total of five conical bits and two wedge shaped bits were used. In the first set of experiments one cut was made into a rock block before there are any existing cuts, then the spacing was changed to make subsequent cuts. For all the bits the spacing was changed to $0.5,1.0,1.5 \mathrm{in}$. and subsequent cuts were made to maximum possible depth of about 1.5 in. The cutting pressure, penetration pressure and the continuous change of depth of cutting were plotted on the chart plotter. The change of cutting and penetration forces with the changing depth of cut for a typical bit (U76K) are shown in Figures 4.1a - 4.1d. These figures show that the cutting and penetration forces increases as the depth of cutting is increasing in all the cases of spacing. The required cutting and penetration forces are reduced in the cases of $0.5 \mathrm{in}$. spacing and 1.0in. spacing, but the required forces are almost unchanged in the case of $1.5 \mathrm{in}$. spacing. The force values are plotted along the $\mathrm{Y}$-axis and the increasing depth of cut is plotted along $\mathrm{X}$-axis. A brief description of the experimental results using the bits is given in the following sections.

U76K: U76K bit has a tip angle of $70^{\circ}$ and its tip diameter is $9.53 \mathrm{~mm}$. For the first cut (Figure 4.1a), when there was no pre-existing cuts on its sides, the average penetration force was about $1925 \mathrm{lbf}$ and the cutting force was about $1330 \mathrm{lbf}$. Figure $4.1 \mathrm{~b}$ shows the variation of cutting force and penetration force with depth of cut at a spacing of $0.5 \mathrm{in}$. When another cut was made at about 0.5 in. from the first cut $(0.5$ in. spacing) the average penetration force required to cut to the same depth of $1.5 \mathrm{in}$. was reduced to 630 
lbf that is only $33 \%$ of the initial penetration force, and cutting force was about $560 \mathrm{lbf}$ that is $40 \%$ of the initial cutting force required. The land/ridge was completely removed and there was a clean free face available for the subsequent cuts.

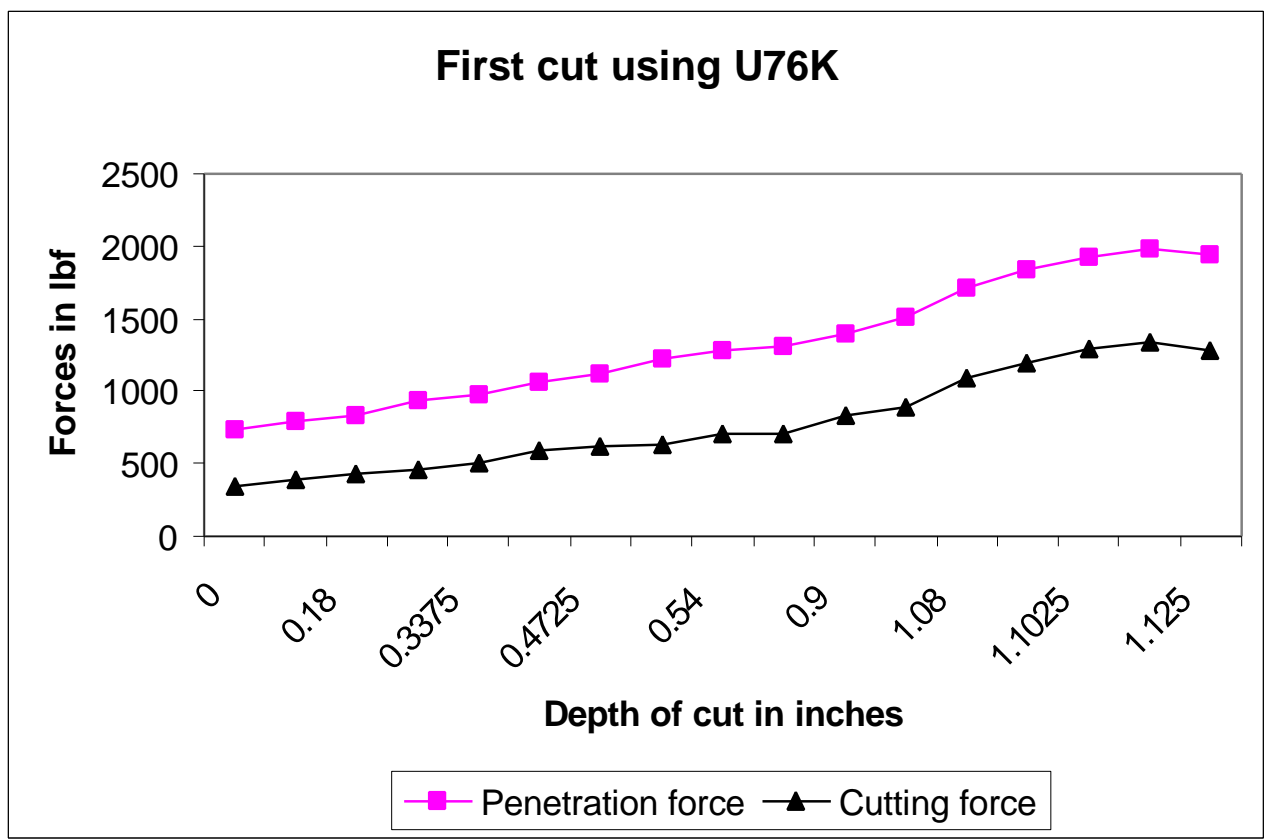

Figure 4.1a First cut using U76K (penetration and cutting forces)

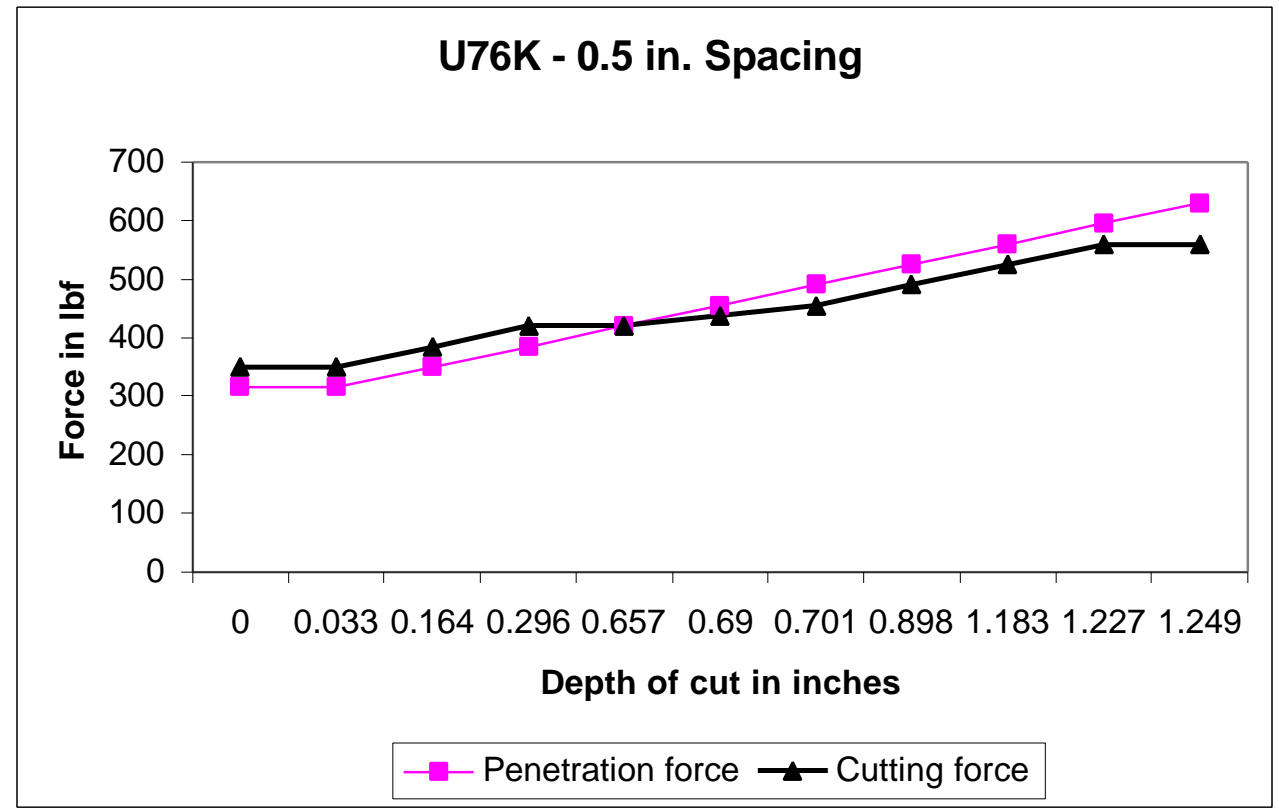

Figure 4.1b U76K - 0.5 in. spacing (penetration and cutting forces) 
When the spacing was increased to 1 in. (Figure 4.1c) the penetration force was $1155 \mathrm{lbf}(60 \%$ of the initial penetration force) and the cutting force was $805 \mathrm{lbf}$ (about $60 \%$ of the initial cutting force). The removal of land/ridges was good.

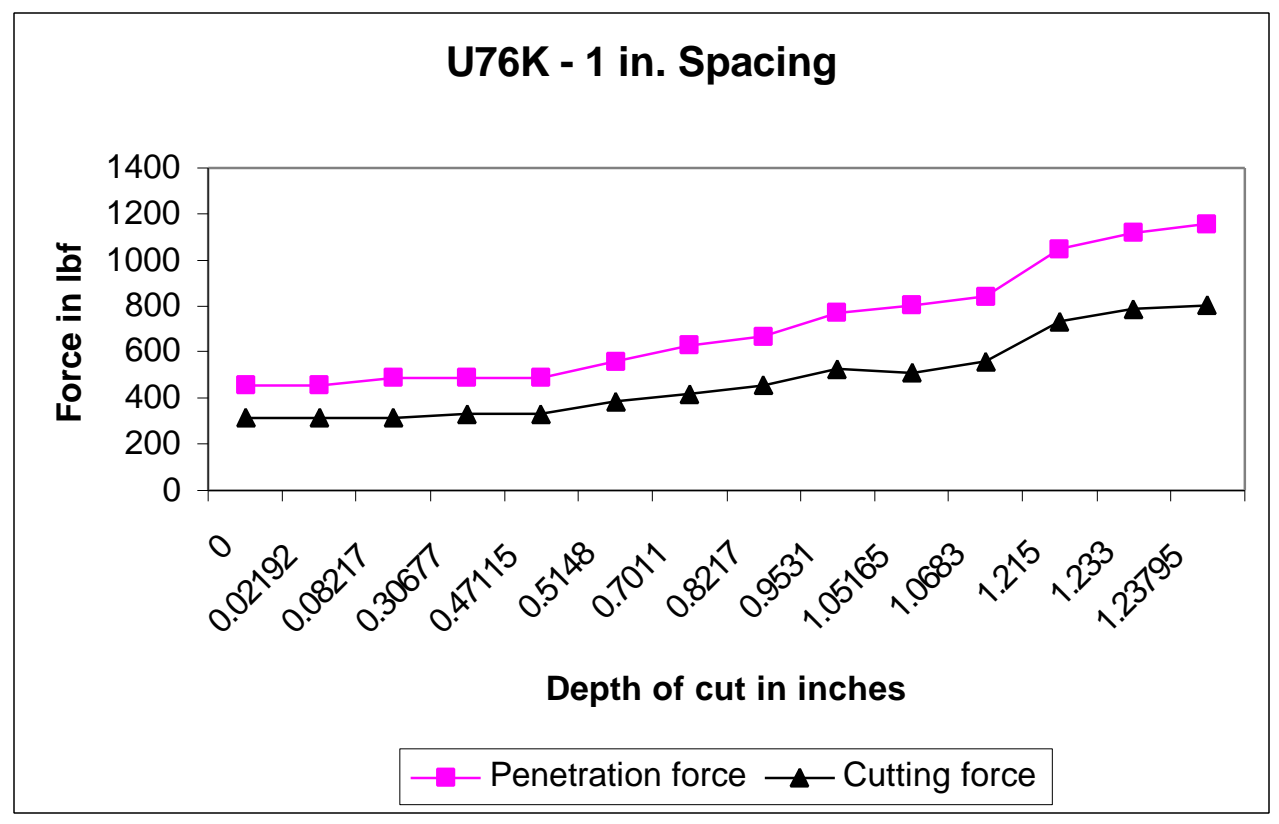

Figure 4.1c U76K - 1 in. spacing (penetration and cutting forces)

When the spacing was increased to 1.5 in. (Figure 4.1d) the penetration force was $1925 \mathrm{lbf}$ (same as the initial penetration force required) and cutting force was $1260 \mathrm{lbf}$ (about $95 \%$ of the initial cutting force), this may show that there is no influence of the previously cut grooves when the spacing is $1.5 \mathrm{in}$. for these type of bits. The land/ridge removal was not satisfactory this also shows that there is not much influence of the existing (pre-cuts) when the spacing is increased to $1.5 \mathrm{in}$. 


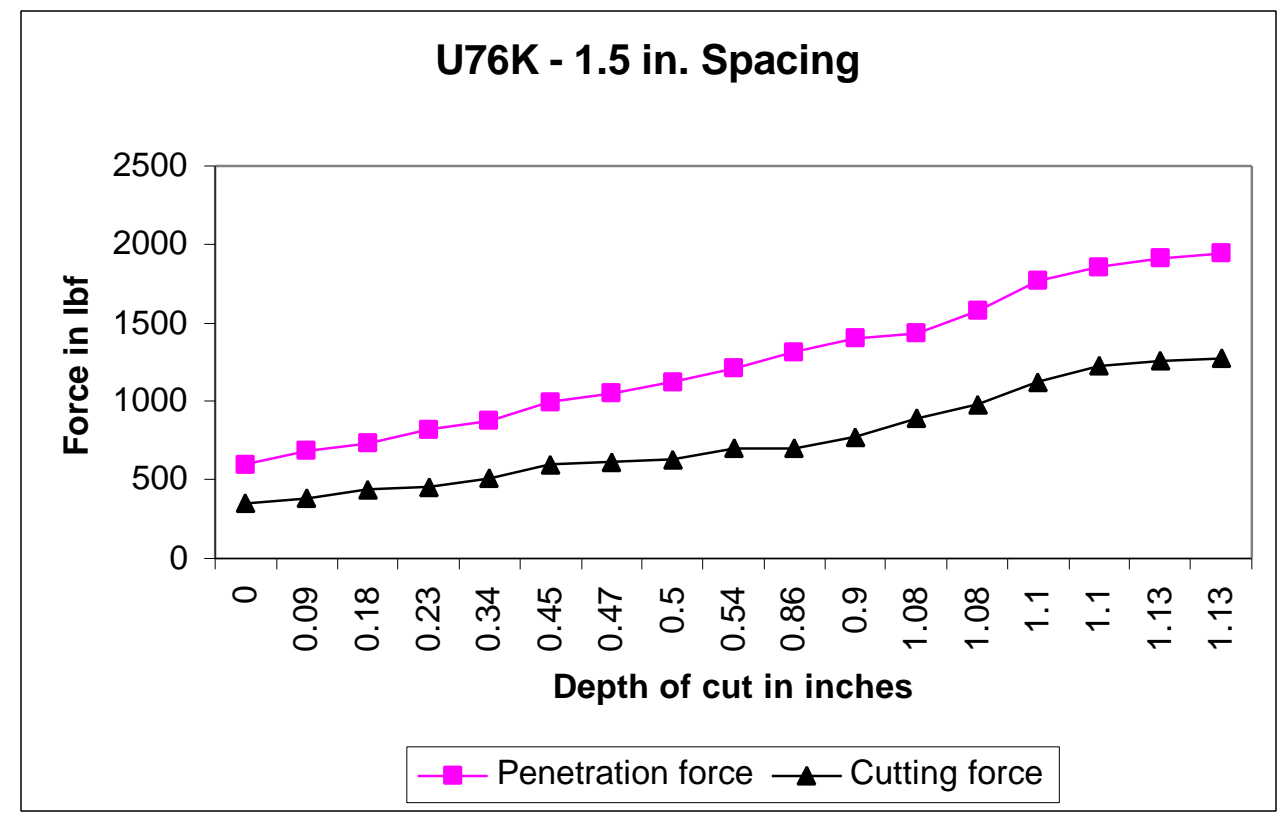

Figure 4.1d U76K - 1.5 in. spacing (penetration and cutting forces)

Figure 4.2a shows the variability of penetration force, and Figure $4.2 \mathrm{~b}$ shows the variability of cutting force using U76K. These figures show that the amount of required penetration and cutting forces are increasing with increasing bit spacing.

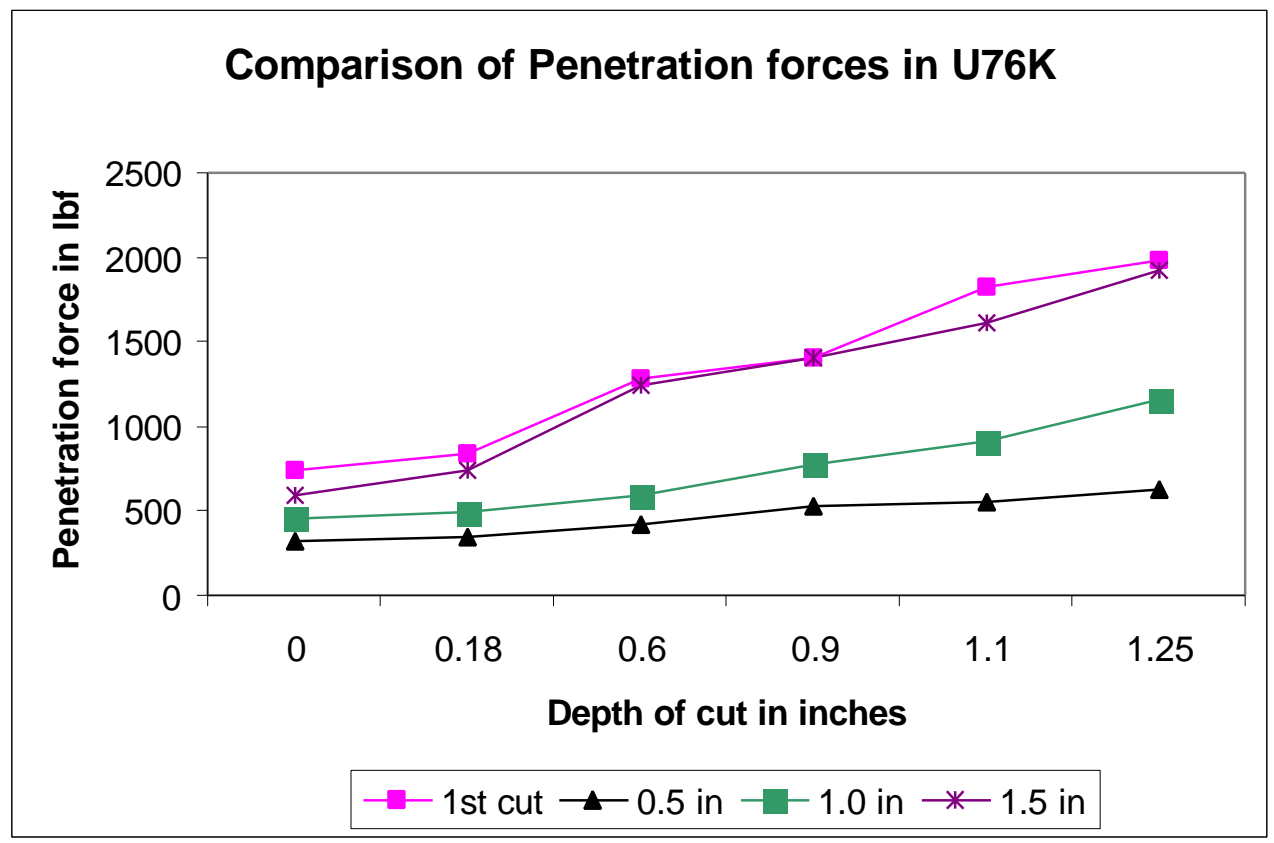

Figure 4.2a Comparison of penetration forces in $\mathbf{U 7 6 K}$ 


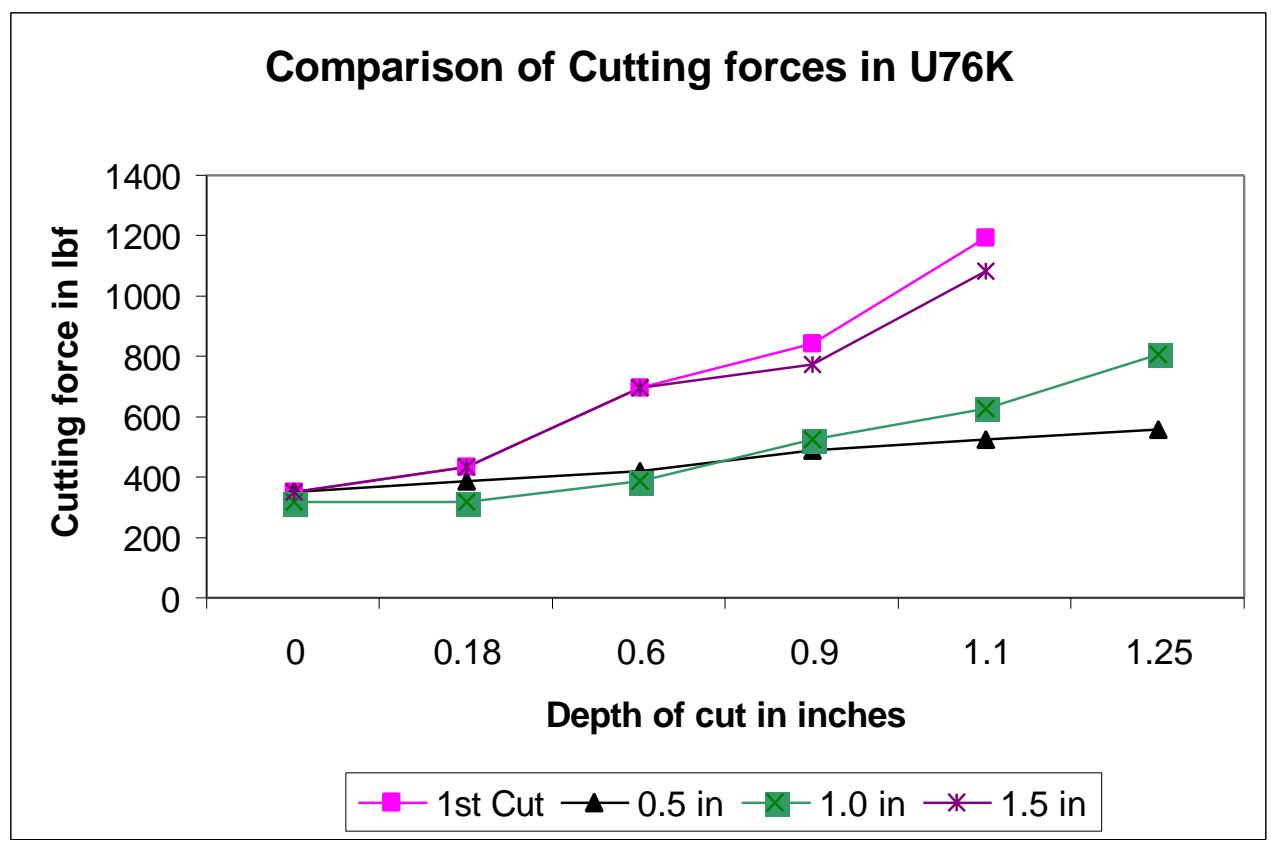

Figure 4.2b Comparison of cutting forces with U76K

Figure 4.2c shows the amount of specific respirable dust generated at the three spacings $0.5,1.0$, and 1.5 in. It shows the amount of respirable dust collected in both the top and bottom cascade impactors. It can be seen from these figures that the amount of respirable dust produced increases with increasing bit spacing. For all other cutting bits used in the study only the graphs comparing the variation of penetration and cutting force are presented here.

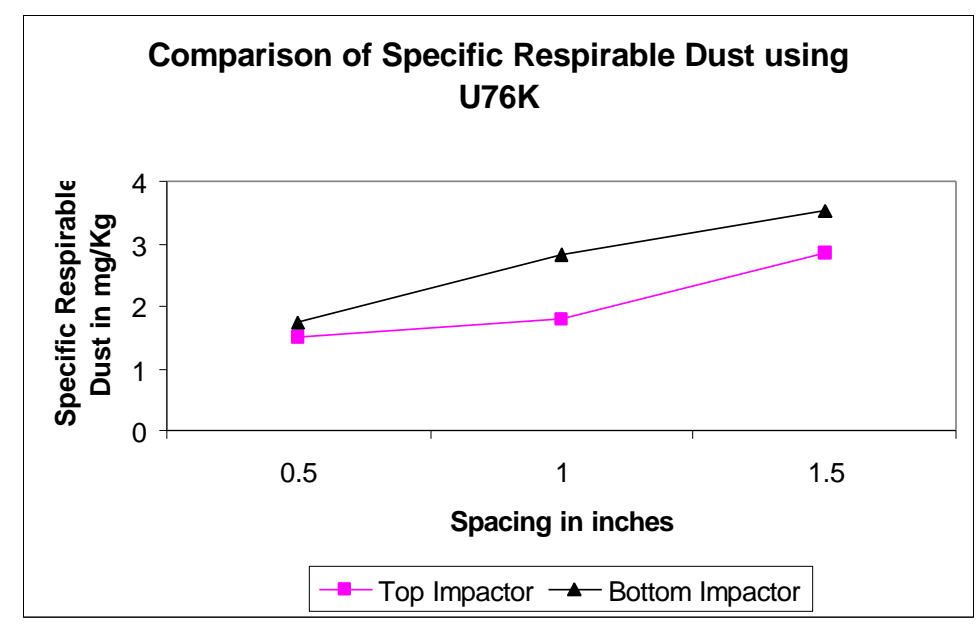

Figure 4.2c Comparison of respirable dust using U76K 
The Figure 4.2d shows the specific energy changes in U76K at different spacings, the specific energy changes from $96 \mathrm{~J} / \mathrm{Kg}$ to $162 \mathrm{~J} / \mathrm{Kg}$ when the spacing changes from 0.5 to $1.5 \mathrm{in}$.

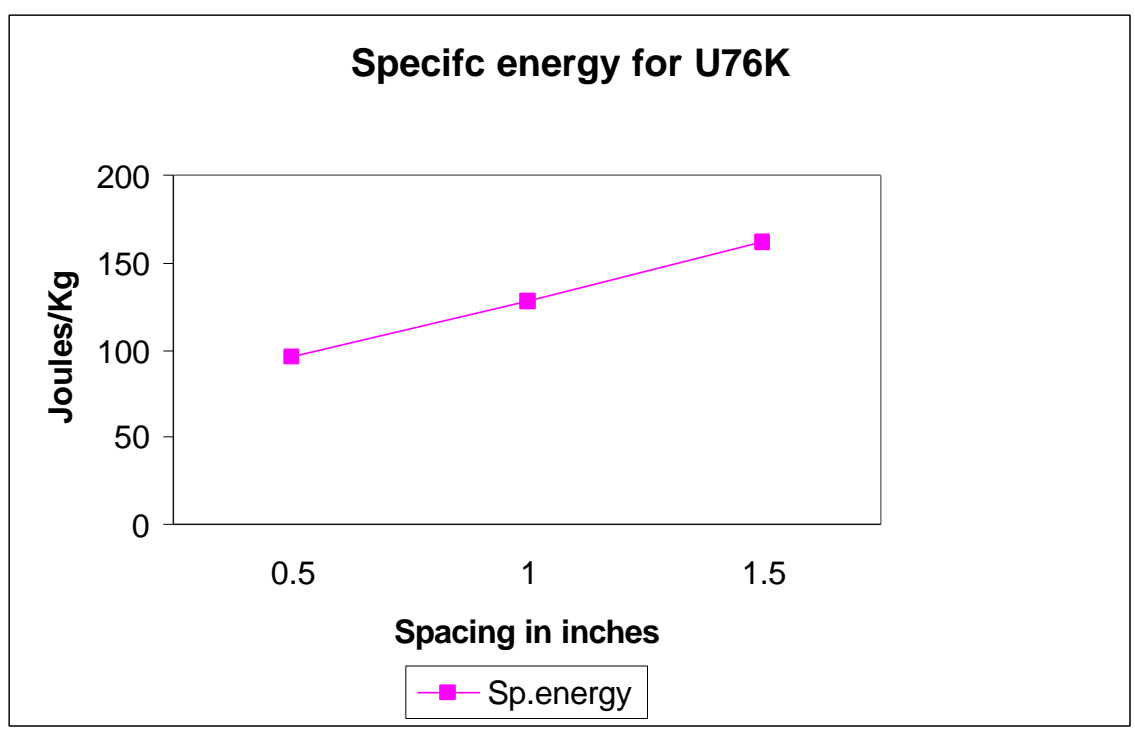

Figure 4.2d Comparison of specific energy using U76K

U82HDLR: The U82HDLR bit has a tip angle of $75^{\circ}$, and a tip diameter of $12.7 \mathrm{~mm}$. Figure 4.3a shows the penetration forces at three different spacings using the U82HDLR Figure $4.3 \mathrm{~b}$ shows the cutting forces using the same bit.

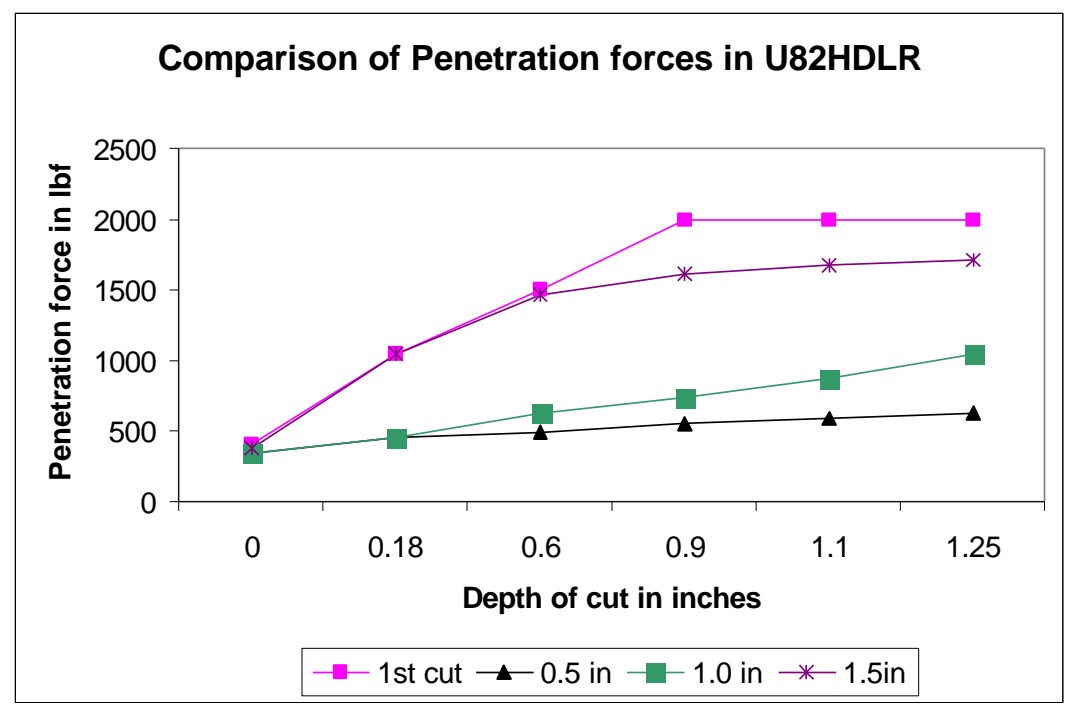

Figure 4.3a Comparison of penetration forces using U82HDLR 


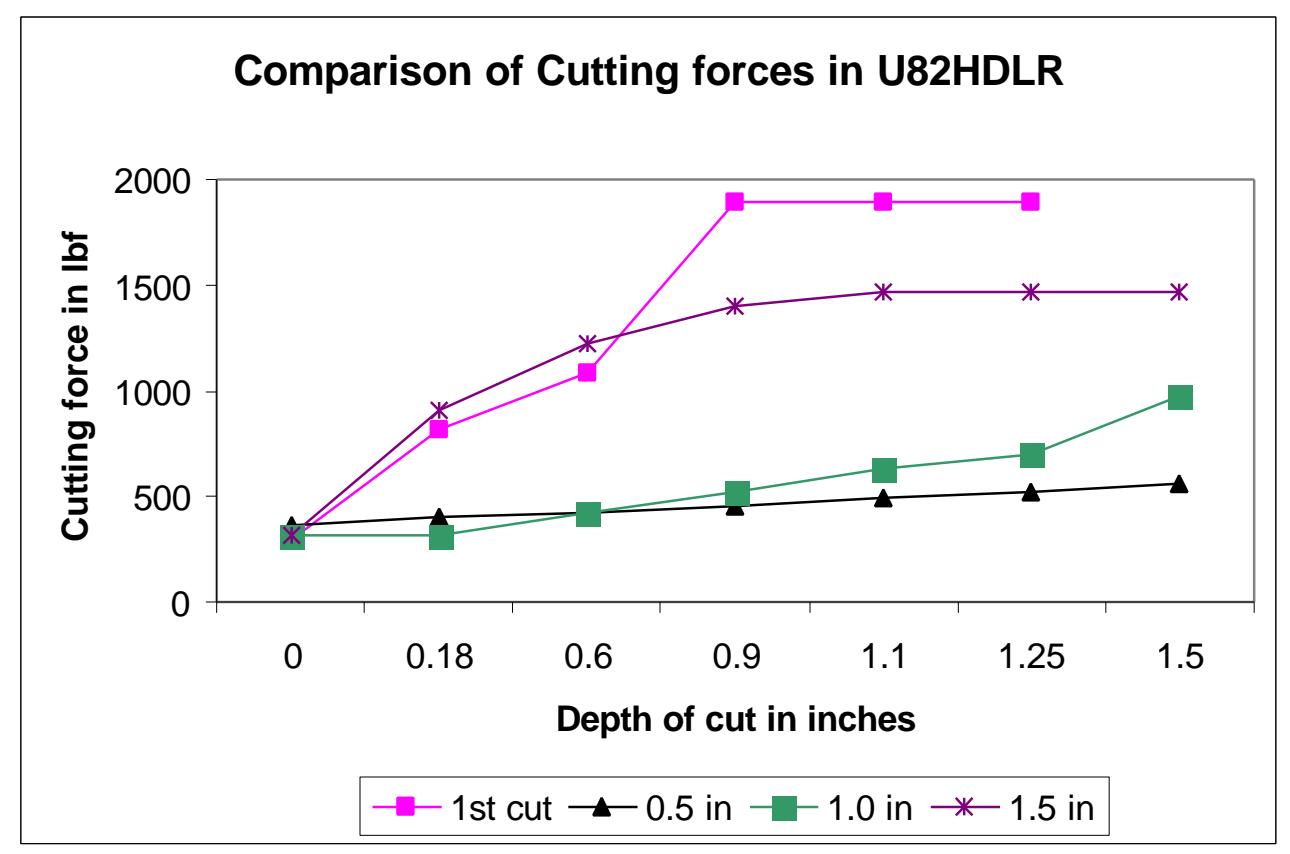

Figure 4.3b Comparison of cutting forces using U82HDLR

The penetration force required for the first cut was $1995 \mathrm{lbf}$ and cutting force was $1890 \mathrm{lbf}$. The penetration force at a spacing of $0.5 \mathrm{in}$. was reduced to $1155 \mathrm{lbf}(60 \%$ of the first cut) and the cutting force was reduced to $875 \mathrm{lbf}(46 \%$ of the first cut) the land/ridge removal was very good. When the spacing is increased to $1.0 \mathrm{in}$. the penetration force required was reduced to $1575 \mathrm{lbf}$ ( $75 \%$ of the initial) and cutting force was reduced to $1120 \mathrm{lbf}$ (60\% of the initial) and the land/ridge removal was also satisfactory. When the spacing was increased to $1.5 \mathrm{in}$. the penetration force was $1925 \mathrm{lbf}$ (98\% of the initial) and the cutting force was $1470 \mathrm{lbf}(80 \%$ of the initial). This shows that the penetration force required at 1.5 in. spacing was not different from the penetration force required in the first cut, though the cutting force was little less, a spacing of $1.5 \mathrm{in}$. also had not much influence on the land/ridge removal. Figure $4.4 \mathrm{c}$ shows the amount of specific respirable dust generated during the cutting using 
U82HDLR bit. The figure shows the amount of specific dust collected in both top and bottom impactor. It can be seen from Figure $4.3 \mathrm{c}$ that the amount of respirable dust generated increases from $2.5 \mathrm{mg} / \mathrm{kg}$ to $2.8 \mathrm{mg} / \mathrm{kg}$ in the top cascade impactor and from $3.75 \mathrm{mg} / \mathrm{kg}$ to $4.1 \mathrm{mg} / \mathrm{kg}$ in the bottom cascade impactor when the spacing was increased from 0.5 to $1.5 \mathrm{in}$.

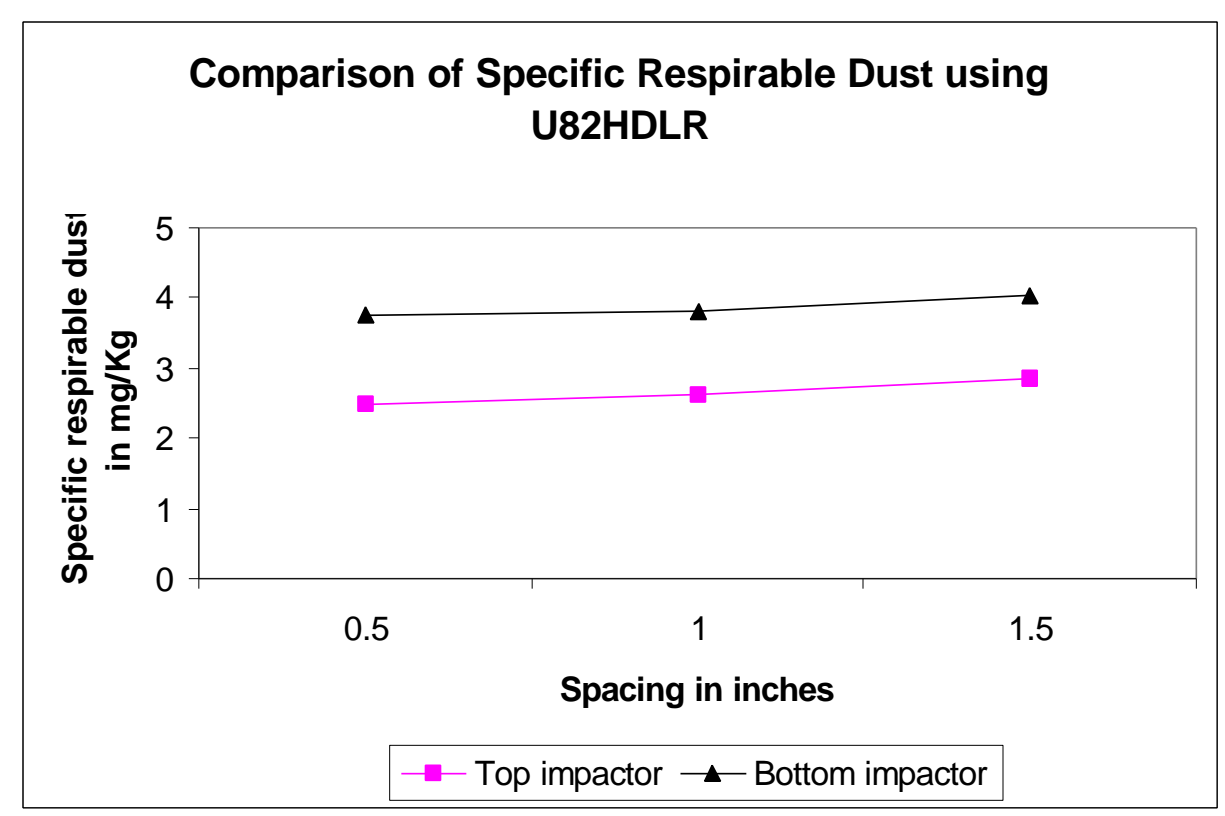

Figure 4.3c Comparison of respirable dust using U82HDLR

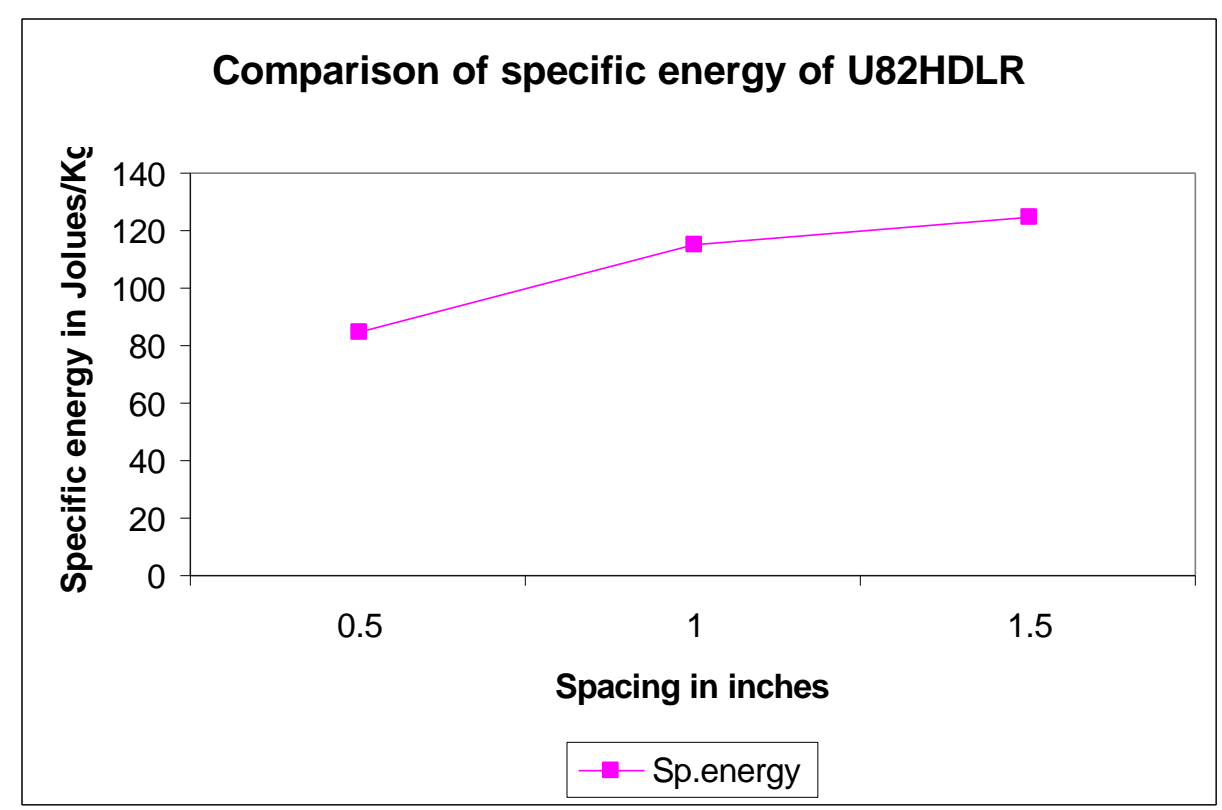

Figure 4.3d Comparison of specific energy using U82HDLR 
Figure 4.3d shows the variation of Specific energy in U82HDLR when the spacing changed from 0.5 to $1.5 \mathrm{in}$. The specific energy changed from $85 \mathrm{~J} / \mathrm{Kg}$ to $125 \mathrm{~J} / \mathrm{Kg}$.

U85HLR: The U85HLR bit has a tip angle of $75^{\circ}$, and a tip diameter of $11.11 \mathrm{~mm}$. Figure $4.4 \mathrm{a}$ and $4.4 \mathrm{~b}$ shows the variability in penetration and cutting forces at various spacings using the U85HLR bit. When the first cut was made the penetration force required was $2170 \mathrm{lbf}$ and the cutting force was $1890 \mathrm{lbf}$. When another cut was made with a 0.5 in. spacing the penetration force was reduced to $1155 \mathrm{lbf}$ (about $53 \%$ of the initial) and the cutting force required was $735 \mathrm{lbf}$ (only $40 \%$ of the initial). The land/ridge was completely removed. When the spacing was increased to $1.0 \mathrm{in}$. the penetration force was about half of the initial penetration force required and the cutting force was $805 \mathrm{lbf}$ (45\% of the initial). The land/ridge removal was good. When the spacing was increased to $1.5 \mathrm{in}$. the penetration force was $1890 \mathrm{lbf}$ ( $88 \%$ of the initial) and the cutting force was $1890 \mathrm{lbf}$ (same as in the case of first cut). It was not able to remove land/ridge in this case. Figure $4.4 \mathrm{c}$ shows the increase of respirable dust with the increase of spacing in the bitU85HLR.

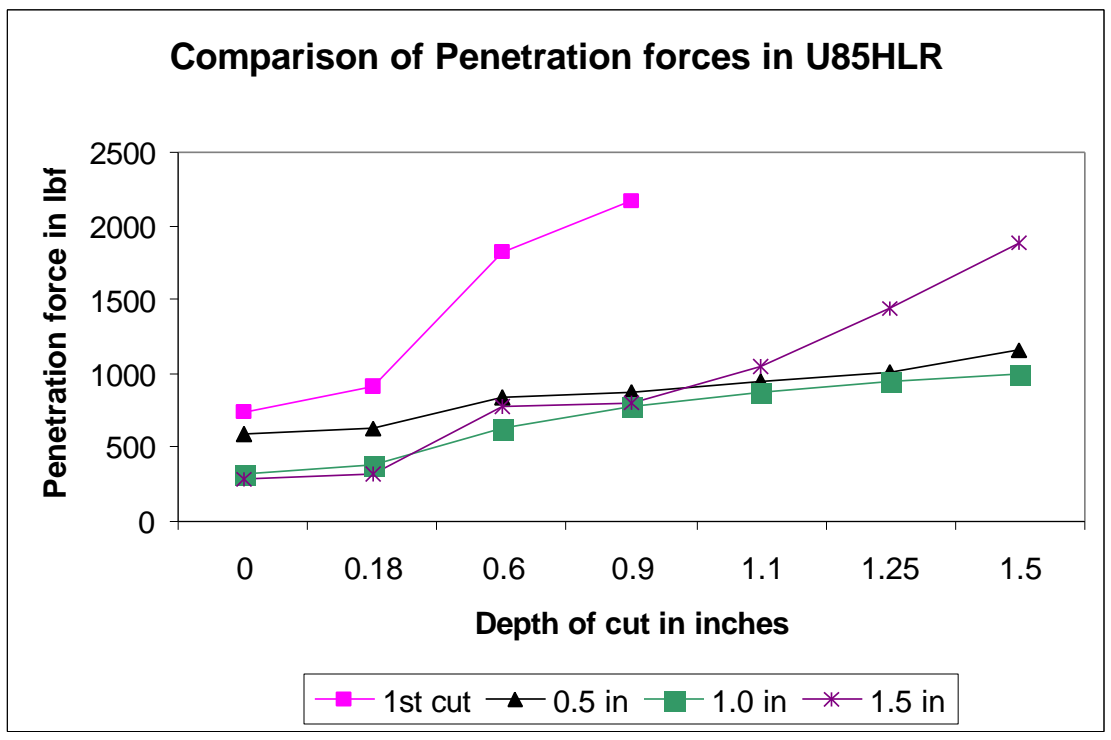

Figure 4.4a Comparison of penetration forces using U85HLR 


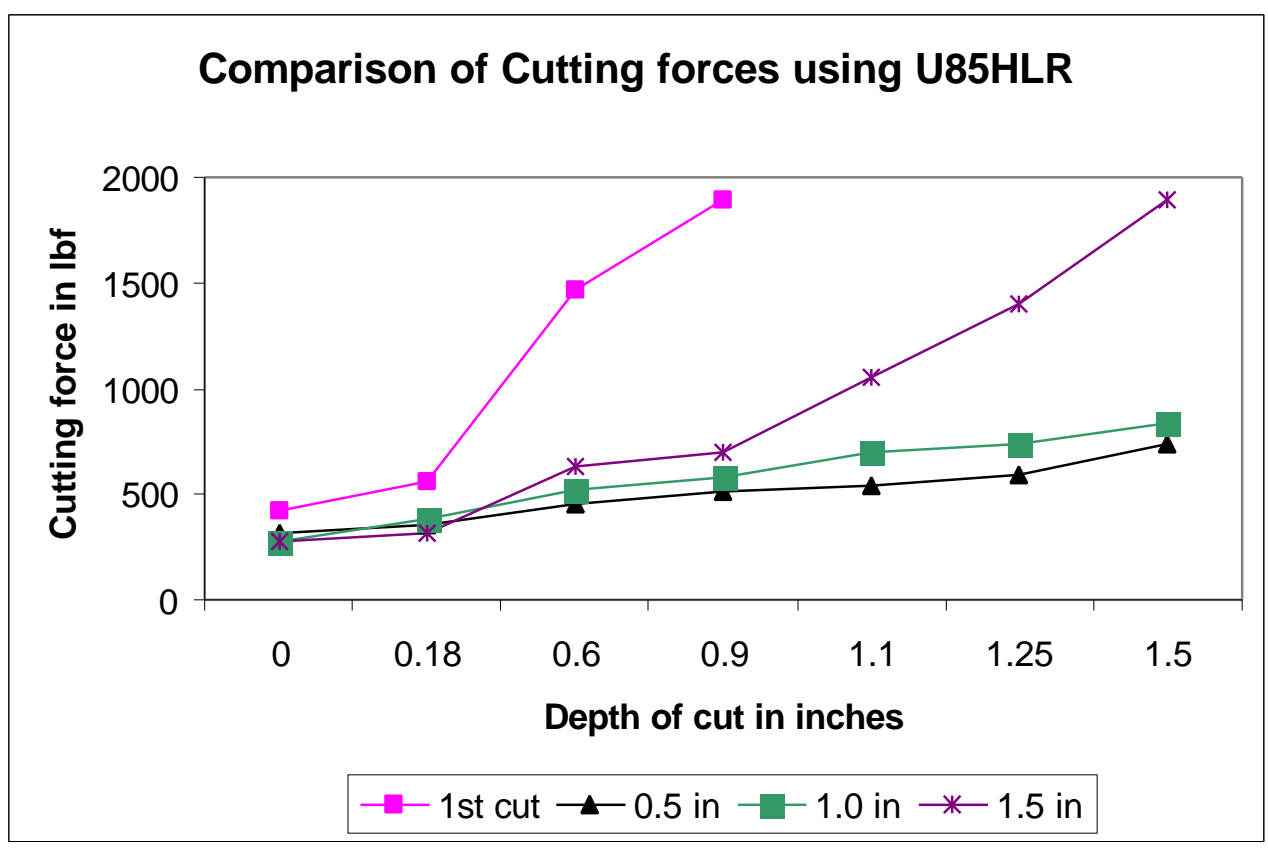

Figure 4.4b Comparison of cutting forces using U85HLR

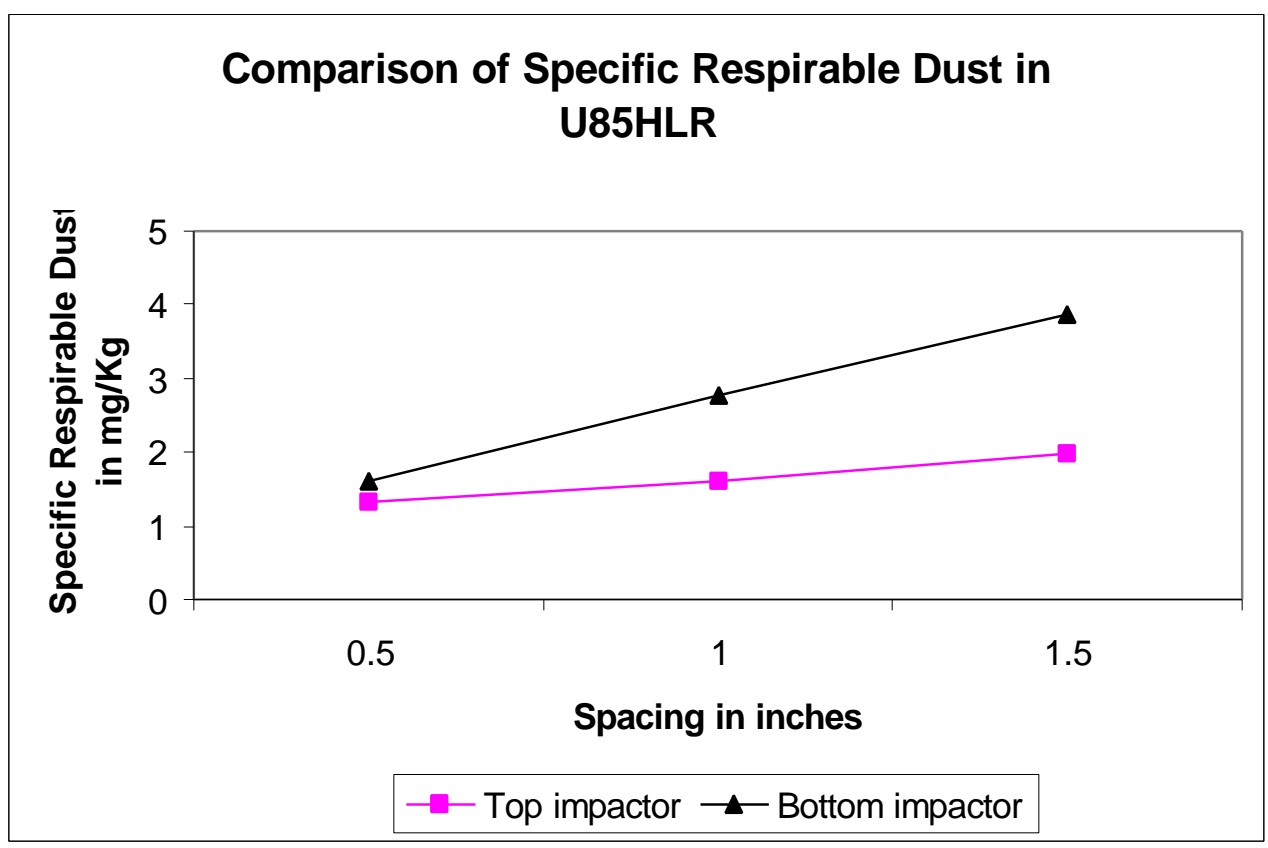

Figure 4.4c Comparison of specific respirable dust using U85HLR 
The amount of specific respirable dust changes from $1.6 \mathrm{mg} / \mathrm{kg}$ to $3.8 \mathrm{mg} / \mathrm{kg}$ in the bottom impactor and $1.3 \mathrm{mg} / \mathrm{kg}$ to $1.97 \mathrm{mg} / \mathrm{kg}$ in the top cascade impactor using the U85HLR bit.

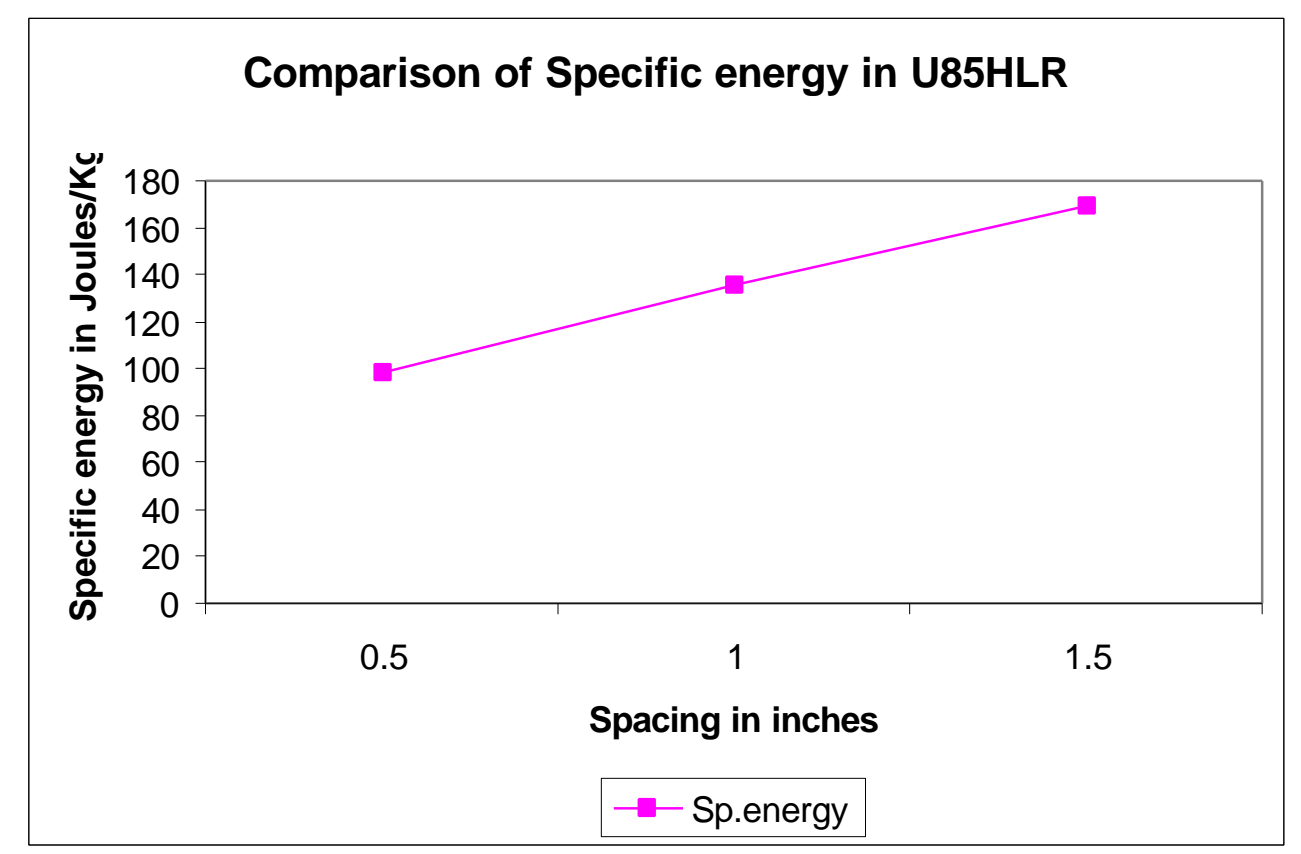

Figure 4.4d Comparison of specific energy using U85HLR

Figure $4.4 \mathrm{~d}$ shows the variation of specific energy when the spacing is changed from 0.5 to 1.5 in. using the U85HLR cutting bit. The specific energy changed from about 100 $\mathrm{J} / \mathrm{kg}$ to $170 \mathrm{~J} / \mathrm{kg}$.

U94HDLR: The U94HDLR bit has a tip angle of $75^{\circ}$, and tip diameter of $19.05 \mathrm{~mm}$. Figures $4.5 \mathrm{a} \& \mathrm{~b}$ shows the variability of penetration force and cutting forces using the U94HDLR cutting bit. The penetration force for the first cut (when there were no preexisting cuts on the block) was about $1925 \mathrm{lbf}$ and the cutting force was about 1750 lbf. When another cut was made with a 0.5 in. spacing the penetration force reduced to 
$1575 \mathrm{lbf}(80 \%$ of the initial) and the cutting force was reduced to $1120 \mathrm{lbf}(64 \%$ of the initial). The penetration and cutting forces at a spacing of $1.0 \mathrm{in}$. were same as in the case of $0.5 \mathrm{in}$. spacing. For the case of $1.5 \mathrm{in}$. spacing the penetration force was $1820 \mathrm{lbf}$ (97\% of the initial) and the cutting force was 1575 lbf (90\% of the initial), this may also show that the influence of preexisting cuts at a spacing of $1.5 \mathrm{in}$. in the case of U94HDLR is also little. The land/ridge removal was good in the case of 0.5 in. and 1.0 in. spacing but not satisfactory for a 1.5 in. spacing. Figure $4.5 \mathrm{c}$ shows the amount of specific respiarble dust generated using the same bit. In this case also the amount of respirable generated increased as the bit spacing increased from 0.5 to 1.5 in.

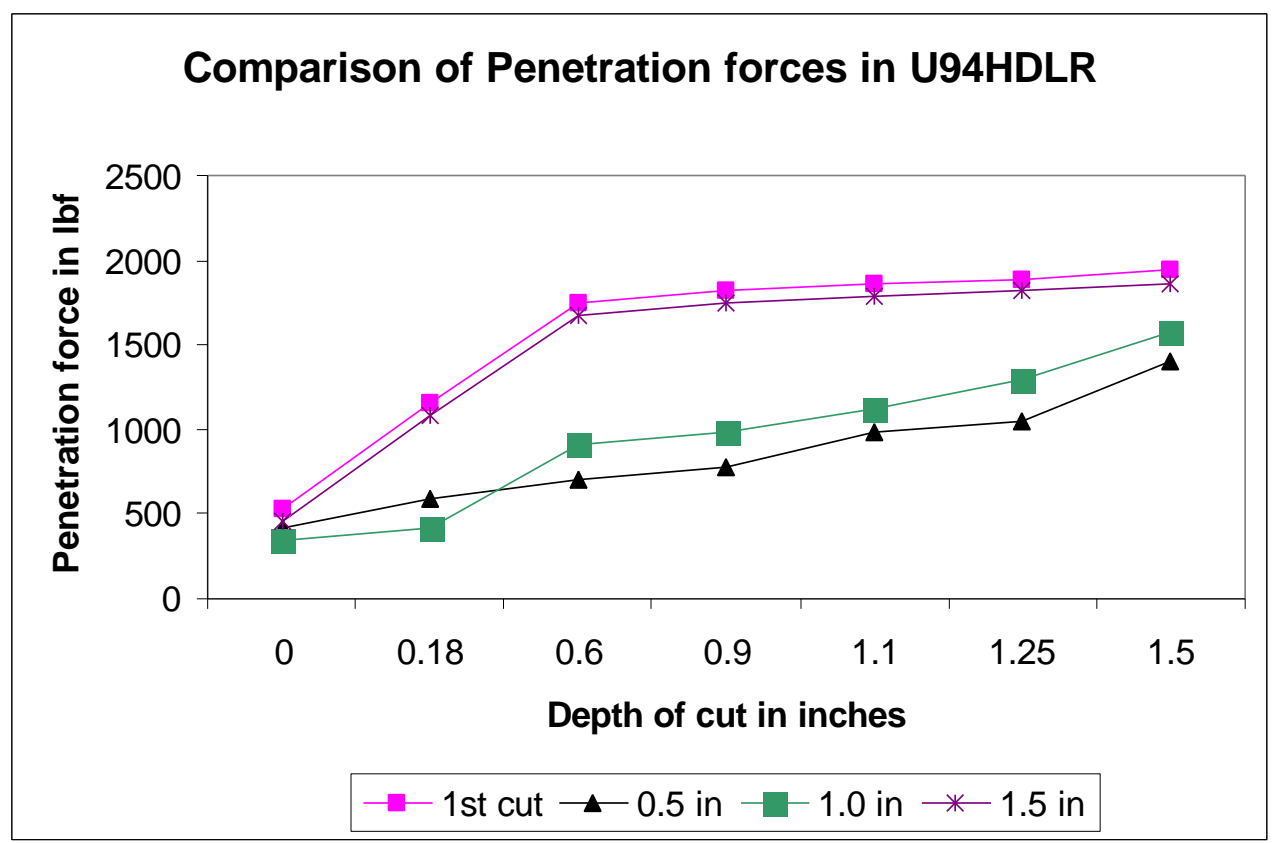

Figure 4.5a Comparison of penetration forces using U94HDLR 


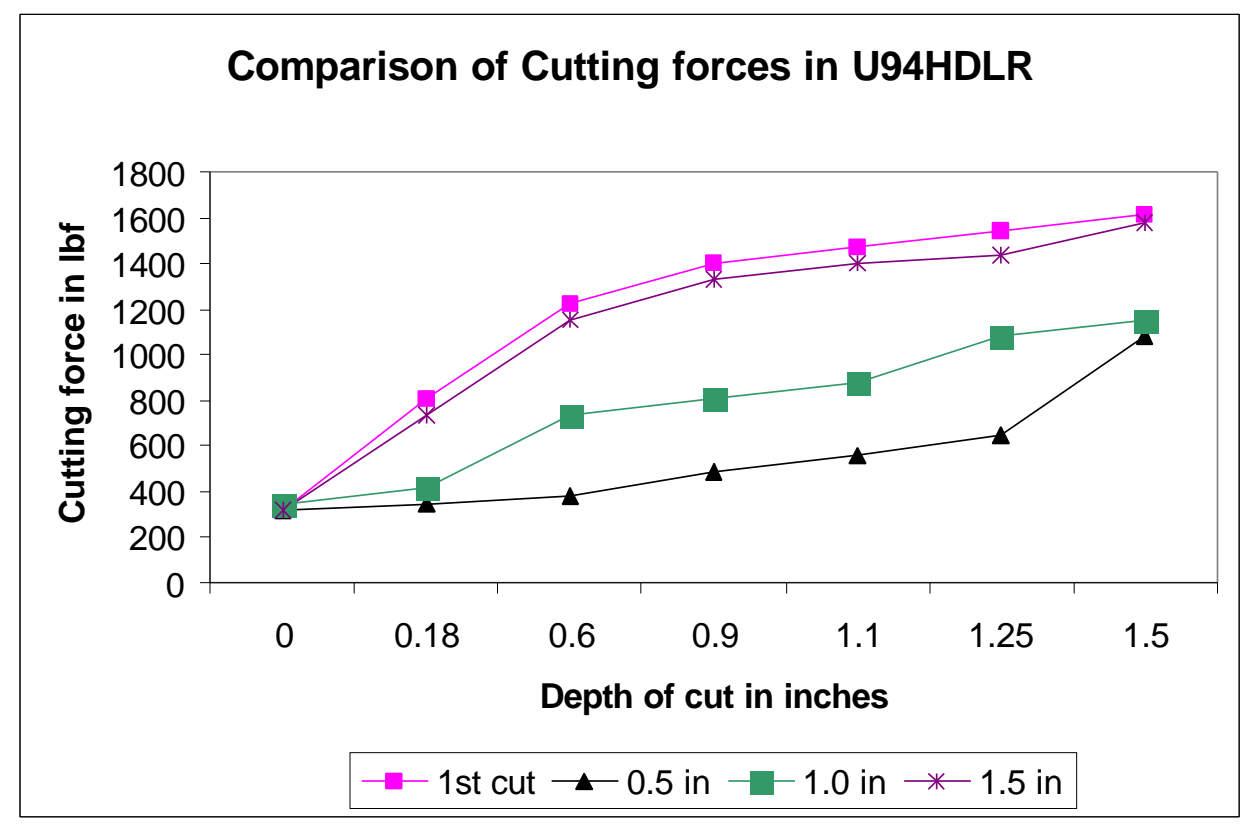

Figure 4.5b Comparison of cutting forces using U94HDLR

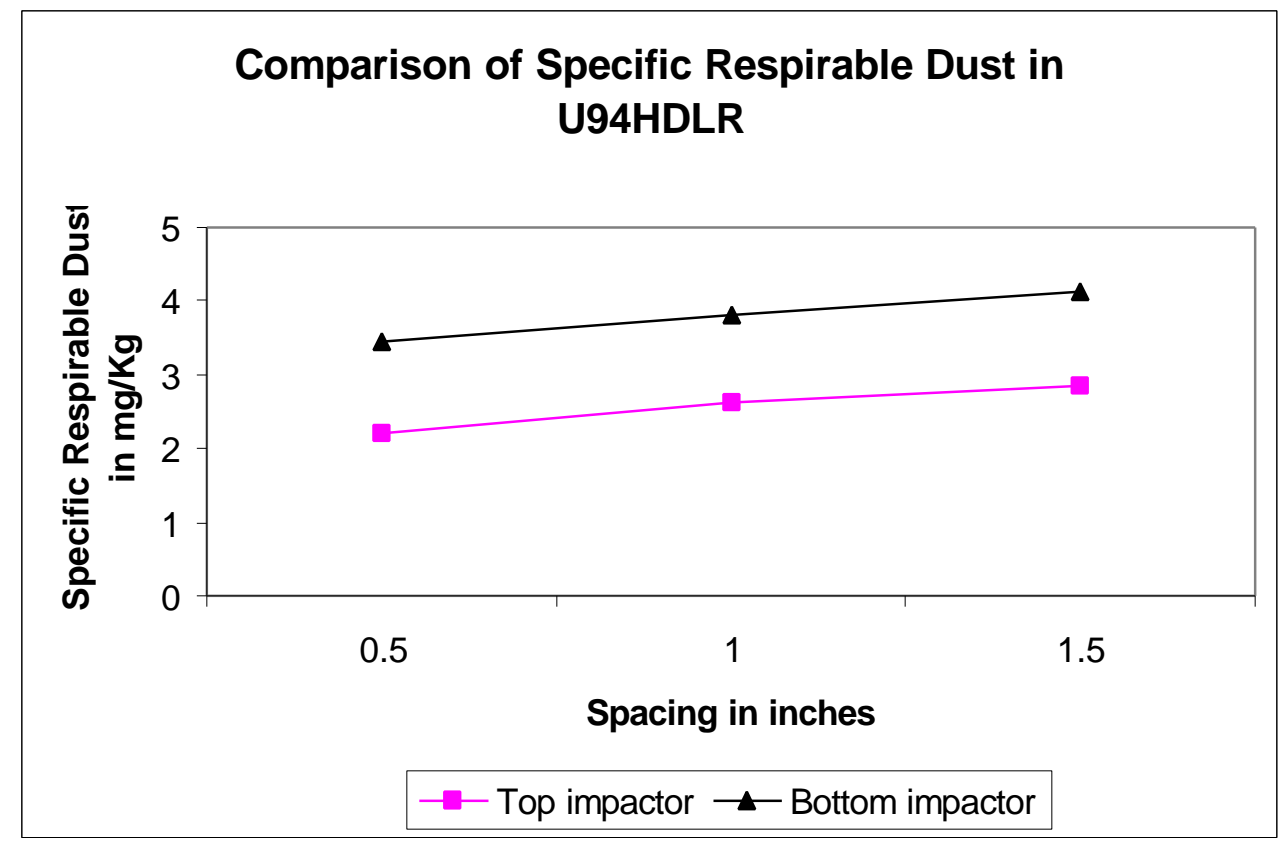

Figure 4.5c Comparison of specific respirable dust using U94HDLR 


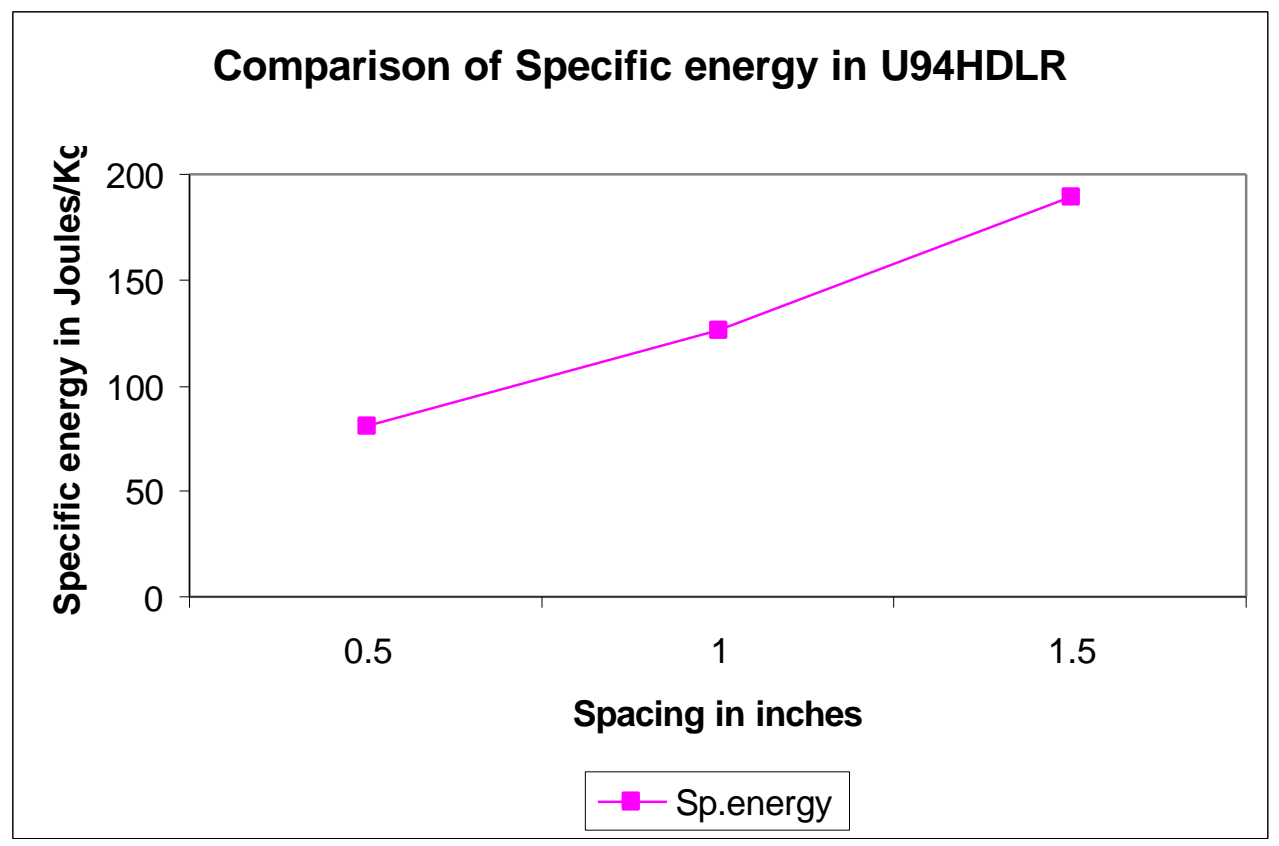

Figure 4.5d Comparison of specific energy using U94HDLR

Figure $4.5 \mathrm{~d}$ shows the specific energy changes at different spacings using the U94HDLR cutting bit. The specific energy changed from $80 \mathrm{~J} / \mathrm{kg}$ to $190 \mathrm{~J} / \mathrm{kg}$ when the bit spacing changed from $0.5 \mathrm{in}$. to $1.5 \mathrm{in}$.

U95HDLR: The U95HDLR bit has a tip angle of $100^{\circ}$ on the top, $85^{\circ}$ middle and $64^{0}$ bottom and it has a tip diameter of $26.61 \mathrm{~mm}$. Figures $4.6 \mathrm{a} \& \mathrm{~b}$ shows the penetration force and cutting forces using the U95HDLR cutting bit. The penetration force in the first cut was $3080 \mathrm{lbf}$ units (maximum of all the 5 types of bits) and the cutting force was $1890 \mathrm{lbf}$. The bit was not able to cut to a depth of 1.5 inches as the bit was large in size and smaller in height the body of the bit started touching the block of rock when the depth was about 1.2 in. and it was producing lot of dust. Figure 4.6c shows the amount of specific respirable dust generated in the cutting process using the U95HDLR bit. It shows that the amount specific respirable increases with increase of spacing. 


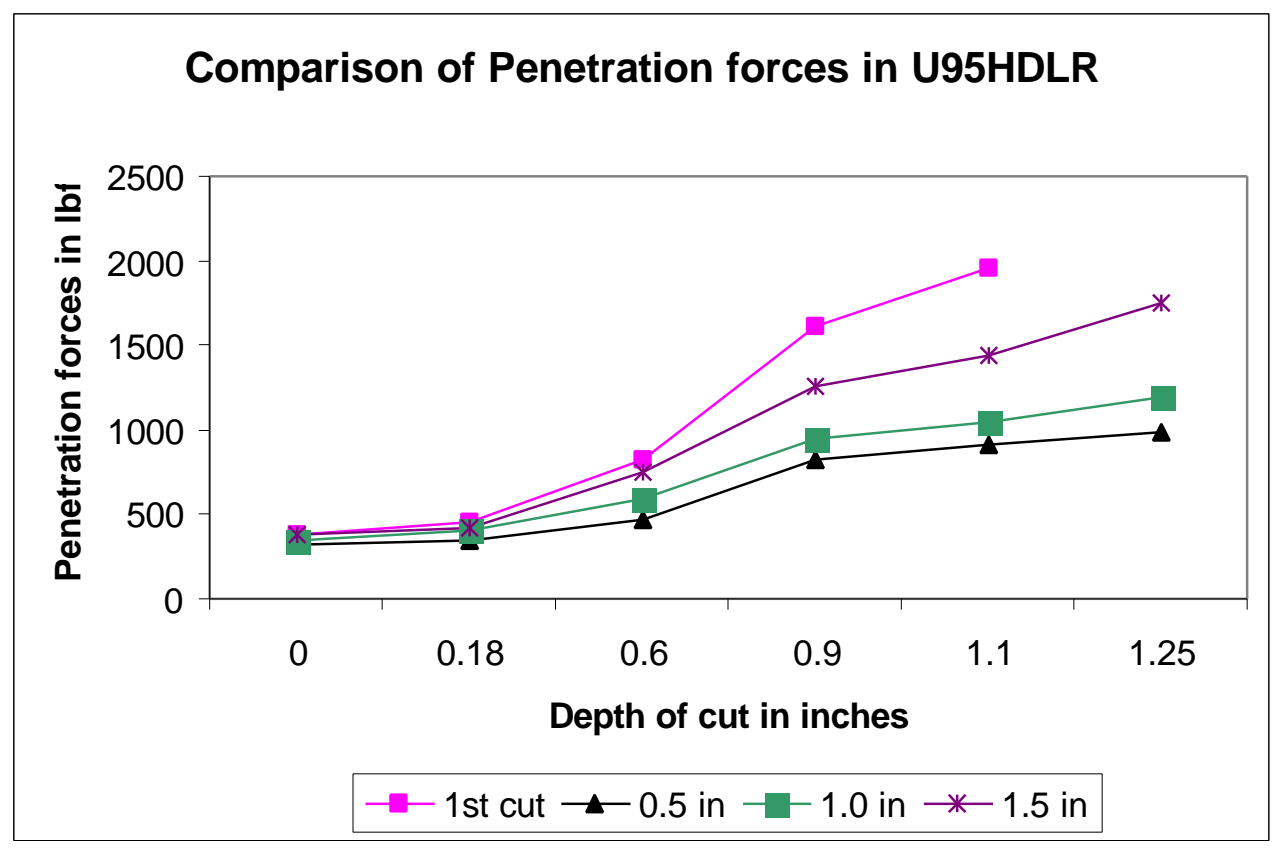

Figure 4.6a Comparison of penetration forces using U95HDLR.

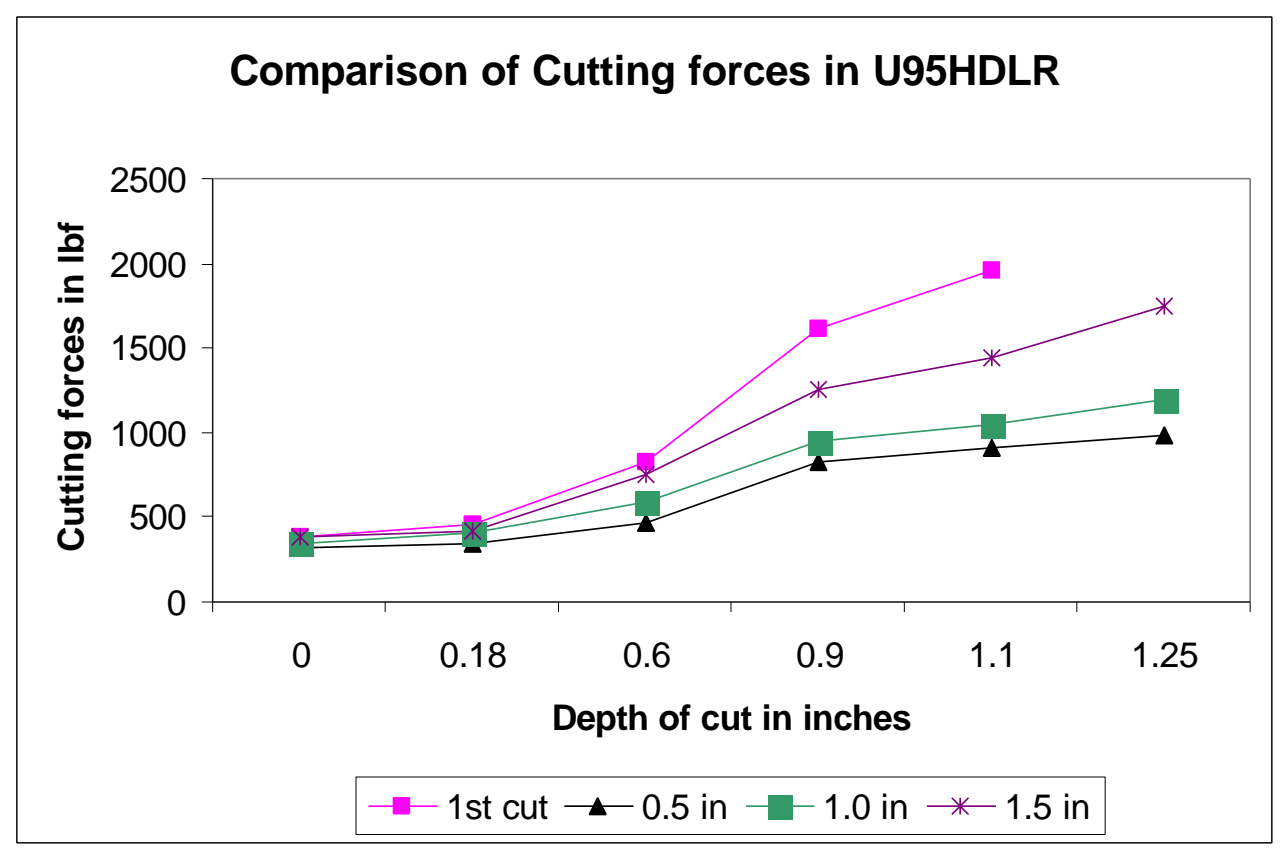

Figure 4.6b Comparison of cutting forces using U95HDLR. 


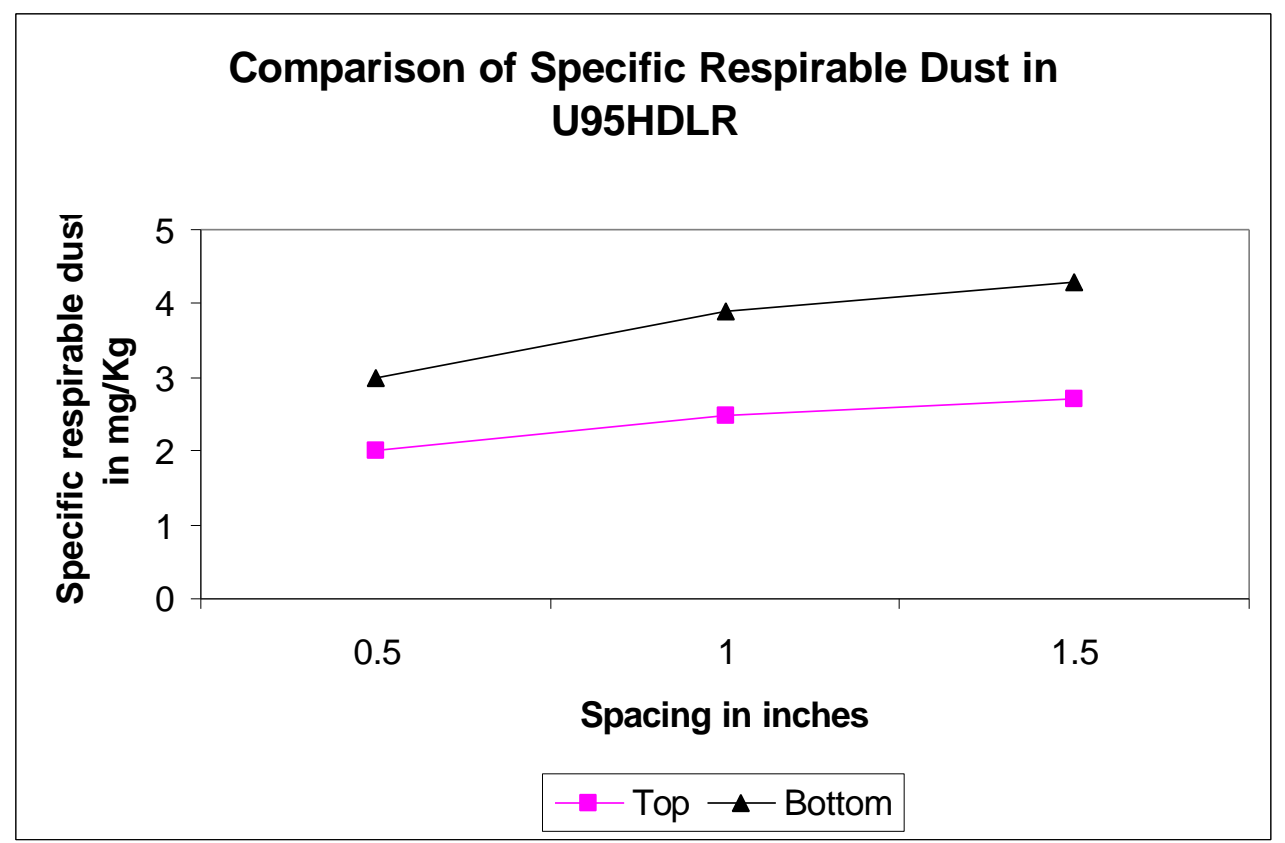

Figure 4.6c Comparison of specific respirable dust using U95HDLR.

Figure 4.6d shows the specific energy changes using U95HDLR cutting bit. When the spacing was changed from $0.5 \mathrm{in}$. to $1.5 \mathrm{in}$. the required specific energy changed from about $70 \mathrm{~J} / \mathrm{kg}$ to $180 \mathrm{~J} / \mathrm{Kg}$.

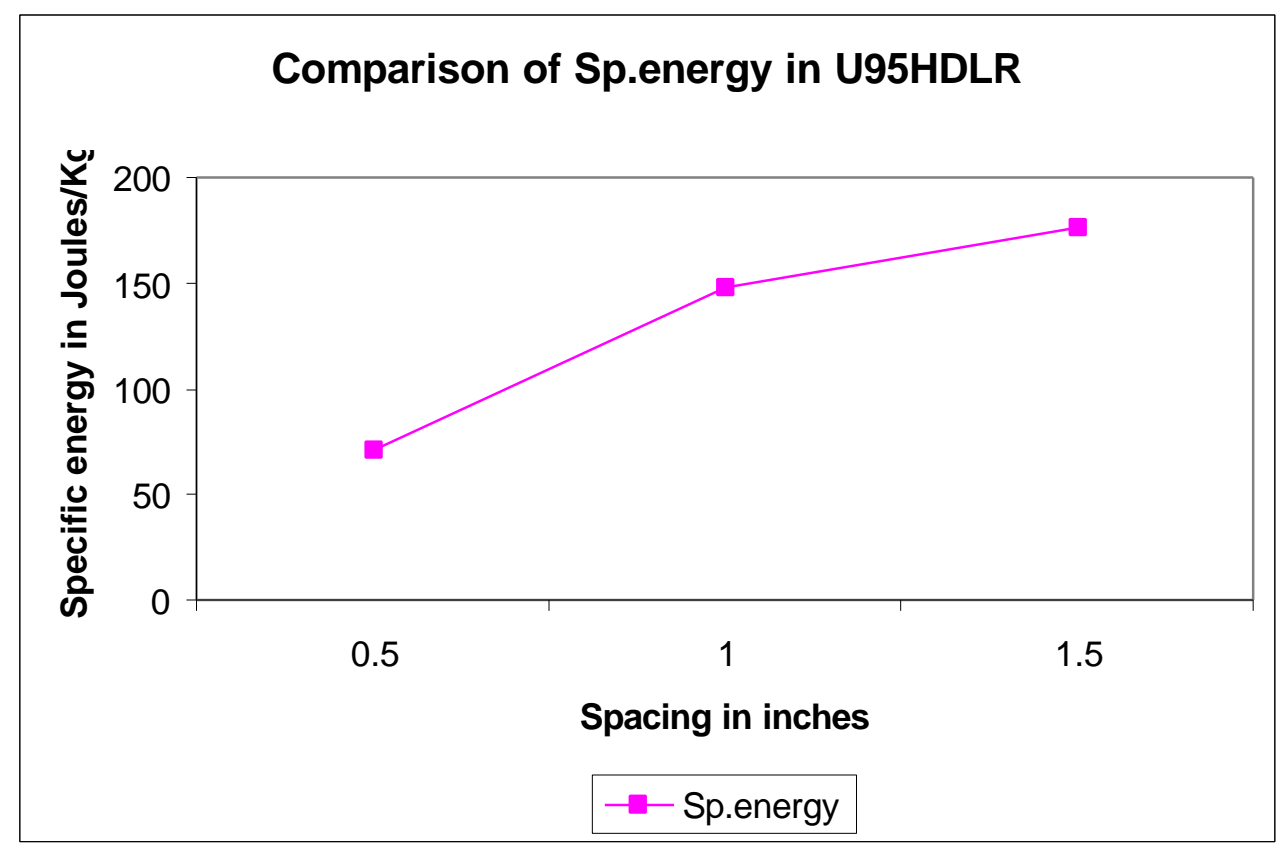

Figure 4.6d Comparison of specific energy using U95HDLR 
The Figures $4.7 \mathrm{a} \& \mathrm{~b}$ shows the penetration and cutting forces using the drag bit KR-225 with a 2.25 inch gage width. The results shows the amount of penetration and cutting forces required increases with increasing bit spacing. Figures $4.7 \mathrm{c}$ shows the amount of specific respirable dust generated using the same cutting bit. The amount of respiarble dust increases from $2.0 \mathrm{mg} / \mathrm{kg}$ to $3.5 \mathrm{mg} / \mathrm{kg}$ in the bottom cascade impactor.

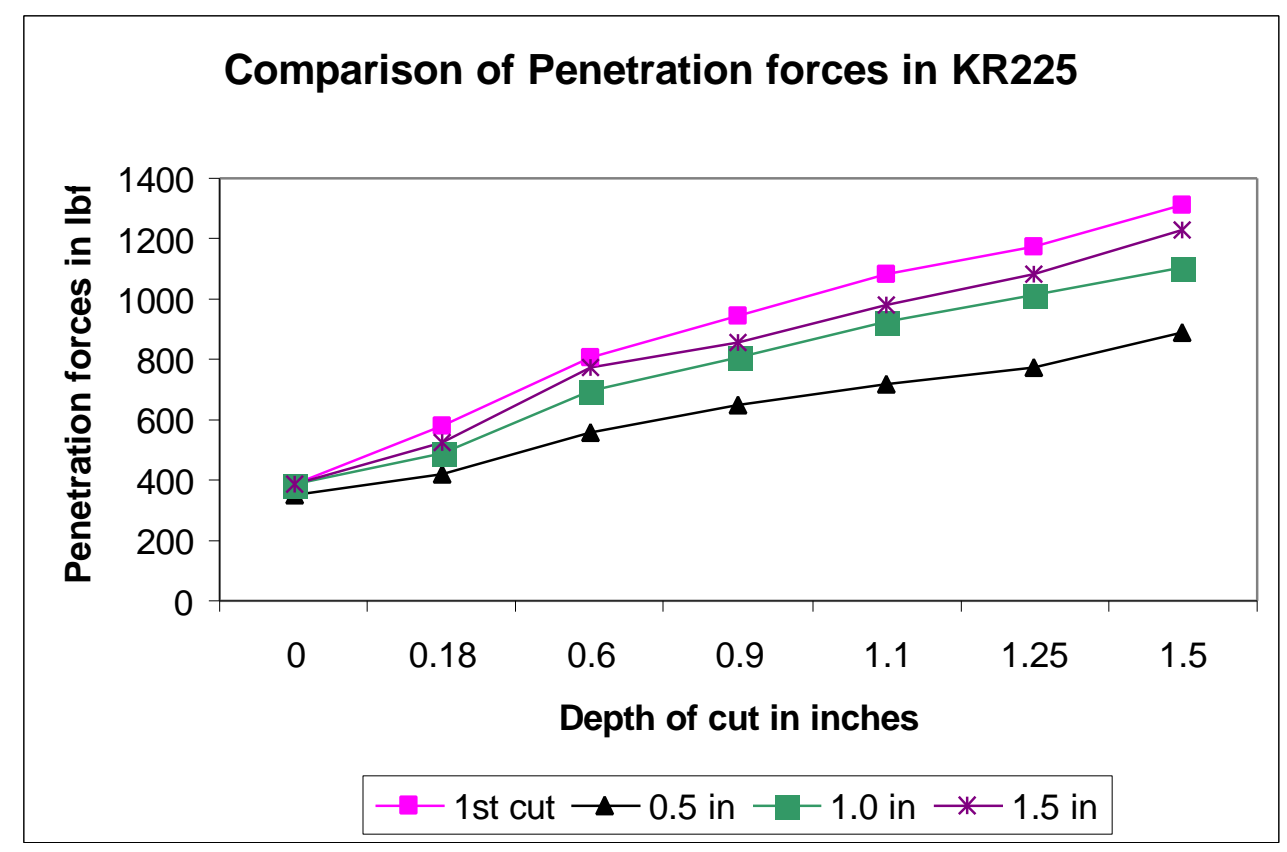

Figure 4.7a Comparison of penetration forces using KR225 drag bit.

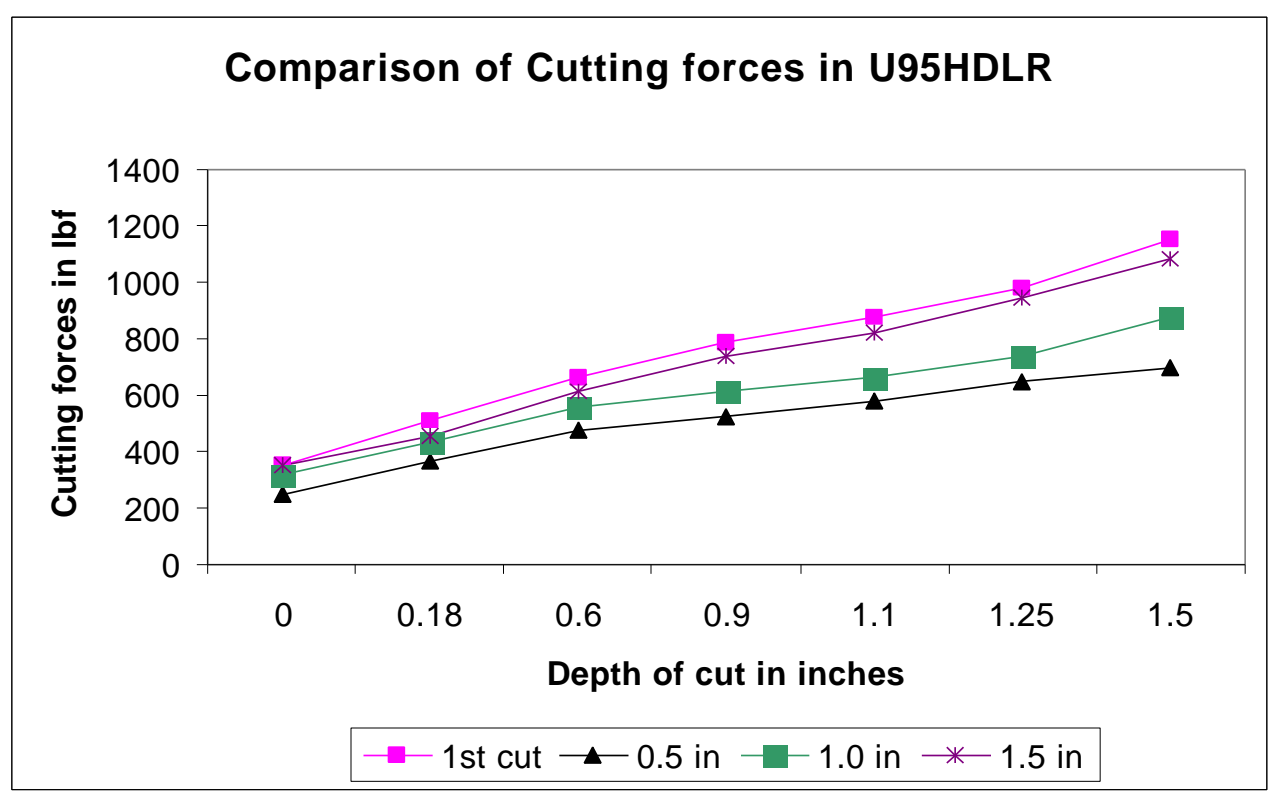

Figure 4.7b Comparison of cutting forces using KR225 drag bit. 


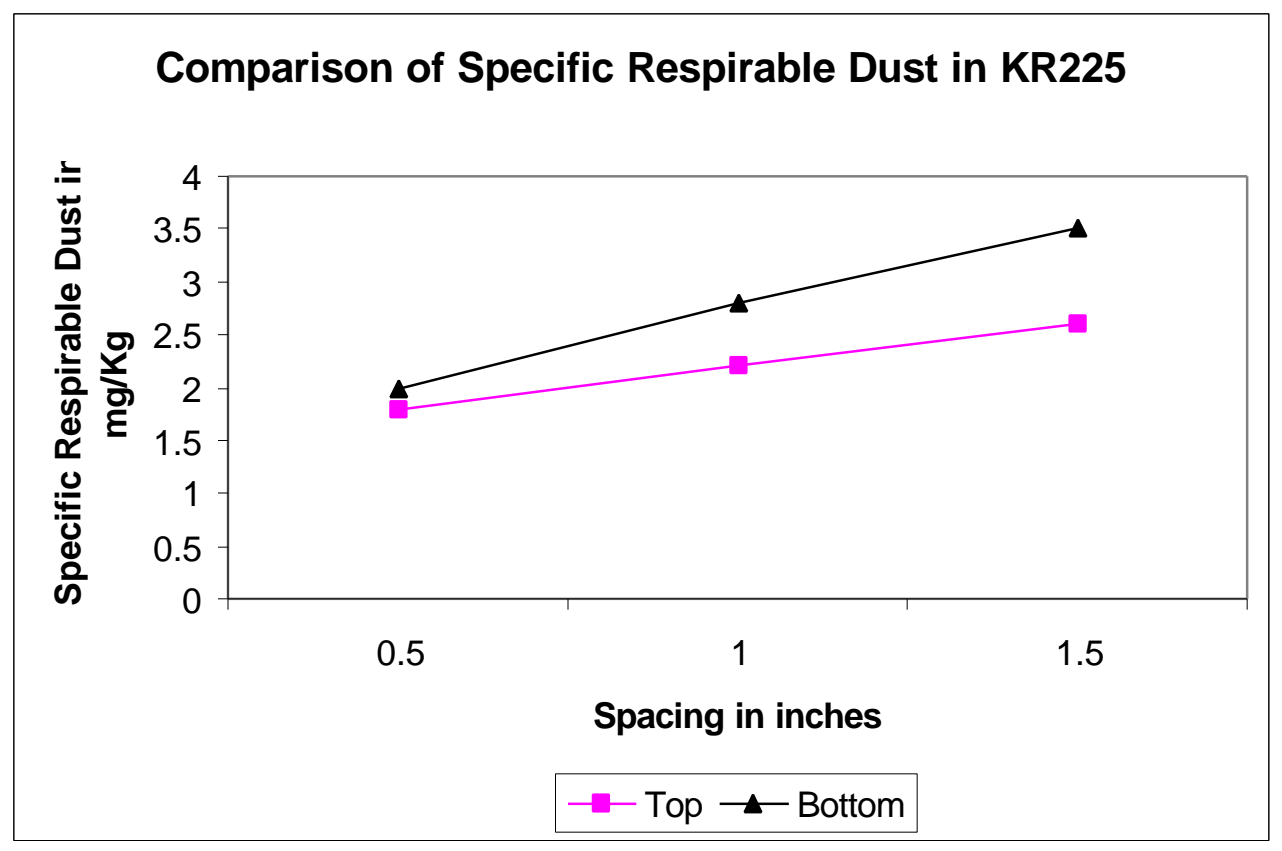

Figure 4.7c Comparison of specific respirable dust using KR225 drag bit.

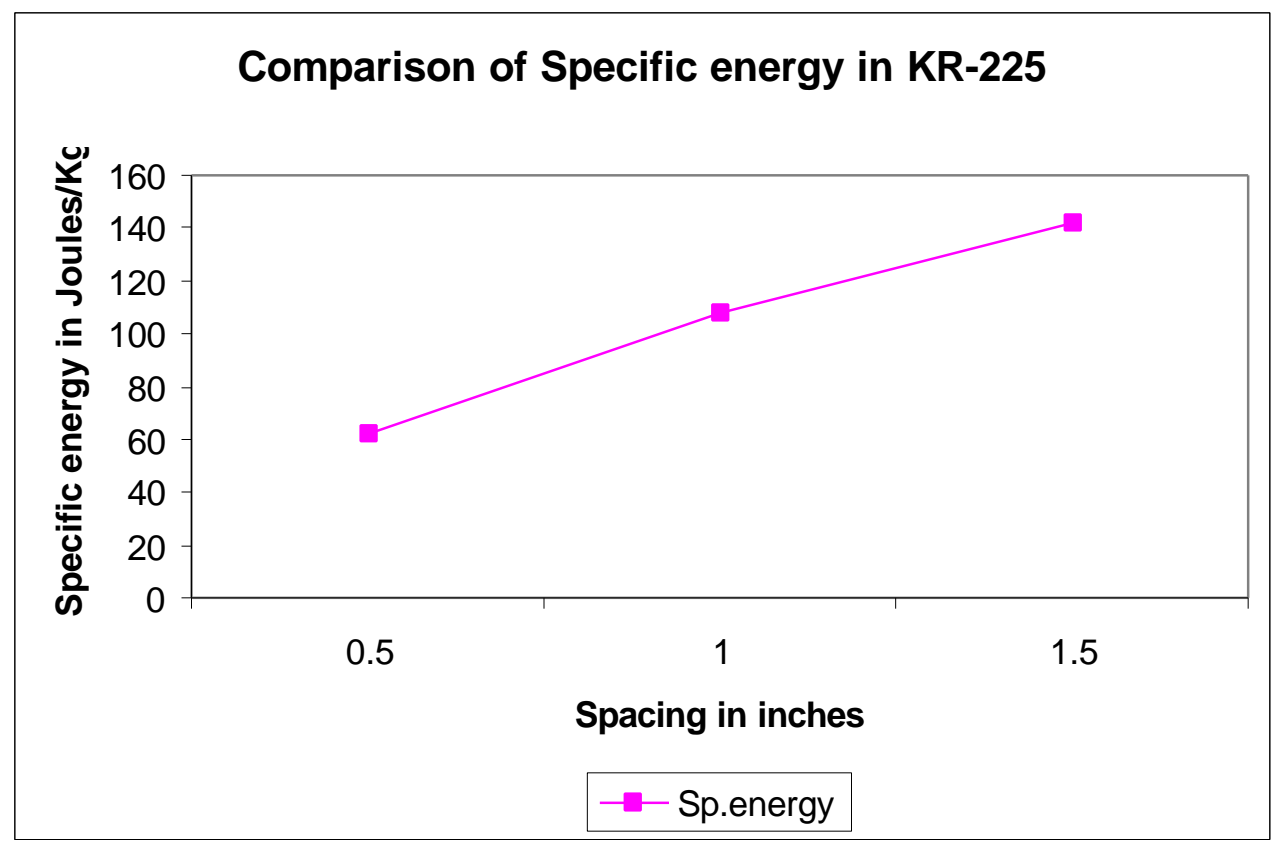

Figure 4.7d Comparison of specific energy using KR225 drag bit. 
Figure $4.7 \mathrm{~d}$ shows the changes in the required specific energy when the spacing was changed from $0.5 \mathrm{in}$. to $1.5 \mathrm{in}$. using the KR-225 drag bit. The specific energy changed from $60 \mathrm{~J} / \mathrm{Kg}$ to $140 \mathrm{~J} / \mathrm{Kg}$.

Figures $4.8 \mathrm{a} \& \mathrm{~b}$ shows the penetration and cutting forces using the KR-300 drag bit with 3inch gage width. Figure $4.8 \mathrm{c}$ shows the amount of specific respirable dust generated using the KR-300 bit.

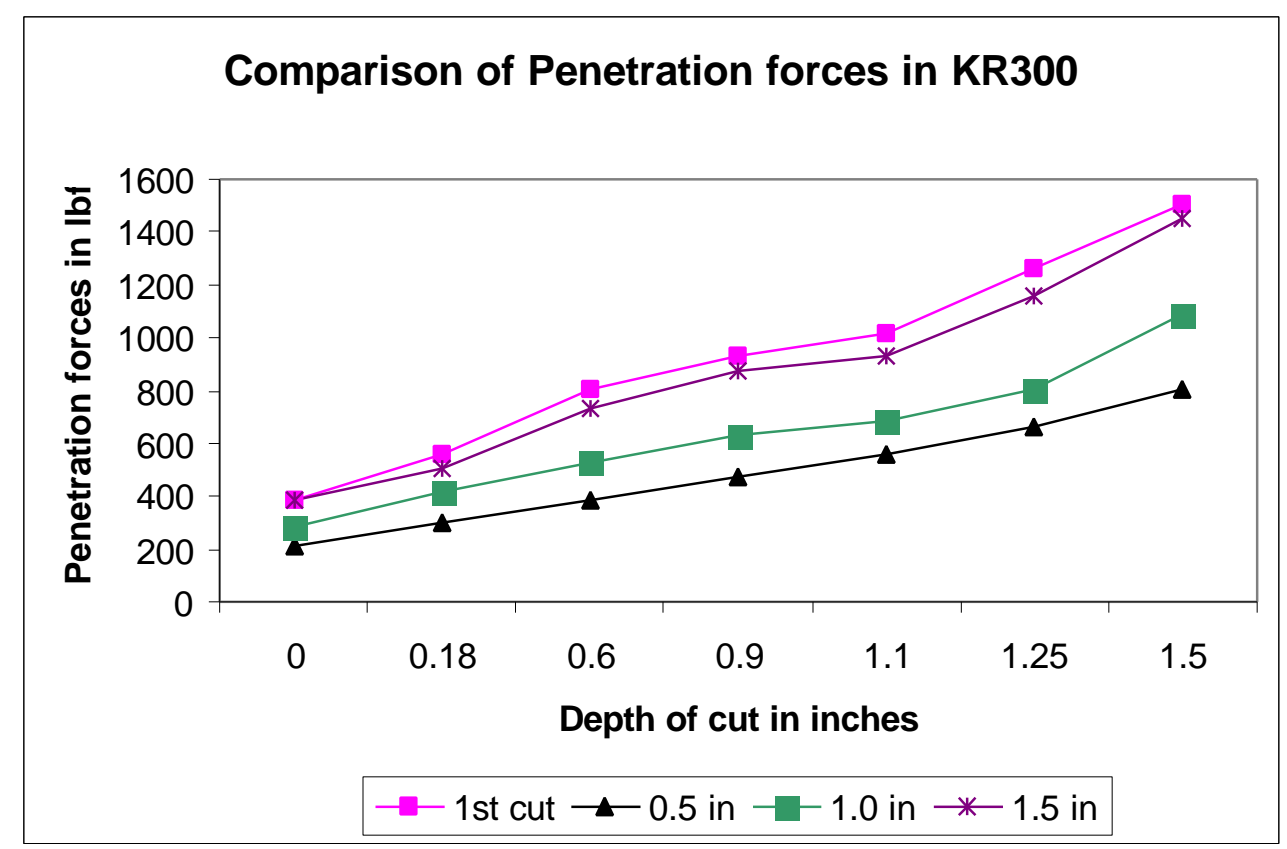

Figure 4.8a Comparison of penetration forces using KR300 drag bit.

Figure $4.8 \mathrm{c}$ shows that the amount of specific respirable dust generated in the case of KR -300 drag bit changed from $2 \mathrm{mg} / \mathrm{Kg}$ to $3 \mathrm{mg} / \mathrm{Kg}$ in the top cascade impactor and from $2.25 \mathrm{mg} / \mathrm{Kg}$ to $3.8 \mathrm{mg} / \mathrm{Kg}$ when the spacing changed from $0.5 \mathrm{in}$. to $1.5 \mathrm{in}$. 
Figure $4.8 \mathrm{~d}$ shows the variation of specific energy when the spacing was changed from $0.5 \mathrm{in}$. to $1.5 \mathrm{in}$. using the same KR-300 cutting bit. The required specific energy changed from $52 \mathrm{~J} / \mathrm{Kg}$ to $126 \mathrm{~J} / \mathrm{Kg}$.

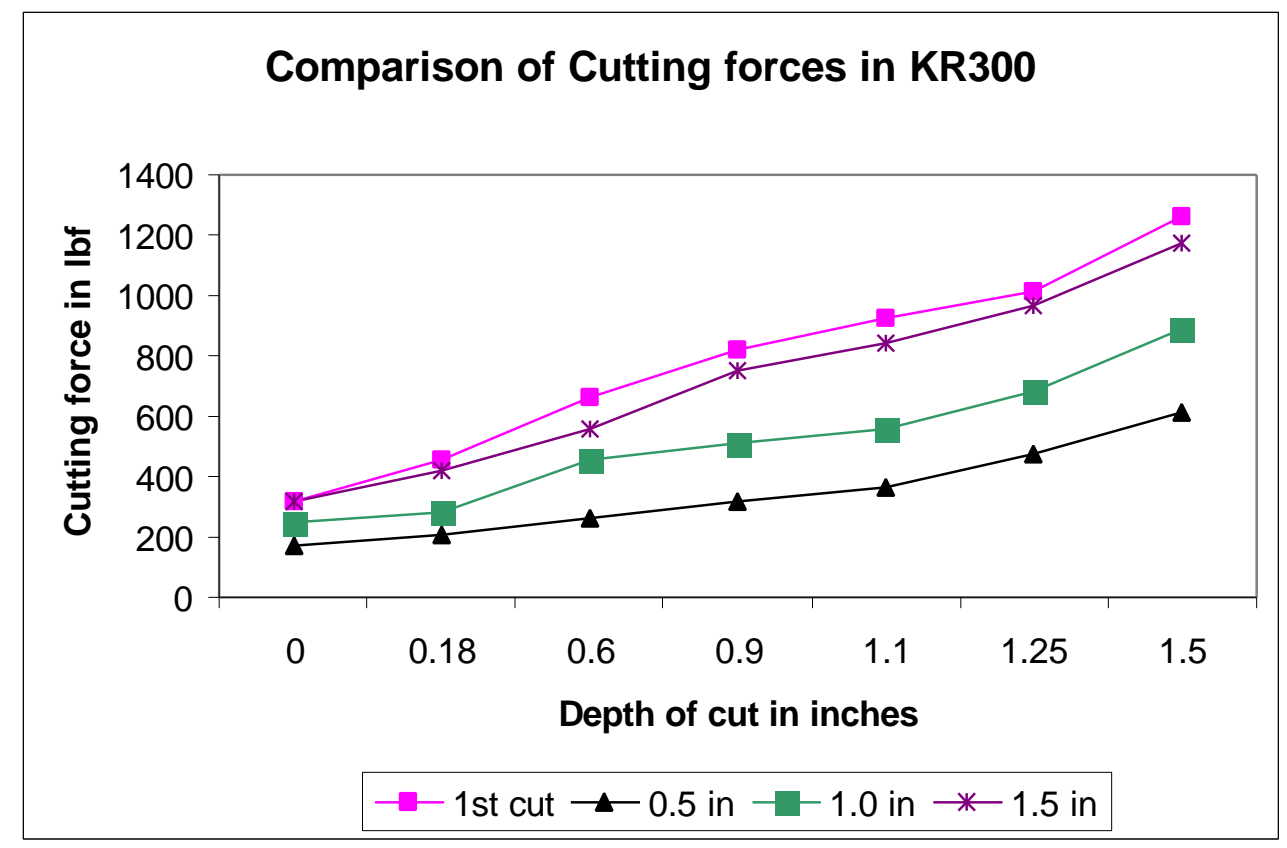

Figure 4.8b Comparison of cutting forces using KR300 drag bit.

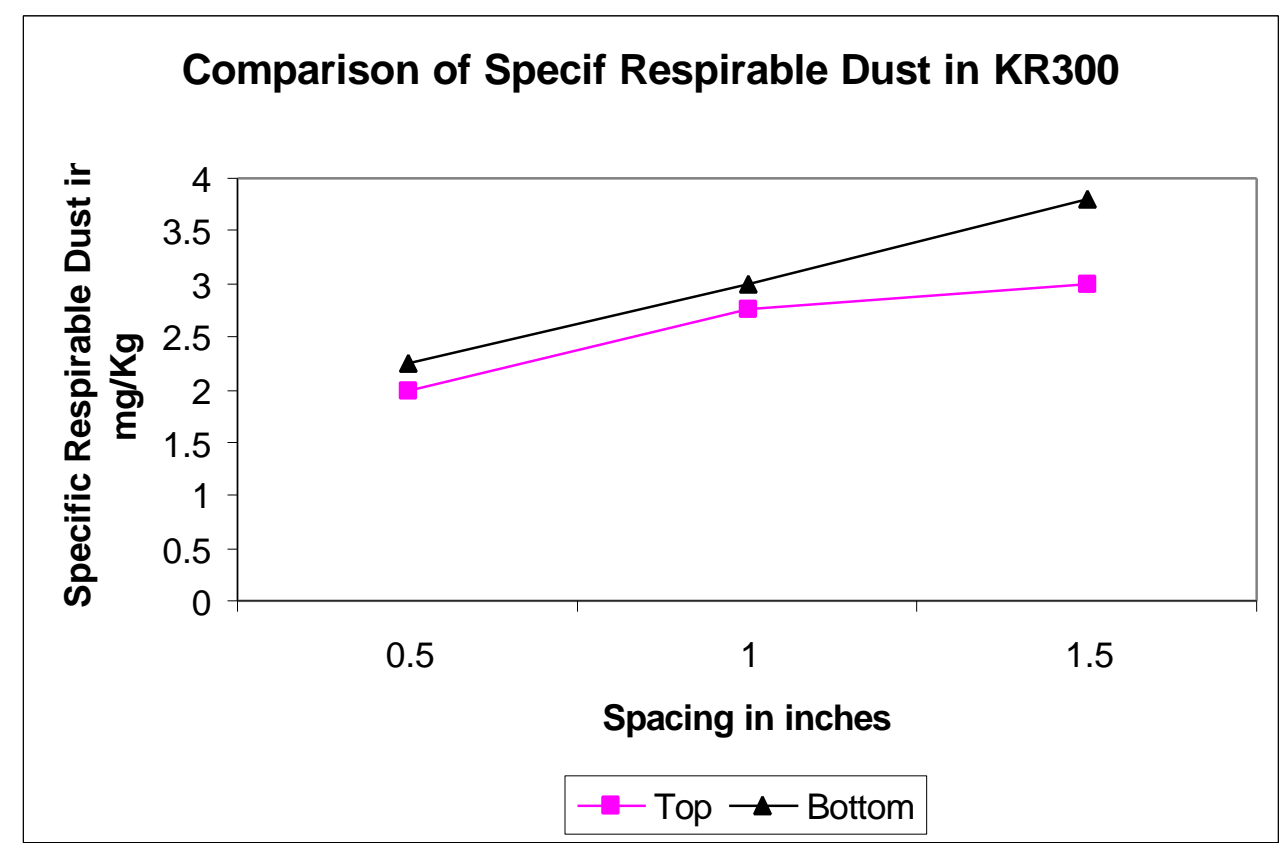

Figure 4.8c Comparison of specific respirable dust using KR300 drag bit. 


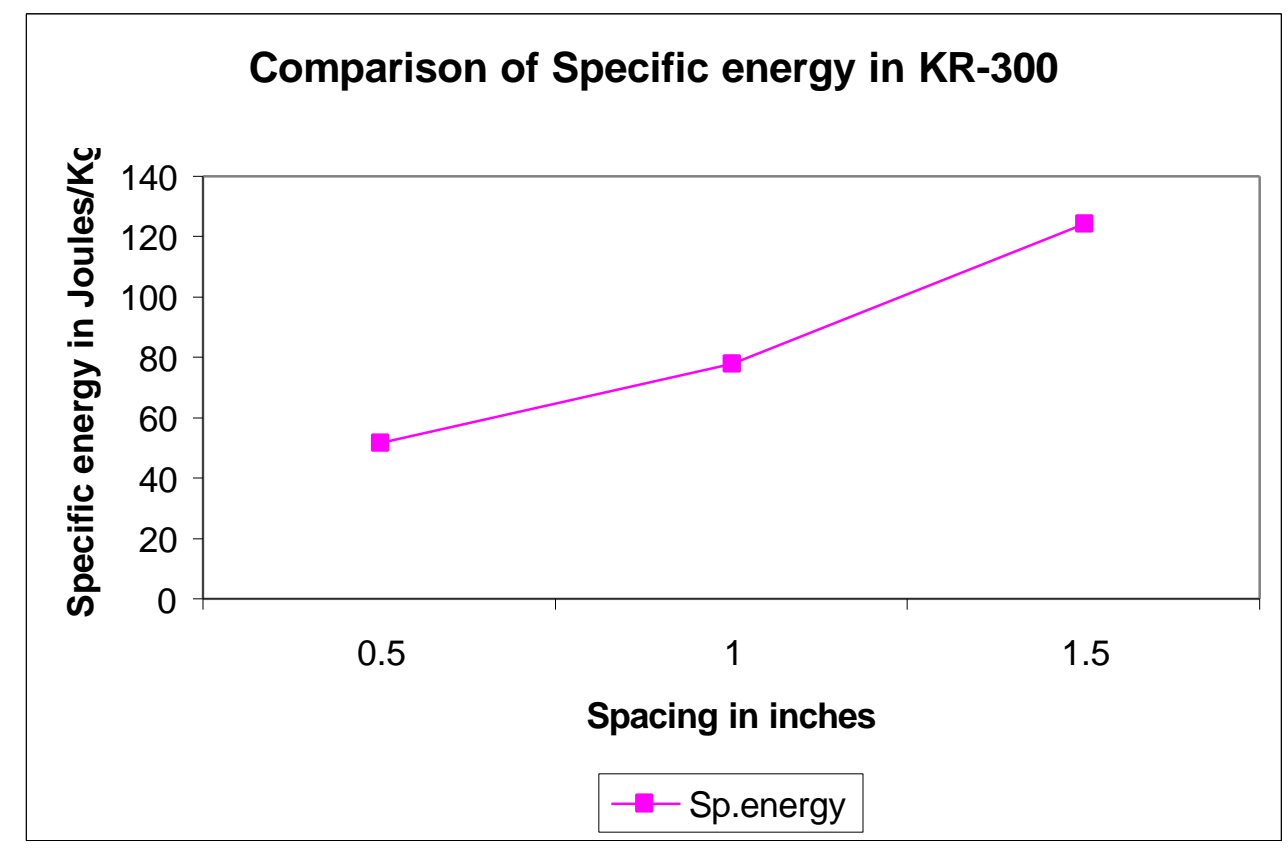

Figure 4.8d Comparison of specific energy using KR300 drag bit.

\subsection{Effect of bit spacing}

The figures showing the amount of specific respirable dust using all the bits were shown at respective places, all the tests conducted shows that the amount of specific respirable dust increases with increase of bit spacing in both conical and wedge shaped bits. As the spacing increases the grooves made by the bits will not be able to interact with each other to remove the lands/ridges. Instead regrinding occurs and results in more respirable dust generation.

\subsection{Effect of bit tip angle}

The values of penetration force and cutting forces shows that as the tip angle increases the amount of forces required to cut the rock increases. The amount of respirable dust generated also increased as the bit tip angle increased. As the bit tip angle is increasing the bit tip size was increasing in the case of conical bits, which indicates that as the size of the bit tip increases the amount of penetration and cutting forces required to 
cut the rock and the amount of respirable dust increases. In the case of wedge shaped bits as the size of the wedge tip was increasing the amount of respirble dust and the amount of forces increased. Since the rate of advance was limited it required less impact between the bit tip and rock to break, hence the fracture initiation and propagation were also limited. Therefore bit tip size has limited effect on the specific respirable dust generaed. Figures4.9a \& b shows the comparison between all the conical bits used. Figure 4.9a shows the penetration forces required for all the five conical bits at 1 in. spacing. It is observed that as the bit tip angle increases the required penetration forces increases but when there is a free face available adjacent to a cut it will require less forces and less energy to cut the rock. So in the case shown here as the spacing was only 1 in. there was an influence if available free face so some bits with bigger angles required less force. Figure $4.9 \mathrm{~b}$ shows the variation of cutting forces required for all the bits.

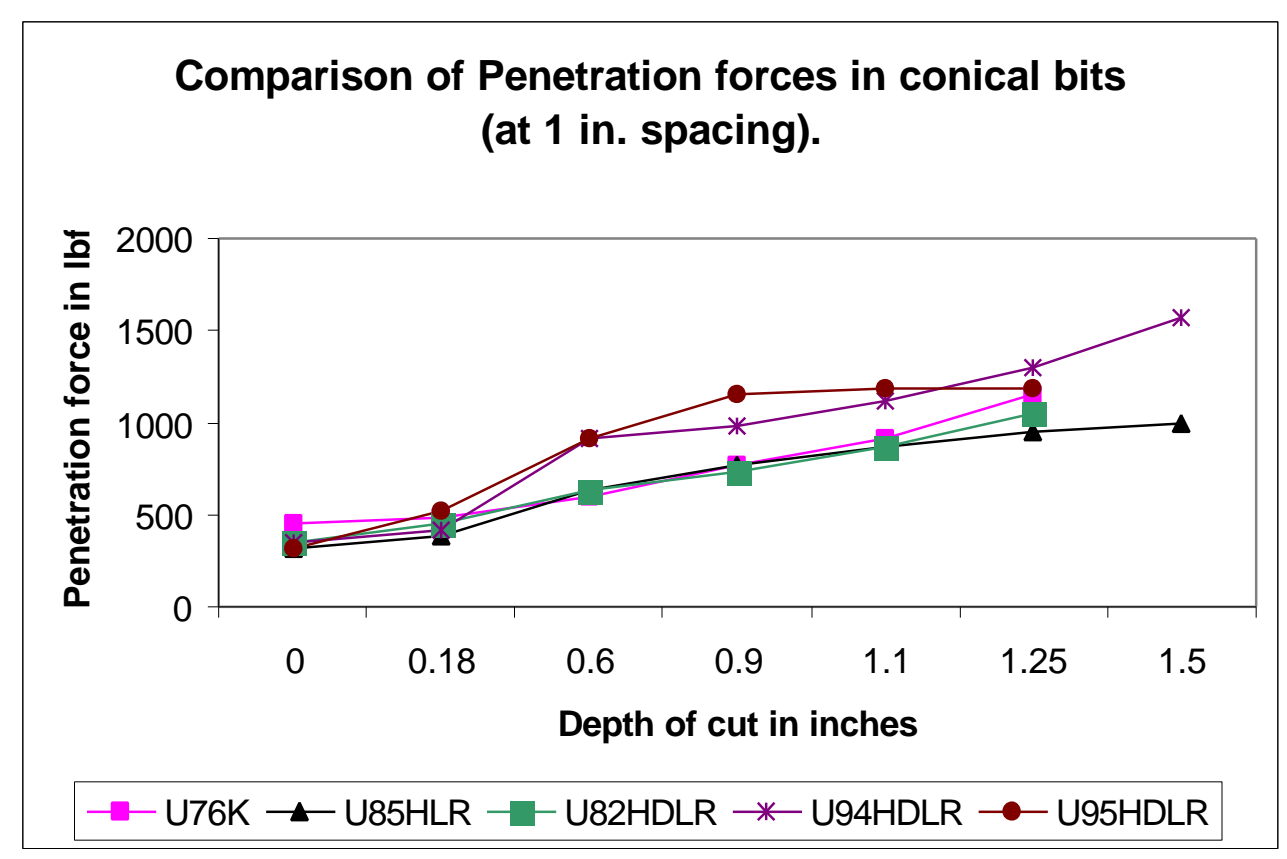

Figure 4.9a Comparison of penetration forces in conical bits at 1 in. spacing. 


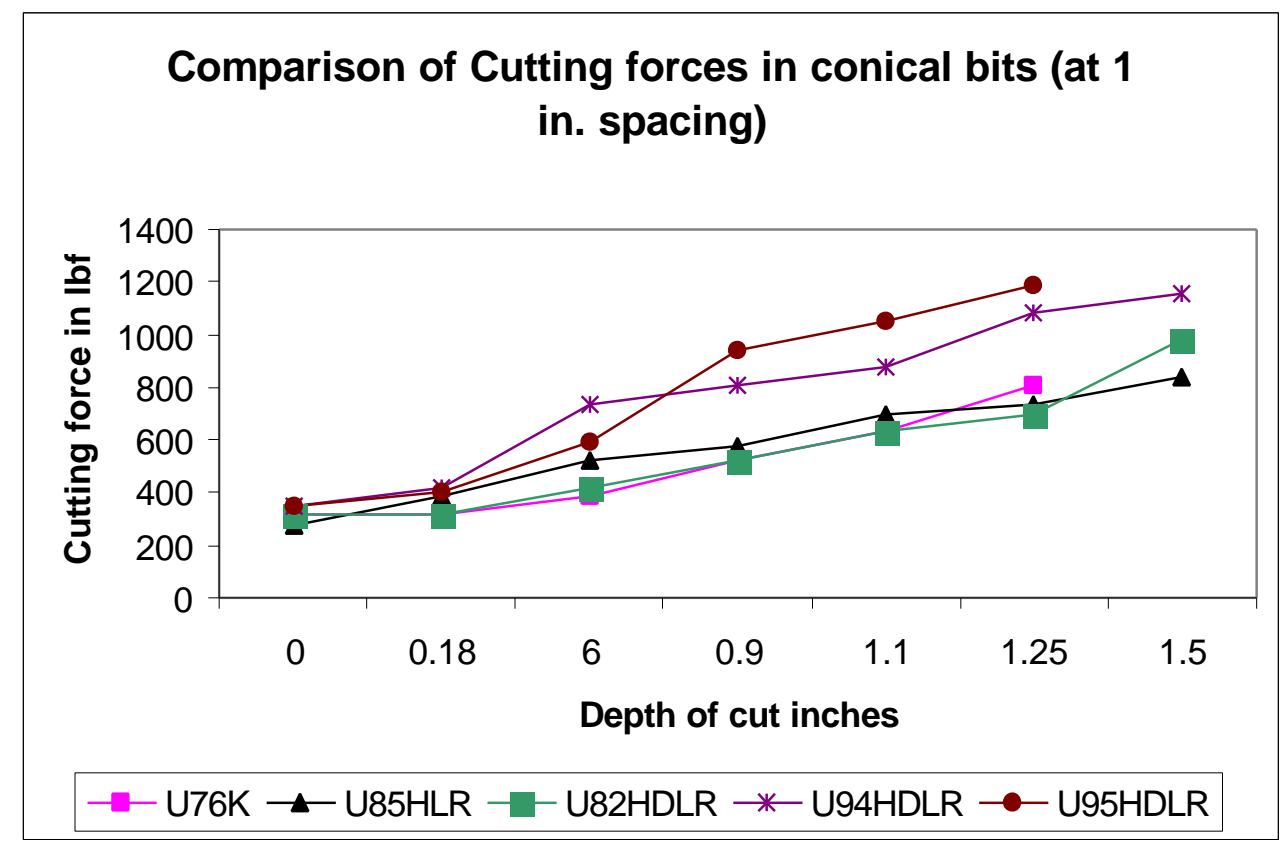

Figure 4.9b Comparison of cutting forces in conical bits at 1 in. spacing.

Figure 4.9c shows the comparison of specific respirable dust generated using all the five conical bits. The bits are arranged in the increasing order of their bit tip angles and bit tip sizes it can be seen from the figure that as the angle of the bit tip is increasing the amount of specific respirable dust being generated in the cutting process is increasing, in single bit experiments. Figure 4.9d shows the comparison of specific energy required at various spacings using all five cutting bits. It can be seen from this figure that as the angle of the bit tip is increasing the specific energy to cut the rock is increasing in the set of experiments conducted. 


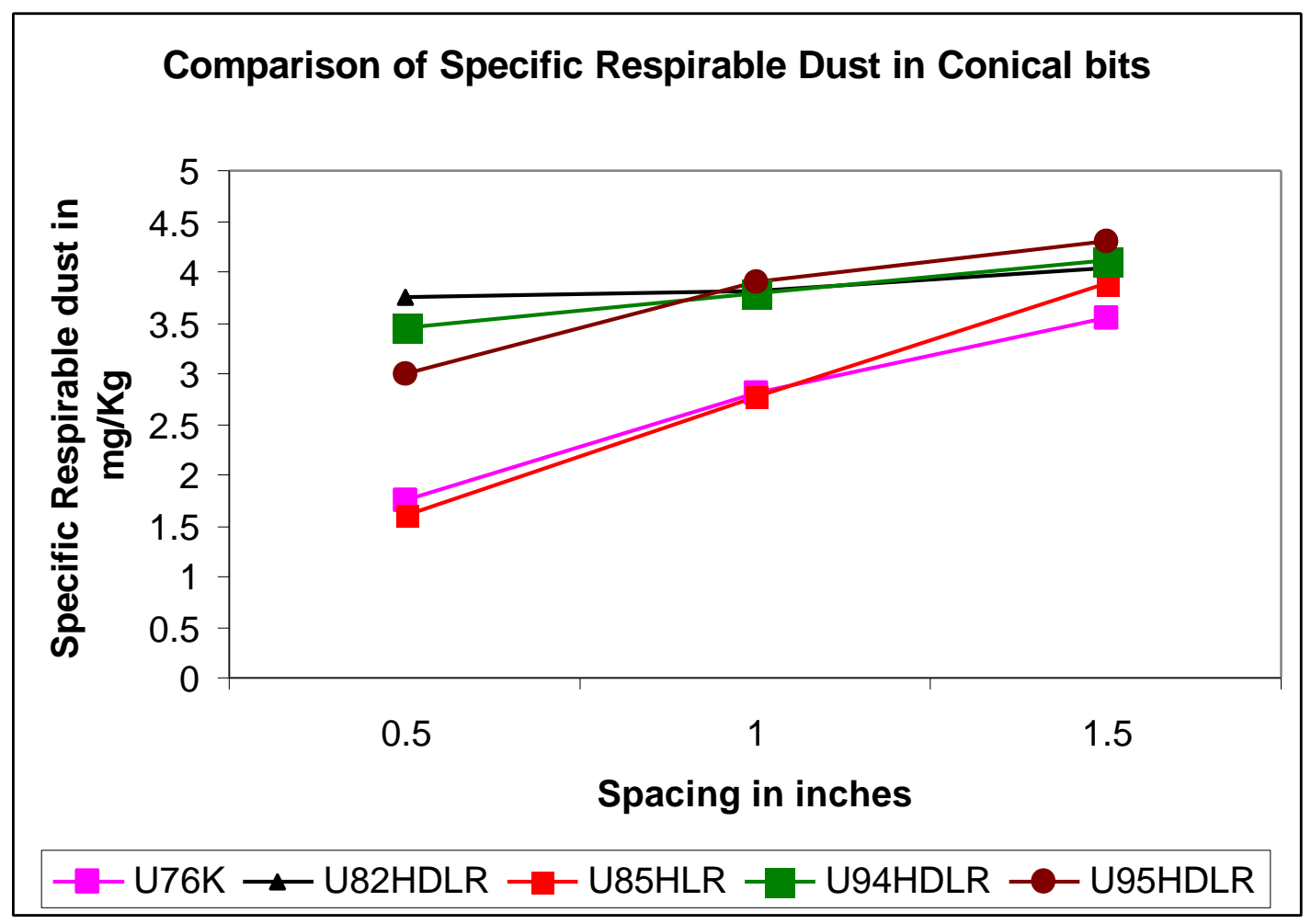

Figure 4.9c Comparison of specific respirable dust using conical bits.

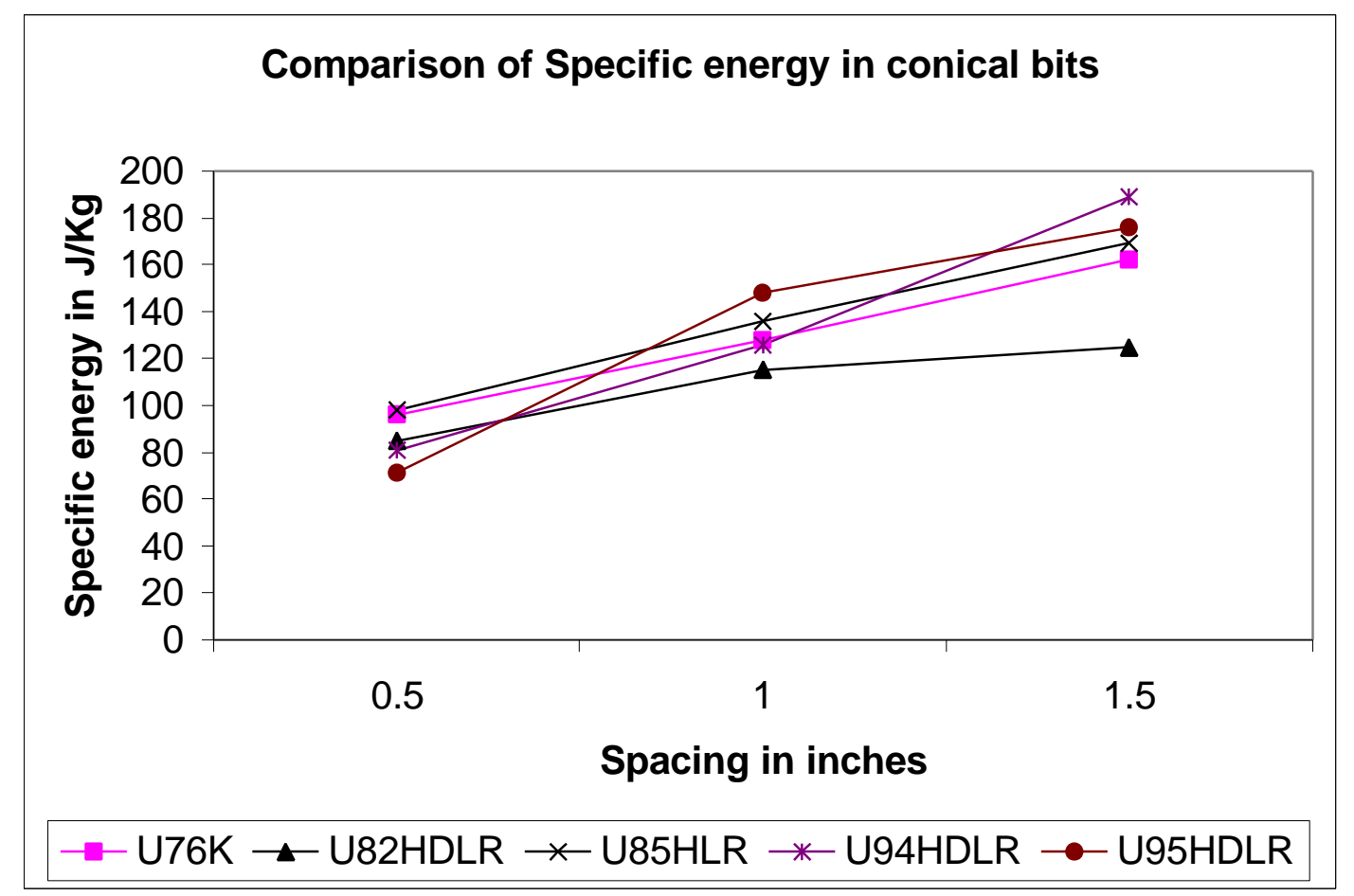

Figure 4.9d Comparison of specific energy using conical bits. 
Figure $4.10 \mathrm{a} \& \mathrm{~b}$ shows the comparison of penetration and cutting forces using the two drag bits KR225 and KR300. It can be seen from the figures that as the gage width of the bit is increasing the required penetration and cutting forces are decreasing due to better interaction between the two cuts. In the case of drag bits used as the gage width is increasing there was a better land/ridge removal due to interaction between two adjacent cuts. Figure 4.10c shows the variation of specific respirable dust using both drag bits. It shows that as the gage size is increasing its producing more specific respirable dust due to a larger surface area rubbing against the rock. Figure $4.10 \mathrm{~d}$ shows the variation of specific energy using the drag bits. It can be seen that as the gage size is increasing the specific energy required is reduced, because a larger bit produced more amount of rock product and the specific energy is reduced.

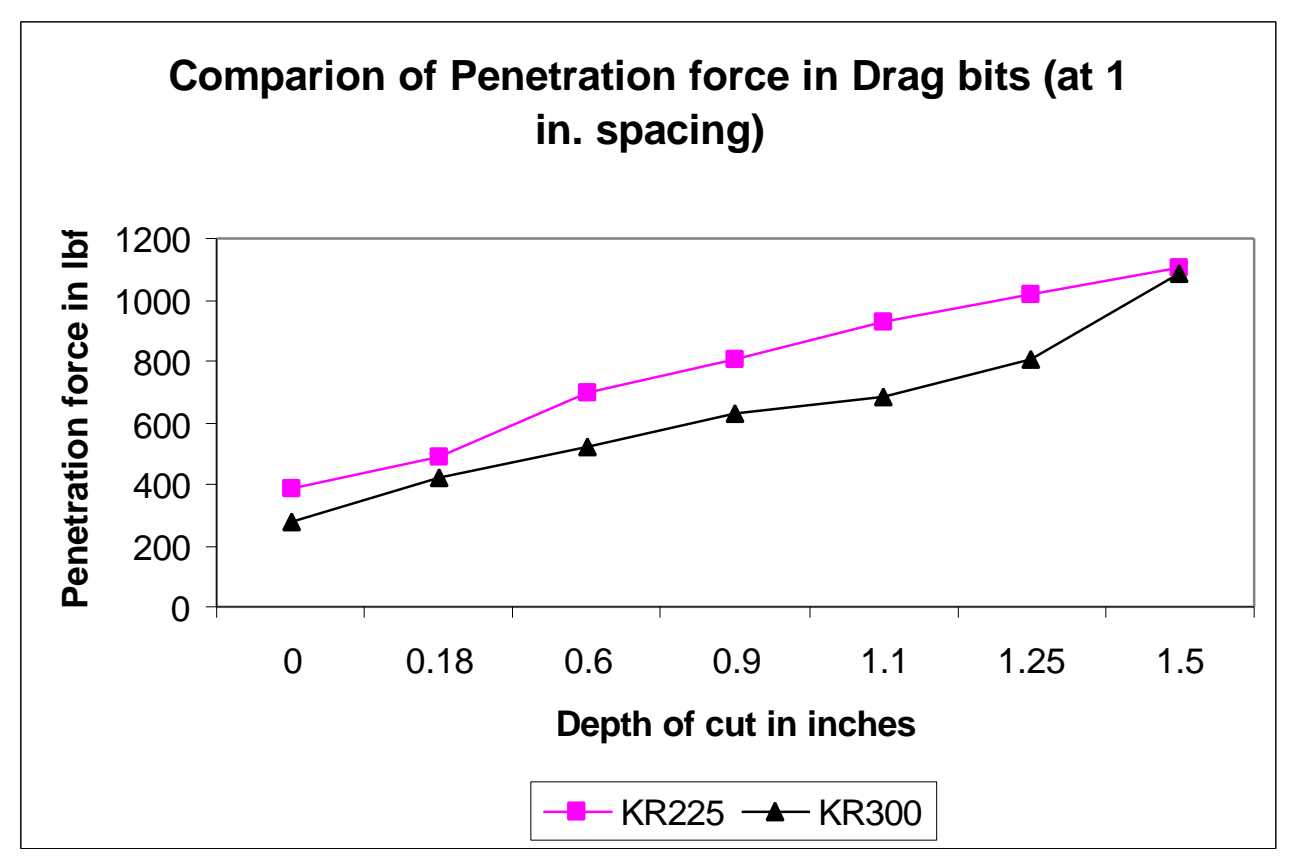

Figure 4.10a Comparison of penetration forces in drag bits. 


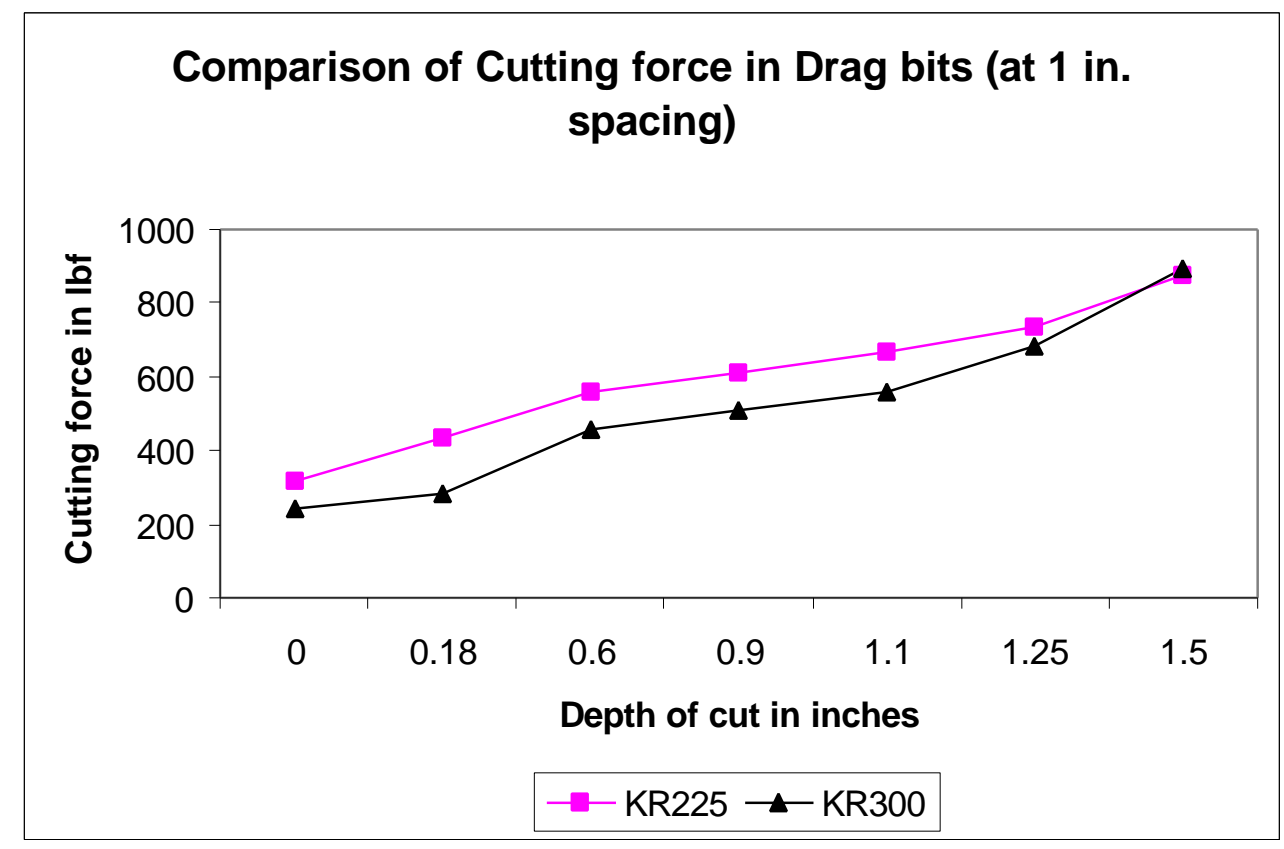

Figure 4.10b Comparison of cutting forces using drag bits.

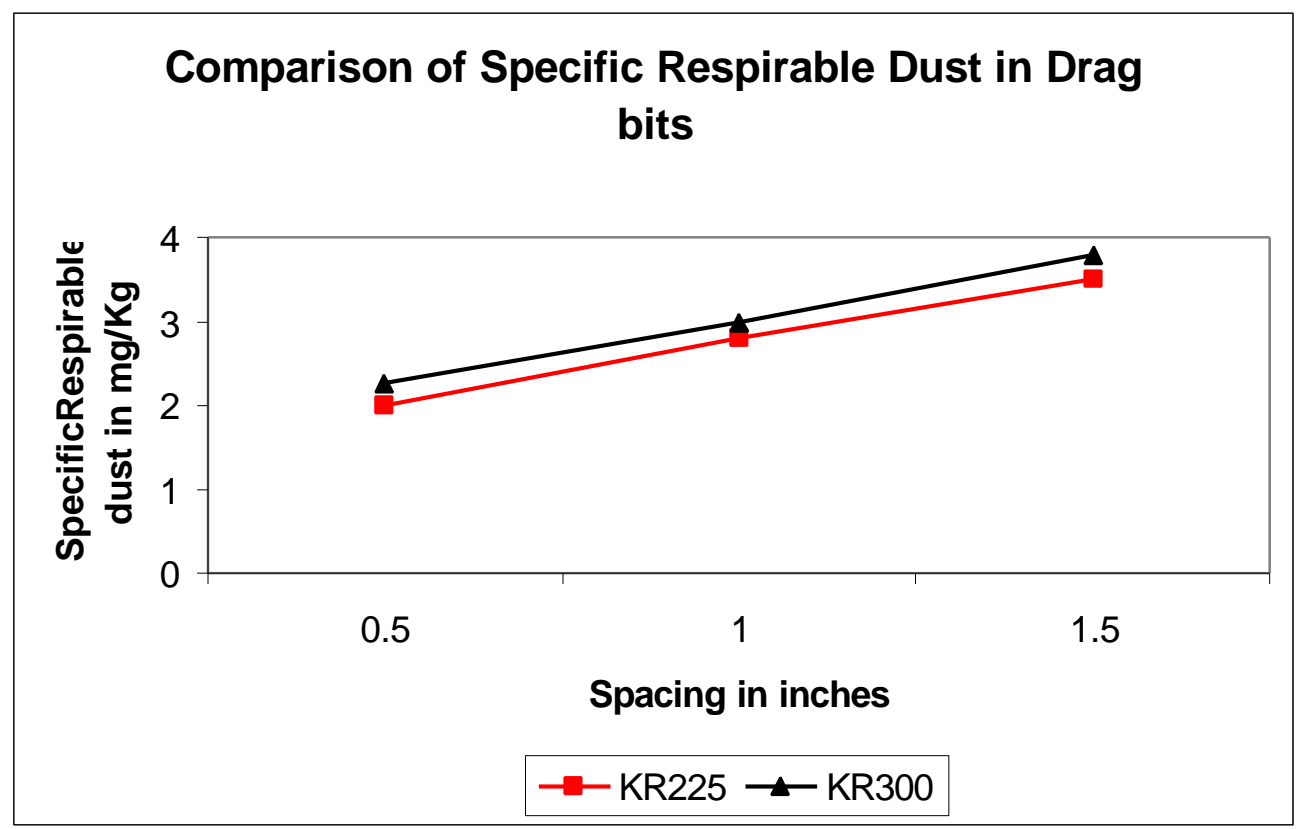

Figure 4.10c Comparison of specific respirable dust using drag bits. 


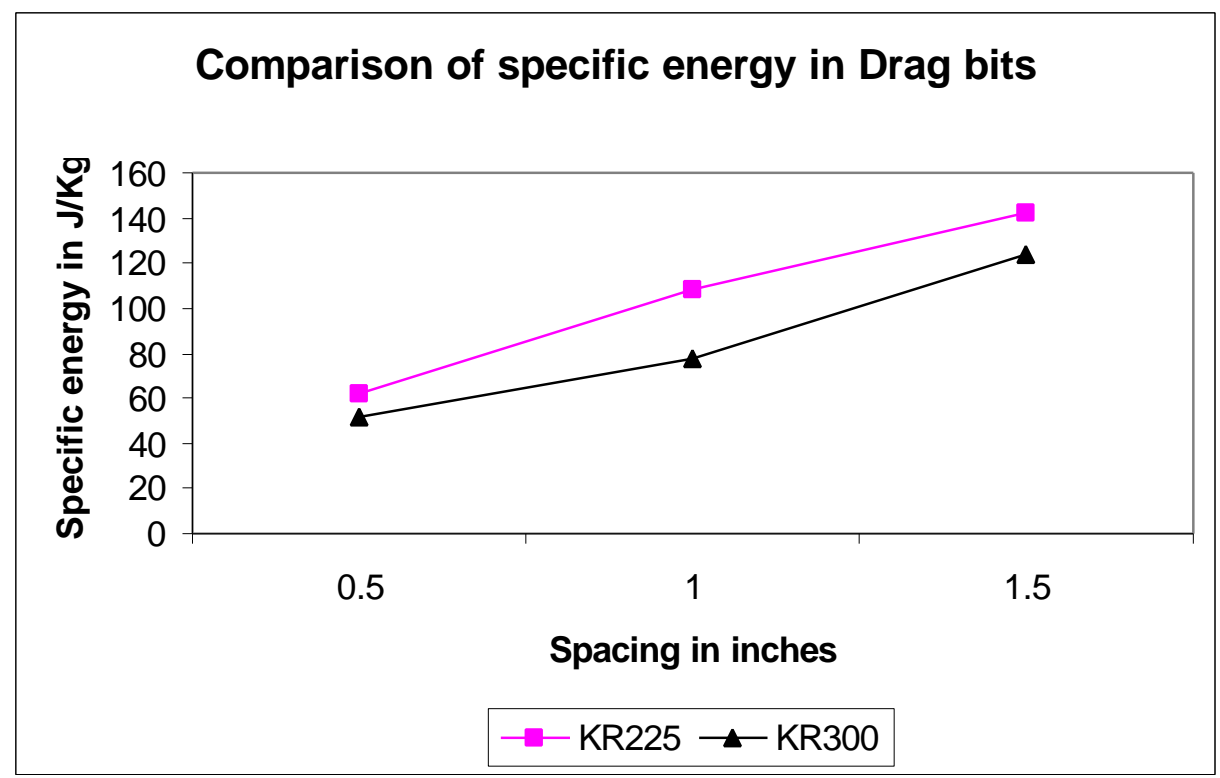

Figure 4.10d Comparison of specific energy in drag bits.

\subsection{Additional experiments in alternate cutting sequence}

As described in the section 3.6 additional experiments were conducted to evaluate the effect of cutting sequence on the amount of specific energy required to cut the rock using all the five conical bits and the two wedge shaped bits. The tests are conducted at a spacing of $1.5 \mathrm{in}$ and to a depth of about $1.5 \mathrm{in}$. in all the cases. Figure 4.11 shows the comparison of the specific energies in both cases. The results in the Figure 4.11 shows that there is about $11-20 \%$ reduction in the required to cut the rock in the alternate cutting sequence. 


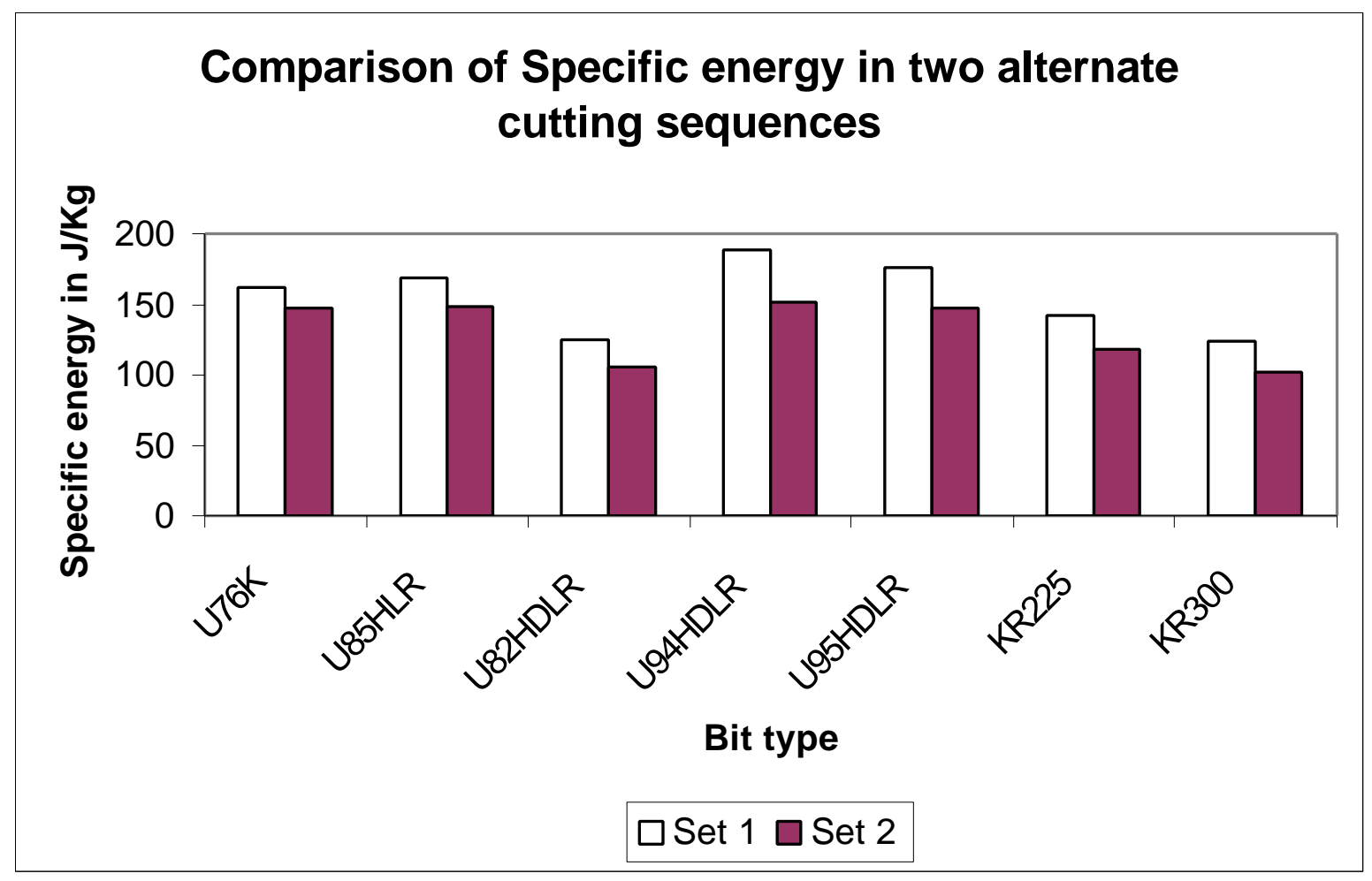

Figure 4.11 Comparison of specific energy in two alternate cutting sequences.

\subsection{Mechanism of failure of rock}

In quasi - static indentation initial wedge - rock interaction results in high stress concentration (compression and shear) at the area of contact zone, which will result in crushing of the material in the vicinity of the contact zone. As the stress exceeds the strength of the material, it results in pulverization of the interface zone. As the wedge penetrates further and the loading continues, the pulverization of the contact zone extends until sufficient tensile stresses develop to initiate failure, the extension of the pulverization zone stops, hence failure of the specimen occurs, similarly in rotary cutting process, bit compresses and pulverizes the material against the bit until sufficient shear stress develops to cause chipping. The failure characteristics of the material also depends on the void spaces or porosity of the material. Porous materials like coal require more 
penetration into the block before it fails. So in the case of softer materials which requires more penetration of the bit, a bit with longer tip size (height of the bit tip should be more) in order to avoid the rubbing of bit body against the material is required. Where as harder material like sandstone requires less penetration but more impact for failure. So in the case of harder materials bit with larger tip size (wider bit tip) is required to produce more impact. From the energy consumption point of view a larger bit requires more energy because of more surface area of contact with the rock, the specific energy required may also be more because energy is lost is abrasion. The specific respirable dust generation may be more with larger bit tips in the case of single bit experiments because of larger surface area of contact of bit with the material and abrasive interaction.

In multiple bit experiments only if we can remove the land/ridge the specific energy and specific respirable dust will decrease with increasing bit tip size because the angle of breakage is more, it favors the larger bit tips. However, such an advantage may not be very effective when cutting coal due to the damping of impact energy in coal, most of the energy will be spent in abrasion than impaction. Therefore for coal, a longer bit tip with smaller width and stream lined body is recommended, but in the case of rock a shorter and wider bit tip is needed.

In the experiments carried out the rate of advance of the machine was limited in order to maximize the depth of cut that can be reached in the first cut, to $1.5 \mathrm{in}$. for the largest bit tip, otherwise the largest bit will get stuck at larger advance depths, hence the cutting experiments were kept to a very shallow depth per revolution and resulted in less 
impact, less fracture initiation and propagation and resulted in spending more energy in abrasion. However in multiple bit experiments when the ridges are removed the larger bit has advantages in requiring less specific energy and producing less specific respirable dust. 


\section{CONCLUSIONS}

A number of experiments were conducted in this study to examine the relationship between cutting parameters like the cutting force, penetration force, bit spacing and cutting sequence and the bit geometry parameters like the bit tip angle, bit tip size and the type of the bit (conical or drag bits).

The objectives of this study were to provide a clean cut face in a cutting cycle and to reduce the amount of respiarble dust being generated in the cutting process. The average penetration and cutting forces in all the experiments conducted (using both conical and drag bits) were found to be increasing with increasing bit spacing, and with increasing bit tip angle (in conical bits). In the case of drag bits the amount of specific energy required was found to be decreasing with increasing gage size. Due to better interaction between the two adjacent grooves the bits with bigger gage sizes were able to remove more rock with less energy, so the specific energy is reduced.

The average specific respirable dust was found to be increasing with increasing bit spacing in both conical and drag bits. As the angle of the bit tip is increasing the amount of specific respirable dust is found to be increasing. In the case of drag bits as the size of the gage increases the amount of respirable dust produced is to found to be increasing same as in the case of conical bits. 
When compared to conical bits the drag bits required little more energy to cut the rock but the amount of spacific dust was found to be less in the case of drag bits. As the bit tip size was more in the drag it produced more dust and required more energy. The change of cutting sequence in both the conical and drag bits improved the cutting efficiency by reducing the specific energy required from $11 \%$ to $20 \%$.

As the bit spacing is increasing there was no interaction between two adjacent cuts and the bits were not able to remove the land/ridge to produce a clean cut face. At 1.5inch spacing none of the bits (both conical and drag bits) used in this study were able to remove the lands/ridges between two adjacent grooves satisfactorily. As the bit spacing was increasing there was a regrinding in the grooves and there was more respirable dust being produced in the cutting process. It was found that large tipped bits were able to remove the land/ridge and provide a better clean cut face. 


\section{REFERENCES}

Achanti, V.B., 1998, "Parametric study of dust generation with rock ridge breakage analysis using a simulated continuous miner", Ph.D. Dissertation, Department of Mining Engineering, West Virginia University, Morgantown, 83 pp.

Anon., 1953, "Third quarterly report on vibratory drilling oil wells", Drilling Research Inc., Battelle Memorial Institute, August.

Anon., 1982b, "Instruction manual for series 290 Marple personal cascade impactors", Bulletin No. 290I.M-3-82, Anderson Samplers, Inc., Atlanta, GA, 33 pp.

Barker, J.S., 1964, “A laboratory investigation of rock cutting using large picks”, Int.J. of Rock Mech. Min. Sci., Vol.1, pp. 519-534.

Bieniawski, Z.T., 1967, "Theory of rock fracture process", International Journal of Rock Mech. Min. Sci., Vol.1, pp. 519-534.

Cheatham, J.B., Jr., 1958, “An analytical study of rock penetration by a single bit tooth”, Proceedings of $8^{\text {th }}$ Annual Drilling and Blasting Symposium, University of Minnesota, Minnesota.

Clark, G.B., et al., 1972, “An investigation of thermal - mechanical fragmentation of rock”, Univ. of Missouri- Rolla, RMERC, Annual Report, July.

Dumbleton, J.J., O’dogherty, M.J., and Shepard, R., 1958, “ The effects of blade angle and other factors on coal ploughing”, Mechanical Properties of Non - Metallic Brittle Materials, Pergamon Press, London, pp. 399-418.

Evans, I., and Murrel.S.A., 1958, "Conference on mechanical properties of non metallic brittle materials", Butter Worths, London, pp. 432-450.

Evans, I., and Pomeroy, C.D., 1966, "Strength fracture and workability of coal", Pergamon Press, London, pp. 218-235.

Evans, I., 1984, “A theory of cutting force for point attack bits", Technical note, International Journal of Mining Engineering, pp. 63-71. 
Gnirk, P.F., and Cheatham, J.B., Jr., 1965, “An experimental study of single bit tooth penetration into dry rock at confining pressures of 0 to 5,000 psi”, J. of SPE, Vol.5, No.2, June, pp. 117-130.

Hanson, B.D., and Roepke, W.W.,1979, "Effect of symmetric bit wear and attack angle on airborne respirable dust and energy consumption”, USBM RI 8395, 24 pp.

Hartman, H.L., 1959, "Basic studies of percussion drilling”, Mining Engineer, January, pp. 68-75.

Hill, R., 1950, “Mathematical theory of plasticity”, Clarendon Press, Oxford.

Hurt, K.G., and Evans, I., 1980, “ A laboratory study of rock cutting using point attack tools", Proceedings of $21^{\text {st }}$ U.S. Symposium on Rock Mechanics, University of Missouri, Rolla, pp. 112 - 122 .

Hurt, K.G., and Evans, I., 1981, “ Point attack tools: An evaluation of function and use for rock cutting”, Mining Engineering, March, pp. 673-675.

Jung, S.J., and Khair, A.W., 1989, "Study of coal fragmentation under conical bit indentation", Proceedings of $30^{\text {th }}$ U.S. Symposium on Rock Mechanics, West Virginia University, pp. 469-476.

Kennametal Inc., 1996, “Top tools underground”, Kennametal Mining Products, Latrobe, PA, pp.12-17.

Khair, A.W., 1984, "Design and fabrication of a Rotary Coal Cutting Simulator", Proceedings of the Coal Mine Dust Conference, West Virginia University, Morgantown, pp 190-197.

Khair, A.W., and Devilder, W.M., 1986, "Correlation of fragment size distribution and fracture surface in coal cutting under various conditions", Proceedings of the International Symposium on Respirable Dust in Mineral Industries, The Pennsylvania State University, University Park, October, pp. 46. 
Khair,A.W., Reddy, N.P., and Quinn, M.K., 1989, “Mechanisms of coal fragmentation by a continuous miner", Mining Science and Technology, Elsevier, Amsterdam, Netherlands, Vol.8, pp. 189-204.

Ladanyi, B., 1972, "Rock failure under concentrated loading", $10^{\text {th }}$ U.S.Symposium on Rock Mechanics, pp. 363-387.

Lindquist, P.A., Lai, H.H., and Alm, O., 1984, "Indentation fracture development in rocks continuously observed with a scanning electron microscope", International Journal of Rock Mechanics and Mining Sciences, Vol. 21, pp. 165-182.

Lundburg, B., 1974, "Penetration of rock by conical indentors", International Journal of Rock Mechanics and Mining Sciences, Vol.11, pp. 209-214.

Miller, M.H., and Sikarskie, D.L., 1968, "On the penetration of rock by three dimensional indentors", International Journal of Rock Mechanics and Mining Sciences, Vol.5, pp. 375-398.

Nishimatsu, Y., 1972, "Mechanics of rock cutting”, International Journal of Rock Mechanics and Mining Sciences, Abstr. 9, pp. 261-270.

O’Dogherty, M.J., and Burney, A.C., 1963a, “A laboratory study on the effect of cutting speed on the performance of two coal cutter picks", Colliery Engineering, Vol. 40, No.468, Feb., pp. 51-54.

O’Dogherty, M.J., and Burney, A.C., 1963b, “A laboratory study on the effect of cutting speed on the performance of two coal cutter picks", Colliery Engineering, Vol. 40, No.469, Mar., pp. 111-114. 
Pariseau, W.G., and Fairhurst, C., 1967, “The force-penetration characteristics for wedge penetration into rock", International Journal of Rock Mechanics and Mining Sciences, Vol. 4, No.2, pp. 165-180.

Paul, B., and Sikarskie, D.L., 1965, “A preliminary theory on static penetration by a rigid wedge into a brittle material", Transactions of SME-AIME, Dec. pp. 372-383.

Pomeroy, C.D., and Brown, J.H., 1968, "Laboratory investigation of cutting processes applied to coal winning machines”, Journal of Strain Analysis, Vol.3, No.3, pp. 232 243.

Pomeroy, C.D., 1963, "Breakage of coal by wedge action”, Colliery Guardian, Vol. 207, Nov., pp. 642-677.

Pomeroy, C.D., 1964, "Breakage of coal by wedge action", Colliery Guardian, Vol. 208, July, pp. 115-121.

Reddy, N.P., 1988, "Characterization of coal breakage by continuous miners", Ph.D. dissertation, Department of Mining Engineering, West Virginia University, Morgantown, 184pp.

Reichmuth, D.R., 1963, “Correlation of force-displacement data with physical properties of rock for percussive drilling systems", $5^{\text {th }}$ U.S. Symposium on Rock Mechanics, pp. 33-60.

Roepke, W.W., 1983, "Coal cutting research slashes dust”, Coal Mining and Processing, Vol. 20, No. 10, October, pp. 38-44.

Roepke, W.W., Lindroth, D.P., and Myren, T.A., 1976, “ Reduction of dust and energy during coal cutting using point attack bits”, USBM RI 8185, 53 pp. 
Roepke, W.W., 1984, "General methods for primary dust control during coal cutting", Mining Engineering, Vol. 36, No.6, June, pp. 636-644.

Roxborough, F.F., King. P., and Pedroncelli, E.J., 1981, "Tests on the cutting performance of a continuous miner", Journal of the South African Institute of Mining and Metallurgy, Vol.81, No.1, pp. 9-25.

Roxborough, F.F., and Pedroncelli, E.J., 1982, "A practical evaluation of some coal cutting theories using a continuous miner", Mining Engineer, September, pp. 145156.

Singh, M.M., Johnson, A.M., 1967, "Static and dynamic failure of rock under a hemispherical bit", Transactions of SME-AIME, December, pp. 366-373.

Sikarskie, D.L., and Cheatham, J.B., Jr., 1973, "Penetration problem in rock mechanics", Rock Mechanics Symposium, ASME-AMD, Vol.3, pp. 375-398.

Stecklein, G., Bransteller, R., Arrowood, R., Davidson, D., Laskford, J., Lyle, R., and Nulton, C., 1982, "Basic research on coal fragmentation and dust entrainment", USBM Contract No. J0215009, South West Research Institute, San Antonio, 121 pp.

Strebig, K.C., and Zeller, H.W., 1975, "Effect of depth of cut and bit type on generation of respirable dust", USBM RI 8042, 15pp.

Sun, G., Whittaker, B.N., Singh, R.N., and Waller, M.D., 1992, "Prediction of rock cutting performance using fracture mechanics principles - a review", $11^{\text {th }}$ International Conference on Ground Control in Mining, The University of Wollongong, N.S.W. pp. 644- 651.

Whittaker, D., 1962, "Effect of pick shape on cutting forces", Colliery Guardian, Vol. 207, No.8, Aug, pp. $242-244$.

Whittaker,B.N., and Szwilski,A.B., 1973, "Rock cutting by impact action”, Int.J.Rock Mech. Min. Sci. Geomech Abstr., vol. 9, pp. 659-671.

Werblow, W., 1961, “Coal ploughing”, Colliery Engineering, Aug., pp. 345-350. 


\section{APPENDIX}

\section{Characteristics of conical cutting bits used in the study.}

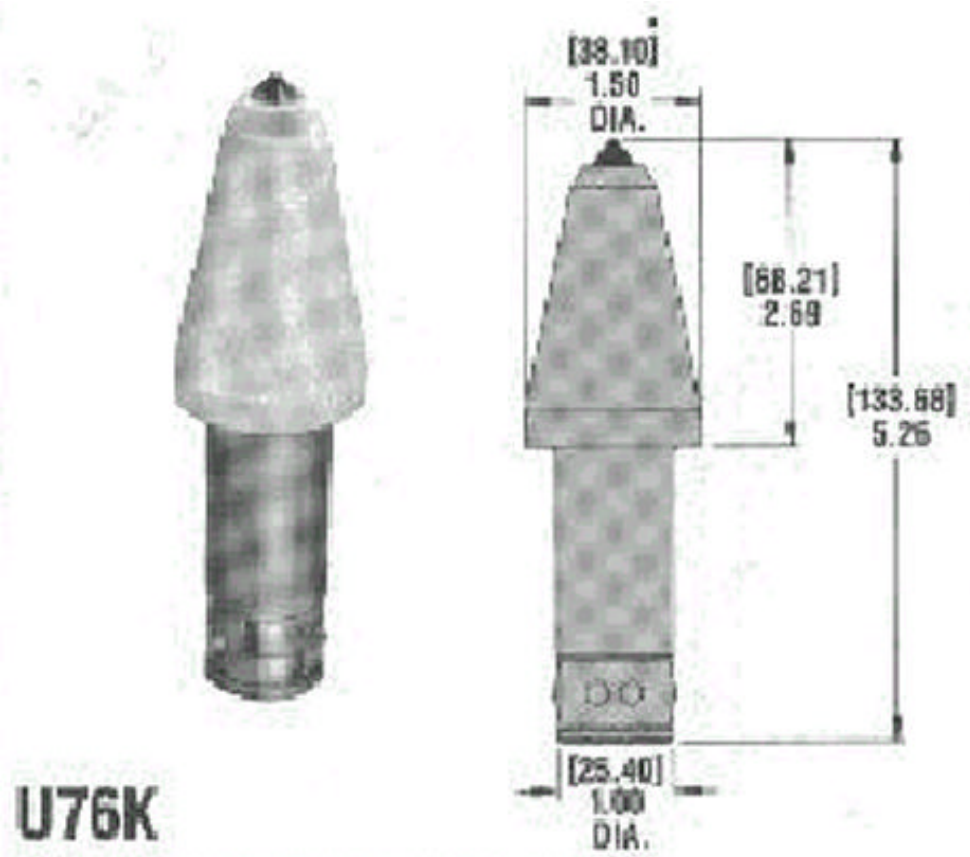

Used for moderate cutting conditions. Angle of the bit tip : $70^{\circ}$. Tip diameter : $9.53 \mathrm{~mm}$

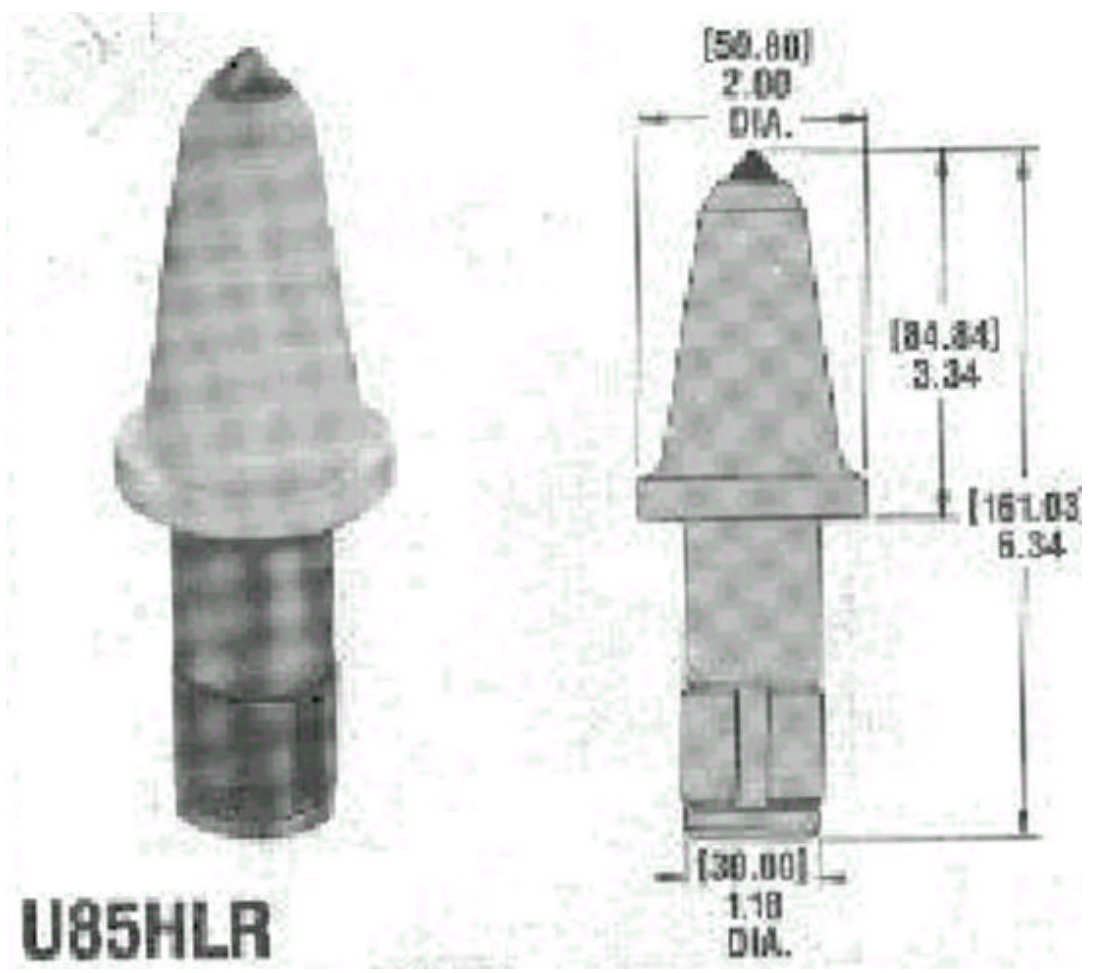

Used hard cutting conditions. Angle of the bit tip : $75^{\circ}$. Tip diameter $: 11.11 \mathrm{~mm}$ 


\section{tip dlameter $1 / \mathrm{s}^{\prime \prime}(12.7 \mathrm{~mm})$}
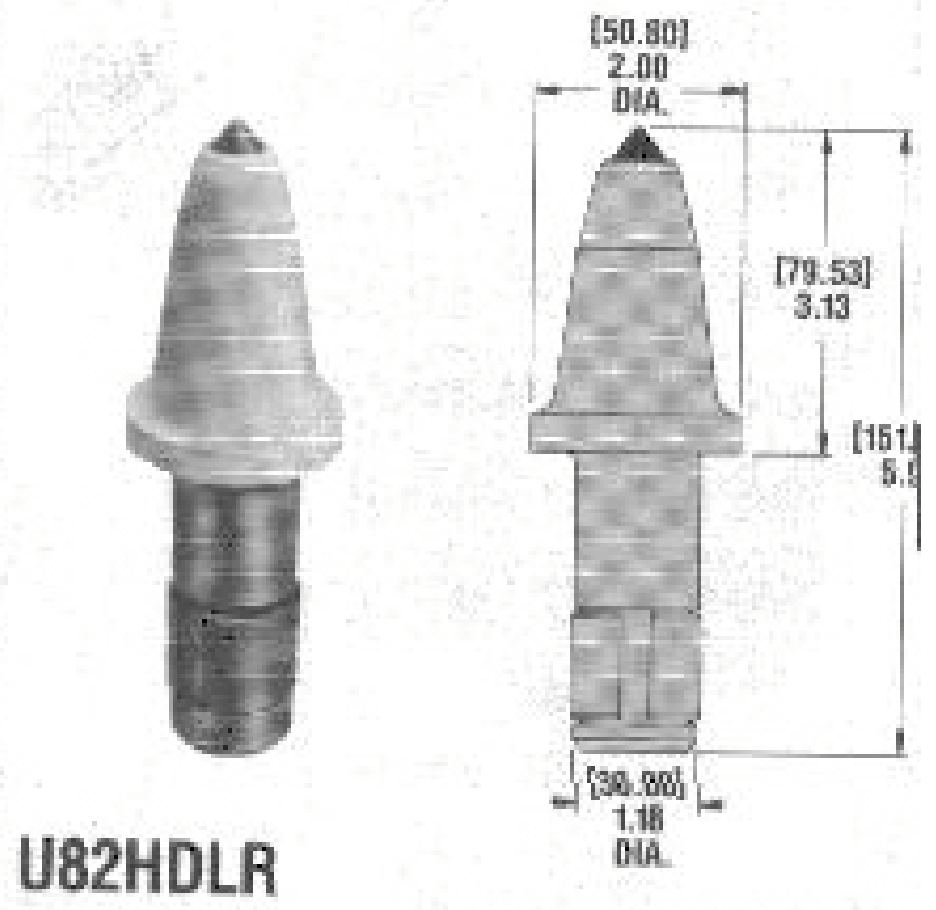

Used in hard cutting conditions. Angle of the bit tip : $75^{\circ}$. Tip diameter : $12.7 \mathrm{~mm}$

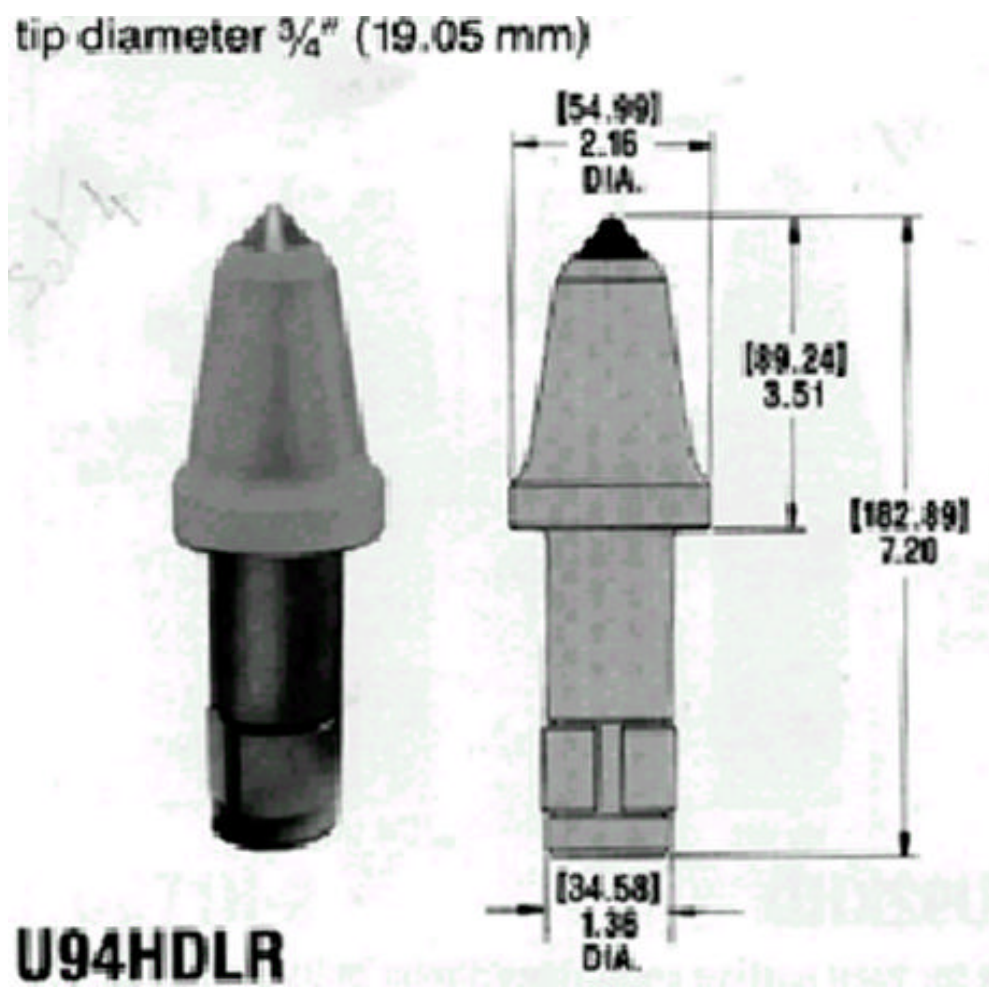

Used in extremely hard cutting conditions. Angle of the bit tip : 750 . Tip diameter : $19.05 \mathrm{~mm}$. 


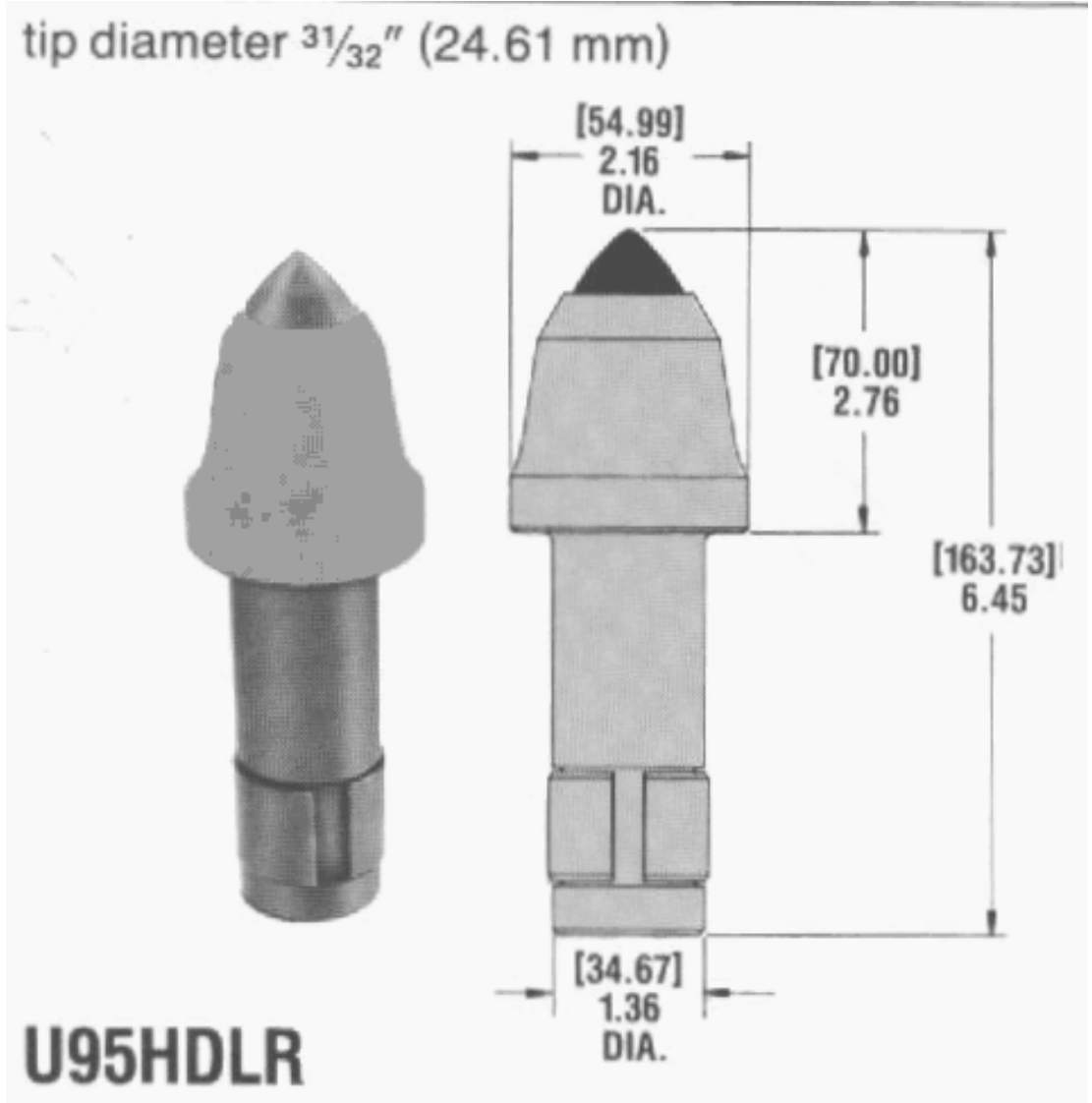

Used in extremely hard cutting conditions. Triple-angle tip : top $100 \%$ middle $85 \%$ bottom $64^{0}$. Tip diameter : $24.61 \mathrm{~mm}$ 